\title{
The changes in life effectiveness following ropes course participation for Becoming an Outdoors -Woman (BOW) participants
}

\author{
Maureen A. Dougherty \\ West Virginia University
}

Follow this and additional works at: https://researchrepository.wvu.edu/etd

\section{Recommended Citation}

Dougherty, Maureen A., "The changes in life effectiveness following ropes course participation for Becoming an Outdoors -Woman (BOW) participants" (2005). Graduate Theses, Dissertations, and Problem Reports. 2311.

https://researchrepository.wvu.edu/etd/2311

This Dissertation is protected by copyright and/or related rights. It has been brought to you by the The Research Repository @ WVU with permission from the rights-holder(s). You are free to use this Dissertation in any way that is permitted by the copyright and related rights legislation that applies to your use. For other uses you must obtain permission from the rights-holder(s) directly, unless additional rights are indicated by a Creative Commons license in the record and/ or on the work itself. This Dissertation has been accepted for inclusion in WVU Graduate Theses, Dissertations, and Problem Reports collection by an authorized administrator of The Research Repository @ WVU.

For more information, please contact researchrepository@mail.wvu.edu. 
The Changes in Life Effectiveness Following Ropes Course Participation for Becoming an Outdoors-Woman (BOW) Participants by

Maureen A. Dougherty

Dissertation submitted to the Davis College of Agriculture, Forestry and Consumer Sciences

at

West Virginia University

In partial fulfillment of the requirements for the degree of Doctor of Philosophy in Forest Resources Science

Chad D. Pierskalla, Ph.D., Chair Steve Selin, Ph.D. Dennis Smith, Ph.D. Kelly Bricker, Ph.D. Robert Kauffman, Ph.D.

\author{
Division of Forestry \\ Recreation, Parks \& Tourism Resources \\ Morgantown, West Virginia \\ 2005
}

Keywords: Ropes Course, Life Effectiveness, Adventure Education Copyright 2005 Maureen A. Dougherty 


\section{ABSTRACT \\ The Changes in Life Effectiveness Following Ropes Course Participation for Becoming an Outdoors-Woman (BOW) Participants}

\section{Maureen A. Dougherty}

The purpose of the study was to examine the changes in life effectiveness following ropes course participation for participants of the Becoming an OutdoorsWoman (BOW) program using a quasi-experimental design. Ropes course participation was also examined as a potential program modification to the existing BOW. The Life Effectiveness Questionnaire (LEQ) was administered to 85 of the 90 participants at the Becoming an Outdoors Woman Program sponsored by the Maryland Department of Natural Resources. Participants in the control group $(\mathrm{N}=65)$ and experimental group $(\mathrm{N}=20)$ both completed a ten question demographic survey and the LEQ on three occasions (pre-test, post-test, and one month follow-up). The experimental group completed a ropes course two weeks following BOW and immediately prior to the posttest. The ropes course participants were also observed using the LEQ observation sheet and a random group $(\mathrm{N}=8)$ was selected to participate in one-on-one interviews one week following the ropes course.

The General Linear Model was used to measure the differences between the three observations for both the control and experimental groups. An independent samples t-test was used to measure the differences between the experimental and control group for each of the three observations. A repeated measures ANOVA was used to measure the differences between the three observations for both groups for each of the eight subscales of the LEQ.

The results showed a significant increase in LEQ scores at the post-test which remained the same at the one month follow-up for the experimental group. The control group also showed a significant increase at the post-test, but the group did return to pre-test levels one month following participation in BOW. These findings do indicate that the ropes course experience did have a long term effect on overall LEQ scores. The Cronbach's Alpha Reliability Estimates indicated strong and consistent reliability scores for the LEQ. 


\section{DEDICATION}

This dissertation is dedicated to soul mate, best friend and husband, John Nissel and our two wonderful children, Madelyne and Bryce. The time and personal sacrifice necessary to complete this project wouldn't have been possible without their ongoing love, support, understanding and encouragement. A very special thanks to John for being my number one supporter who shares the same love of the outdoors and field of recreation. In addition, I would like to dedicate this project to my loving parents, Frank and Peggy Dougherty, who were always there to help in any way possible to care for their grandchildren, prepare meals, and help with housework while continually offering words of inspiration. Being the first generation of college graduates in our family, their support for my advanced educational pursuits has been unending. Lastly, I would like to thank my two guardian angels, my aunt, Betty Moody, and my dear friend, Kim Smith, who have been relentless in providing support and encouragement while helping to celebrate the small milestones throughout this journey. I am truly blessed to be surrounded with by such a close, loving family and wonderful friends. Without these individuals and many others, this project would not have become a reality. 


\section{ACKNOWLEDGEMENTS}

I would like to extend a heart-felt thanks to the many people who were involved in the completion of this dissertation. First of all, I would like to thank the Chair of my committee, Dr. Chad Pierskalla, who was always there to answer questions, provide much needed direction and moral support. I would also like to extend my most sincere appreciation to the others members of my committee, Dr. Steve Selin, Dr. Kelly Bricker, Dr. Denny Smith, and Dr. Robert Kauffman. Their guidance through the entire process was extremely helpful. A very special thanks to Dr. Robert Kauffman for his continual encouragement and help in keeping me on task throughout this endeavor.

I would also like to extend a very special thanks to my loyal friend, Beth Newport, for her companionship and assistance in collecting my data throughout the study. Most sincere thanks to my husband, John, who offered his assistance wherever and whenever needed. Thanks to Dr. Nina Roberts, Dr. Willa Brooks, Dr. Diane Blankenship and Dr. Anne Simmonsen for being good friends and excellent role models in a field that needs more outstanding women.

Without the assistance and support of the Maryland Department of Natural Resources, this project would have not been possible. A special thanks to the women who coordinate the BOW program, Karina Blizzard and Caroline Blizzard for their willingness to work with me on this project and to Rusty Ruszin for being instrumental in the process.

A special thanks to the YMCA Camp Letts of Metropolitan Washington for providing wonderful facilitators and facilities for our day on the ropes course. Other individuals who provided tremendous support include Resha Kreischer-Anderson who helped crunch all of the data, Rose Marie Gurion who acted as my technical advisor and Hala McGiver of Active Image for donating t-shirts for the ropes course participants. A special thanks to Dr. Anne Simmonsen and Dr. Karen Smith for their recommendations in editing this manuscript. A special thanks to all the wonderful and interesting women who participated in the study. Most importantly, I thank the Lord God for all the many blessings in my life! 


\section{Table of Contents}

$\begin{array}{ll}\text { Chapter } & \text { Page }\end{array}$

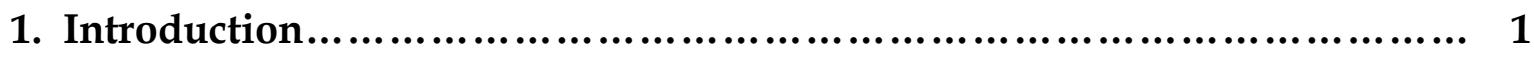

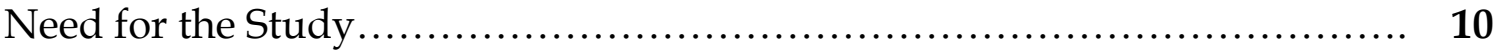

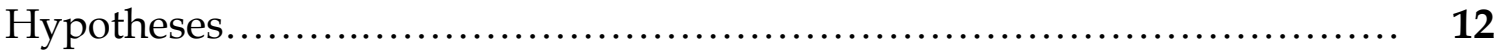

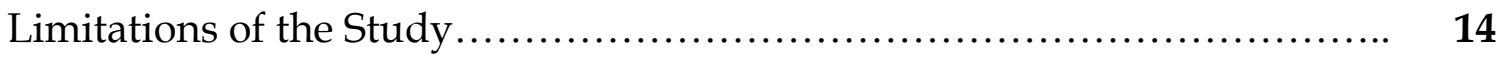

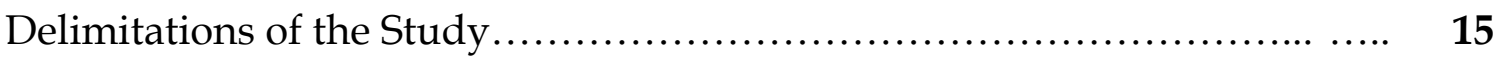

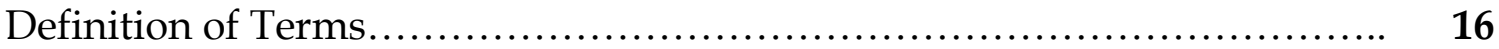

2. Literature Review...................................................................................................... 17

History of Adventure Education in the U.S.............................. 18

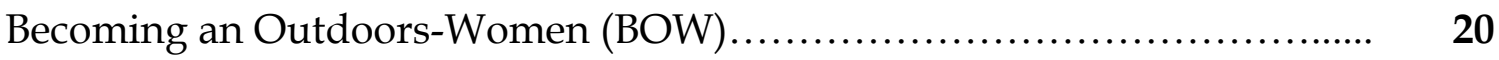

Women and the Outdoors.............................................. 22

Ropes Courses and Experiential Education............................... 26

Life Effectiveness....................................................... 30

Eight Factors of the LEQ ..................................................... 34

3. Methodology ..................................................................................................................... 38

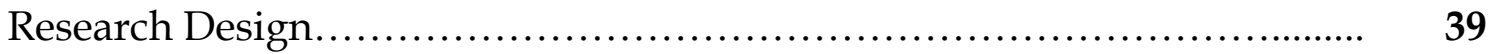

Description of Programs................................................. 40

Instrument Development.............................................. 42

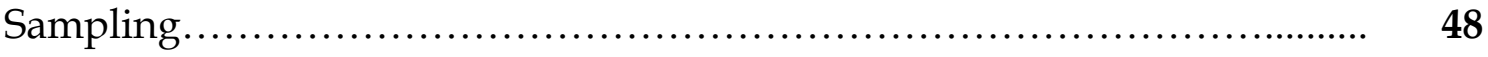

Collection of Data....................................................... 49 
Data Analysis...................................................... 53

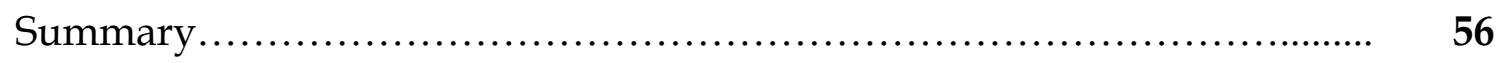

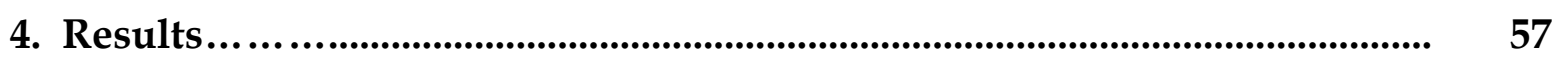

Response Rates.................................................... 57

Demographic Data..................................................... 58

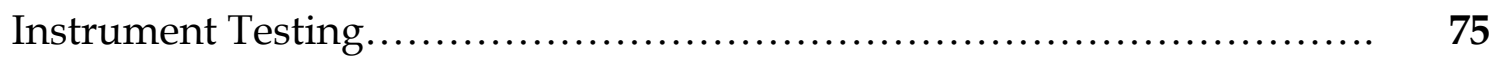

Hypothesis Testing .................................................. $\quad 75$

Results of the Eight Factors of the LEQ for the Control and

Experimental Groups..................................................... 79

Observations of Ropes Course using LEQ Observer Sheet.................. 84

One-on-One Interviews.................................................. 86

Summary of Study Results........................................... 92

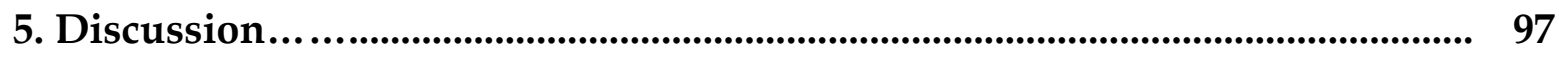

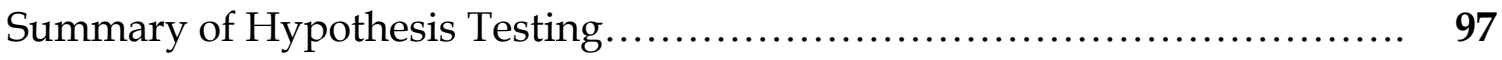

Research Questions Addressed by the Study ............................ 103

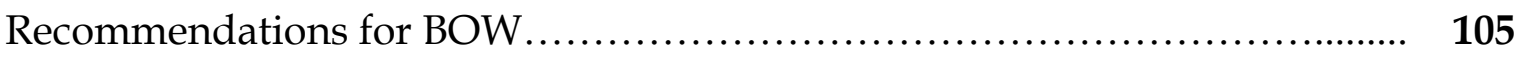

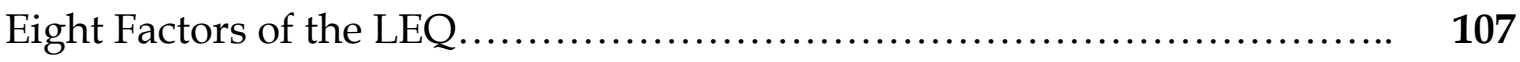

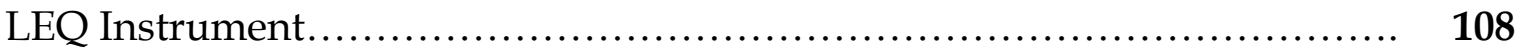

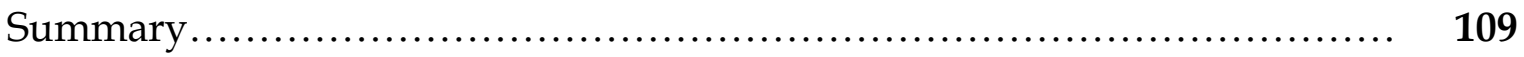

Recommendations for Future Research............................... 111

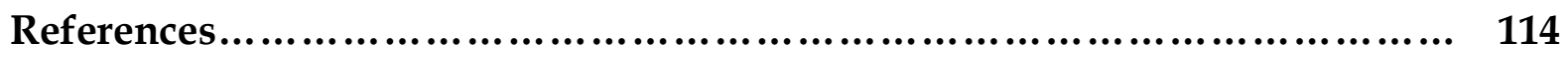

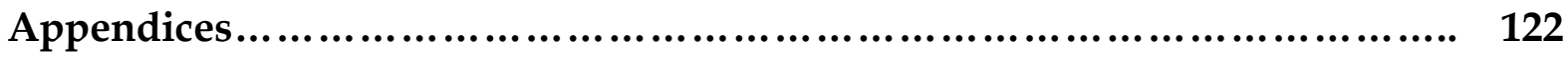




\section{List of Tables/Graphs}

Table/Graph

Page

1. Table 1 Quasi-Experimental Research Design

39

2. Table 2 Eight Factors of the LEQ-H

$\begin{array}{lll}\text { 3. } & \text { Figure } 1 \text { Age Distribution } & 60\end{array}$

$\begin{array}{llll}\text { 4. } & \text { Figure } 2 & \text { Ethnicity Distribution } & 61\end{array}$

$\begin{array}{llll}\text { 5. } & \text { Figure } 3 & \text { Education Distribution }\end{array}$

6. Figure 4 Income Distribution 65

$\begin{array}{llll}\text { 7. } & \text { Figure } 5 & \text { Number of Children } & 67\end{array}$

8. Figure 6 Number of Children at Home 68

$\begin{array}{llll}9 . & \text { Figure } 7 & \text { Marital Status } & 69\end{array}$

$\begin{array}{llll}\text { 10. } & \text { Figure } 8 & \text { Employment Status } & 70\end{array}$

$\begin{array}{llll}\text { 11. } & \text { Figure } 9 & \text { Residence } & 71\end{array}$

12. Table 4 Cronbach's Alpha Reliability Estimates for LEQ 74

13. Table 5 Comparison of LEQ Scores for the Experimental 75 Group

14. Table 6 Comparison of LEQ Scores for the Control Group 76

15. Table 7 Comparison of LEQ Scores for the Experimental 78 and Control Groups

16. Table 8 Eight Factors of the LEQ: Individual mean scores 80

17. Table 9 Eight Factors of the LEQ: Level of Significance for Control and Experimental Groups. 81

18. Table 10 Eight Factors of the LEQ: Self-reported post-test compared to LEQ-Observer (Experimental group) 84

19. Table 11 Coded Responses to One-on-One Interviews 86 


\section{Chapter 1: Introduction}

In 1990, a workshop held at The University of Wisconsin-Stevens Point entitled "Breaking Down Barriers to Participation of Women in Angling and Hunting" participants identified 21 barriers to participation in traditionally male-dominated outdoor pursuits (Thomas, 1997). As a result, a three-day workshop that focused on teaching women the necessary skills to hunt, fish, camp and enjoy other outdoor pursuits was held in Wisconsin in 1991. It was called "Becoming an Outdoors-Woman $(\mathrm{BOW})$ ". Dr. Christine Thomas has been instrumental in sharing this concept that has since been adopted by 40 states and several Canadian provinces.

Many have already benefited by the existence of BOW. According to BOW Director, Diane Lueck, BOW programs have helped to shape the future by providing women with skills to enjoy the outdoors. Resource management agencies benefit because employees gain an understanding of the role of fish and wildlife management. Environmental groups benefit because women are learning the importance of environmental protection. Manufacturers and retailers benefit because woman represent the fastest growing market for outdoor equipment and clothing (www.uwsp.edu/cnr/bow.htm, 2004).

BOW International has grown rapidly throughout the years and now services more than 20,000 women annually (www.uwsp.edu/cnr/bow.htm, 2004). International status and the recent leveling off of overall participation numbers may indicate the program has reached maturity (DeGraaf, Jordan, \& DeGraff, 1999). The overwhelming 
success of BOW will ultimately lead to greater competition whereby modifications to the existing program should be examined. The widespread acceptance and popularity of this program indicates that there have been and still remain a need to help women become more confident and comfortable in the outdoor environment and their pursuit of outdoor adventure activities.

The introduction of adventure education has provided a more structured learning environment that continues to help those who seek a challenge and an opportunity for growth. Adventure education has gained in popularity since its introduction in the United States in the early 1960s when Outward Bound first opened its doors to the American public. Ropes courses were and continue to be an integral part of the Outward Bound program. The course was originally designed by Kurt Hahn in Wales to prepare young sailors for necessary survival skills at sea. Participants of the program would swing on ropes, cross rope bridges between tree tops, and climb up and down roped cargo nets or smooth wooden walls (Priest \& Gass, 1997). The early ropes courses were created to mimic life aboard ship. Ropes courses continue to provide an exciting challenge for individuals of all ages despite the reason for participation.

An underlying premise of ropes courses is the concept of introducing groups of individuals to perceived high risk tasks allows participants to challenge their psychological development and personal growth (Pazmino-Cevallos, 2003). Getting up and over the wall can be symbolic of any personal or professional struggle a participant may be experiencing. Pre-established boundaries are widened, goals are established 
and communication is increased through adventure endeavors such as ropes courses (Ewert, 1988). Assessing the benefits of ropes courses is an important research question in the field (Priest \& Lesperance, 1993; Eagle, Gordon \& Lewis, 2000; Neill, 2003).

There has been a growing body of research focusing on the benefits of ropes courses. However, this body of research has focused itself in terms of the group served, the setting, the instrument used and the type of experimental design used. According to a meta-analysis of 15 studies conducted throughout the 1990s on outcomes of nontherapeutic ropes course studies, ten resulted in statistically significant positive change (Bunting \& Donley, 2002). The recommendations of the meta-analysis encouraged future investigation into specific challenge course components (Bunting \& Donley, 2002).

In terms of the group served on the ropes course, studies have focused on recreational use and outcomes of varied ages, gender and background (Goldenberg, 1997; Goldenberg, Klenosky, McAvoy \& Holman, 2000). More specifically, studies have focused on youth groups (Dyson, 1995; Eagle, Gordon \& Lewis, 2000; Terry, 2002; Boyle, 2002) or college groups (Sottile, Parker \& Watson, 2000). In contrast, fewer studies have focused on the use of ropes courses as a means for professional development for adults (Priest \& Lesperance, 1994; Daniels, 1994; Priest, 1996; Carroll, 1999). Even fewer studies have focused on adult women in a non-therapeutic setting (Hart \& Silka, 1994).

There has been a cluster of studies focusing on the therapeutic use of ropes courses for adolescent girls (Long, 2001) and adult women (Stopha, 1994). Typically, many of these studies focused on the therapeutic application of ropes courses used to 
help participants address and overcome emotional, psychological and behavioral issues. "Women on the Ropes" programs have helped women to overcome fears associated with oppression, sexism and traditional women roles in society (Stopha, 1994).

Many ropes course studies have tended to focus on the instrument used to measure the benefits of ropes courses. Typically, these studies have measured the change in self-concept of the participants on the ropes course (Marsh, Richards \& Barnes, 1986). Instruments used in past studies involving adventure education programs has been designed specifically for assessment purposes and not for measuring developmental changes (Neill, Marsh \& Richards, 2001). Other advocates of the adventure education field have determined "what they have personally seen, heard and felt provides sufficient evidence for many wider claims" that adventure programs work (Neill, 2003 p. 4). Conceptual frameworks for better understanding how and why meaningful change takes place for women experiencing outdoor recreation is scarce (Pohl, Borrie, \& Patterson, 2000). The Life Effectiveness Questionnaire has been developed to identify, evaluate and determine change that occurs in adventure education (Neill et al, 2001).

A few studies have utilized the Life Effectiveness Questionnaire with a simple pre-post test experimental design (Eagle et al, 2000; Boyle, 2002). The validity in a pre-post design depends upon the quality of the instrument, the use of control and/or comparison groups, and whether follow-up testing was conducted (Campbell \& Stanley, 1963). As noted by Neill (2003), a problem with these studies is that they don't 
measure the long term effects which can lead to a better understanding of the impact these programs have on participants.

Outward Bound, Project Adventure and other adventure education programs continue to utilize ropes courses as an integral part of their programs. A natural environment such as a traditional ropes course encourages self-awareness and personal responsibility (Walsh \& Golins, 1976). Ropes courses continue to be utilized by a variety of groups in a multitude of settings and have successfully evolved to meet group and interpersonal development needs. Various studies that have measured the effects of ropes course participation have reported increased trust and cooperation and have improved communication and decision-making skills (Hans, 2000).

Experiential education or "learning by doing with reflection" has gained momentum in the United States over the past 40 years, and this suggests that "people learn best by direct and purposeful contact with their learning experiences" (Priest \& Gass, 1997, p. 17). As noted by Priest (1990), "the premise of adventure education is that change takes place in individuals and groups due to their participation in challenging problem-solving tasks." (p. 114). A full day on a ropes course provides a challenging environment where these problem-solving tasks take place. An intensive, full-day adventure experience at a ropes course likely consists of ice-breakers, de-inhibitizer exercises, and beginning trust and spotting activities (Rohnke, 1989). Upon completion of this sequence of activities, groups are then introduced to the low rope elements where group development is the focus. By following this progression of activities, groups accept challenges and generally succeed; giving them more confidence 
to move on to more difficult tasks (Pazmino-Cevallos, 2003). The final phase of the day introduces the high rope elements and turns the focus to individual challenge with group support. Trained facilitators are imperative to the process of guiding clients through reflective processes so they can discover their own learning through the experience (Priest \& Gass, 1997). Debriefing and reflection greatly contribute to the impact of the learning experience for both groups and individuals and aid in the transfer of learning to everyday living.

Adventure education programs such as ropes courses are designed to offer holistic, incremental and organized activities that enable success, failure, goal setting and choice (McKenzie, 2000). Adventure programs are divided into four specific categories that include recreational, educational, developmental and therapeutic program emphases (Priest \& Gass, 1997); and ropes courses are seemingly aligned with each of these programming areas. For instance, a summer camp may use the ropes course experience as a recreational option, yet an increase in self-confidence for campers may add a developmental focus. School groups, corporations and volunteer organizations utilize ropes courses for educational purposes. Therapeutic programs view the experience as an approach to counseling that offers many parallels to the challenges clients face in their everyday lives.

Numerous variables have been studied related to the impact of ropes course participation. Of all the outcomes of adventure programming that have been examined, self-concept has been widely researched (Marsh, Richards \& Barnes, 1986). Self-concept or self-esteem supports the belief that one can influence one's world (Waters \& 
Goodman, 1990). For women-only groups, ropes courses have evoked positive change in self-efficacy (Hart \& Silka, 1994). Colleges and universities have utilized ropes courses to focus on student development (Sottile, Parker; Watson, 2000) and group development within specific academic courses (Bolduc, 1998). Other research has examined the effectiveness of ropes course in developing organizational trust within corporations (Priest, 1996) and the functioning of heterogeneous work groups (Wagner, 1995). Few studies have focused on overall life effectiveness as a result of ropes course participation.

Although it has been over 60 years since Kurt Hahn helped to lay the foundation for ropes courses, there is still limited information on "why" these courses have not only maintained, but continue to flourish among a wide variety of user groups. According to Neill (1999), the organization, dissemination and communication of research findings about the effects of ropes courses has been limited. For instance, ropes courses seemingly enjoy tremendous popularity for employee motivation programs but skepticism exists about whether these courses have a lasting effect (Moses, 1990). It is only in the examination of outcomes and overall life effectiveness that we can gain a fuller understanding of the need for ropes courses in the United States and worldwide.

The conceptual framework of Life Effectiveness not only offers an alternative to existing, off-the-shelf assessment tools, but also provides a multi-dimensional structure to best examine the individual changes that occur as a result of adventure experiences (Neill et al, 1997). Until recently, the necessary assessment tools needed to determine if 
adventure education changed life effectiveness were not available. There has been a need to look beyond self-concept and locus of control when conducting a thorough examination of self. The Tennessee Self-Concept Scale, Rotter's Locus of Control and Marsh's Self-Concept Questionnaire were used in the development of the Life Effectiveness Questionnaire (LEQ) (Neill, Marsh \& Richards, 2003). In fact, self-concept is tied closely to Life Effectiveness in that if one believes her individual life is effective, she will likely influence one's world. The LEQ provides an opportunity for participants to reflect and report on areas that include achievement motivation, active initiative, emotional control, intellectual flexibility, self-confidence, social competency, leadership and time management (Neill, Marsh \& Richards, 2003). Those studies that have used the Life Effectiveness Questionnaire (LEQ) in conjunction with a one-day ropes course experience include groups of female adolescents (Terry, 2002), 7th grade boys and girls (Boyle, 2002) and co-educational high school students (Eagle, 2000).

The Life Effectiveness Questionnaire is proposed to be efficient, sensitive to change, relevant to adventure programs and encompass a broad range of skills associated with successful living (www.wilderdom.com/tools/leq/LEQ WhatIsLifeEffectiveness.html, 2005). Despite the varied settings and LEQ formats chosen, there is a need to expand upon this conceptual framework to explore the impact that adventure experiences, such as ropes courses, have on an all-women's group. Since this framework is relatively new, it has yet to be applied to a group of professional women in a non-therapeutic setting. As more women attempt to attain a balance among work, family, friends and leisure, it is imperative that overall life effectiveness is 
examined. Furthermore, there have been no published studies that have focused on working women's life effectiveness prior to, immediately after and one month following ropes course participation. This researcher has selected a pre-existing program that is available to women who desire to learn new skills or improve existing skills in various outdoor pursuits and become more comfortable in a wilderness setting.

The setting for the study was the Maryland Department of Natural Resources "Becoming an Outdoors-Woman" (BOW) Program located at the Western Maryland 4-H Center in Garrett County, Maryland. Although this program is primarily made up of Maryland residents, there were also participants from Virginia, West Virginia, Ohio and Wisconsin. All of the women who registered for BOW elected to participate on their own and were not asked or encouraged to do so. Although the BOW program does focus on women, men are welcomed to participate but generally do not. This program and the group of women provided the ideal subjects to investigate whether a ropes course experience would augment the impact of the women-only program.

In addition to examining the life effectiveness of the BOW participants, this study will also examine modifications to enhance the existing BOW program by adding ropes course participation. Since its origin in 1991, BOW has experienced wide-spread growth that has leveled off over the past few years, indicating a stage of program maturity (DeGraaf, Jordan, \& DeGraff, 1999). When programs reach this climax stage in their development, it is important to examine possible modifications that will augment continued growth while maintaining the continued success of the program. 
Other BOW related research has indicated that participants are happy with the current extended weekend structure of BOW and its focus on adult women. Still other surveys indicate a positive correlation between women who participate in BOW and sales of hunting and fishing licenses (www.uwsp.edu/cnr/bow/research.htm, 2005). According to the BOW International website, research has also been conducted on educational needs of women owning non-industrial private forestlands, influential factors on women's participation in hunter safety programs and identifying special programming needs of teachers (www.uwsp.edu/cnr/bow/research.htm, 2005).

The BOW program provides a convenient format for studying women. The growth of BOW has leveled off since 2000 with approximately 20,000 participants per year. However, no available research has yet to examine program modifications that may inspire the continued growth of BOW. Existing available research about the BOW program has either been in the area of program evaluation or has targeted diversification of participants. These studies suggest that $\mathrm{BOW}$ has a positive impact or benefit on its participants. There is a need for research to assist in the program development and review of the existing BOW program since it has achieved international status and has been maximized in overall participation.

An extensive literature review shows no prior research that examines the relationship between participation in a one-day ropes course experience and the perceived Life Effectiveness on a group of women. There are limited published studies (Hart \& Silka, 1994; Stopa, 1994) available on the outcome of women's participation in ropes courses in a non-therapeutic setting. Outcomes from adventure recreation 
experiences can transfer into other realms of daily life and provide a greater sense of empowerment for women (Henderson, 1996). Research findings have indicated that wilderness recreation can influence women's everyday lives by contributing to their self-sufficiency, life perspectives, connection to others and mental clarity (Pohl, Borrie \& Patterson, 2000). This study builds upon prior research conducted with women in outdoor adventure settings so that approaches which train and empower women may be improved.

\section{Statement of the Problem:}

The purpose of this study is to examine changes in the Life Effectiveness of women participating in a three-day training entitled "Becoming an Outdoors Woman". In an effort to measure long-term effects of ropes courses, this study will also look at changes in Life Effectiveness scores following participation in an all day ropes course experience which takes place two weeks following the BOW program.

\section{Need for the Study:}

This study helps to fulfill several important needs in ropes course studies including adult women in a non-therapeutic setting with one month follow up reporting. The study will also examine a potential program modification for BOW that may help contribute to the continued growth of the program. The educational "black box" identified by Ewert (1983) suggests that "we know something works, but we don't know why or how" provides the empirical foundation for this study. Ewert (1987) 
suggests that research look beyond adventure outcomes and "provide an understanding as to why it happened and how it can be made to happen again" (p. 5). The conceptual framework for how and why meaningful changes take place for women experiencing outdoor adventures must also be explored (Pohl, Borrie \& Patterson, 2000).

Although much of the metaphoric facilitation styles used in ropes course experience focus on creating "real life" scenarios, how their participation actually affects individual lives requires continued investigation. As previously mentioned, recreational experiences can transfer into other realms of daily life, resulting in a greater sense of empowerment for women (Henderson, 1996). In order to fully understand how those positive outcomes affect women's everyday lives, there needs to be additional research that gets at "why" (Pohl, Borrie \& Patterson, 2000). Although previous studies have been conducted on facilitating empowerment through challenge models such as ropes courses (Hart \& Skilka, 1994 ; Stopa, 1994), few explain how skills gained in wilderness and ropes course settings are transferable to women's everyday lives (Pohl, 2000). This study builds upon prior research conducted with women in adventure settings so that approaches which train and empower professional women may be improved. This study will also examine potential modifications for the existing BOW program by exposing the experimental group to a ropes course experience. In addition to applying the Life Effectiveness Theory to a new population, this study intends to build upon the existing conceptual framework to expand its usability and to test its reliability. 
A set of research questions and hypotheses were applied to this study. The following research questions are addressed with qualitative data and relate to how ropes course participation contributes to changes in life effectiveness. The hypotheses of the study are addressed with quantitative data and are used to determine if significant changes take place.

\section{Research Questions:}

- What factors of the Life Effectiveness Questionnaire attribute to the change in LEQ scores following BOW and the ropes course experience?

- What factors of the LEQ increase following ropes course participation and maintain at a similar level one month following the experience?

- How do scores on the Life Effectiveness Questionnaire (LEQ) compare among a women-only group and other populations that have been studied? 


\section{Hypotheses:}

H1: There is no difference in Life Effectiveness Questionnaire (LEQ) scores for pre, post and one month post assessments for women participating in the ropes course (experimental group).

H2: There is no difference in LEQ scores for pre, post and one month post assessments for women not participating in the ropes course (control group).

H3: There is no difference in LEQ scores for pre, post and one month post assessments, and between the ropes course (or experimental group) and the nonropes course (or control group).

\section{Limitations:}

The limitations of the study include differences in leadership styles of those individuals selected by Camp Letts to facilitate the ropes course. However, all facilitators are trained by Innerquest, Inc. and will more likely have had similar experiences in facilitating adult groups. The staff consisted of one woman and two men. One man and woman were Caucasian and one man was African American.

Weather conditions on the day of the training were a concern as precipitation could restrict the use of some elements on the course; however, the weather conditions were ideal. Social structures may be another situational variable as these women will not be totally acquainted with each other if they did not have an opportunity to meet while participating in the BOW training. 
The researcher had hoped to make the ropes course portion of the study available to the experimental group the same weekend as the BOW program. Due to pre-determined schedules and time constraints, the ropes course portion of the study could not take place until two weeks following the BOW program. This obviously decreased the amount of women available from which to select the experimental group.

In order to account for all interactions during the observation of the participants on the ropes course, the study should have incorporated at least two additional observers to compare field notes and individual scores while helping to eliminate any observer bias. It is likely that observer expectations may have biased the scores since the researcher wanted the women to succeed (Fraenkel \& Wallen, 2003).

\section{Delimitations:}

Findings of this study are delimited to females participating in the Becoming an Outdoors Woman three-day training. However, controlling for gender differences in an all-women group may allow outcomes to be generalized for other women who enjoy the outdoors and are taking steps to become more comfortable in a wilderness setting.

\section{Assumptions:}

It is assumed that all subjects will provide honest and accurate information at all times and that all subjects will respond to the pre-test, post-test and one month followup survey. This will minimize attrition. Furthermore, it is assumed that all women arriving at the beginning of the BOW program will agree to participate in the study. 
A confirmatory factor analysis of the Life Effectiveness Questionnaire also indicated very good reliability and structural validity (Neill, Marsh, \& Richards, 1997).

\section{Definition of Terms:}

Adventure Education: Miles and Priest (1990) present the following definition of adventure education. "The purpose of adventure education is that change may take place in groups and individuals from direct and purposeful exposure to: challenge, high adventure, and new growth experiences. This is not to say that adventure education causes change; just that it highlights a need to change and supports any personal decisions to make changes." (p.112).

Life Effectiveness: Generically, life effectiveness is defined as "[T] he notion that there are some personal skills that are important factors in how effective a person will be in achieving his/her desires/wishes in life."

(www.wilderdom.com/tools/leq/LEQWhatIsLifeEffectiveness.html, 2005). For the purposes of this study life effectiveness is measured by the Life Effectiveness Questionnaire (LEQ) instrument.

Ropes Course: “A series of artificially designed obstacles made of ropes, cables, swings, logs and nets designed to promote group cooperation as well as individual achievement" (Schoel, Prouty, \& Radcliffe,1988, p. 93). Ropes courses introduce groups 
of individuals to perceived high risk tasks that allow participants to challenge their psychological development and personal growth (Pazmino-Cevallos, 2003). 


\section{Chapter II: Literature Review}

The purpose of this study is to examine changes in life effectiveness of women participating in a three-day training entitled "Becoming an Outdoors Woman". This study built upon the existing work utilizing the Life Effectiveness conceptual framework in conjunction with a one-day ropes course experience. A summary of the review of the literature suggests the following findings. Historically, there has been an underlying premise that ropes course participation provides a perceived high risk experience that often results in beneficial or positive change for the participant. Next, there is a need to study women only groups since women behave and respond to circumstances quite differently when men are not present. Third, given its history, BOW provides a good setting with which to study women only groups in outdoor activities, in this case, the effects of ropes courses on participants. The BOW program was also ideal since potential modifications need to be explored to help ensure continued growth. Fourth, the Life Effectiveness Questionnaire (LEQ) is an instrument that has received increasing interest as a research instrument since it addresses a broader range of concepts than many of the traditionally used instruments (e.g. selfconcept, Rotter's Locus of Control and Marsh's multidimensional Self-Concept Questionnaires). In conclusion, there is a need based on the review of the literature to examine the long term benefits of a ropes course experience on a women's only group. This study fits into a growing body of research that addresses these research needs. 
This study will explore why adventure challenge environments such as ropes courses play a significant role in changing life effectiveness for women. This review will first examine the history of adventure education and prior studies associated with women and outdoor adventure. Then it will examine the development and current status of Becoming an Outdoors-Woman (BOW) and explore program modifications through the implementation of a ropes course. Since the benefits gained by women as a result of their participation in adventure activities provide the essential foundation for this study, ropes course research, especially the limited area involving non-therapeutic groups of women, will be examined. Lastly, literature regarding the relatively new conceptual framework of Life Effectiveness combined with prior studies using one-day ropes courses will provide the need and rationale for this study.

\section{History of Adventure Education in the United States}

A fundamental premise of adventure education beginning with Kurt Hahn was to effect behavioral changes in program participants. Kurt Hahn, revered as the "grandfather of adventure programming" is credited with starting Outward Bound and bringing adventure education to the United States (Priest \& Gass, 1997). In 1965, instructors at the Colorado Outward Bound School, Paul Petzoldt and Ernest Tapley, recognized the need for well trained adventure education instructors, and this resulted in the creation of the National Outdoor Leadership School (NOLS) (Bachert, 1990). Another well recognized organization that evolved from Outward Bound in 1971 was Project Adventure (PA). Project Adventure was initially integrated into school physical 
education programs, with team building and problem solving incorporated into other aspects of students' lives (Prouty, 1990). Project Adventure has long separated itself from the educational system but continues to teach valuable life lessons in a variety of adventure settings. Early Project Adventure leaders in the mid-70's, Karl Ronke, Dick Prouty and others opened the doors to many through their books on "new games" and initiative activities and ropes courses. Activities such as new games and problem solving initiatives help to minimize individual inhibitions and maximize group fun.

By 1977, Paul Petzoldt was the motivating force behind the development of the Wilderness Education Association (WEA) which also focused on the training of quality outdoor leaders (Priest \& Gass, 1997). At approximately the same time, the Association for Experiential Educators (AEE) was established as the umbrella agency responsible for uniting organizations and individuals with similar missions, interests and love of adventure. AEE publishes the Journal of Experiential Education and hosts international conferences on cutting-edge issues within the adventure programming profession (Priest \& Gass, 1997).

In comparison with other disciplines and professions, adventure education remains in the early stages of development, yet a solid and fundamental foundation has been set in place. As new programs and organizations focused on advancing adventure education are developed and existing ones are refined, the need for concentrating on specific populations, such as women-only groups will become increasingly more important. 


\section{Becoming an Outdoors-Woman (BOW)}

The Becoming an Outdoor Woman (BOW) program has provided an excellent format for studying women and, in particular, their working together as a group in outdoor related pursuits. The reaction from participants is similar across the country. Participants have stated, “Many questions were asked and answered and there wasn't one person who felt intimidated by their lack of knowledge" (www.uwsp.edu/cnr/bow.htm, 2004). According to Rhonda Danner, a participant attending the 11th Annual BOW in Maryland, "These are basically male-dominated activities. It's nice to be with all women. This makes the learning more 'friendly'. That's one of the things that attracted me to BOW" (Guynn, 2004).

In 1999, “The Breaking Down Barriers II” workshop was held to help identify three major barriers to participation. These included: 1) lack of minority role models, 2) distance of workshops to urban centers, and 3) perception that minorities are not invited (www.uwsp.edu/cnr/bow/research.htm, 2004). Strategies identified to address these barriers included: 1) diversifying publicity with images of women from a variety of ethnic groups, 2) inviting minority women to attend, and 3) creating role models by training minority women and men to be instructors of the program (www.uwsp.edu/cnr/bow/research.htm, 2004).

BOW International Director, Diane Lueck, conducted her Master's thesis on BOW in 1995. Lueck examined attitudes of women who attended BOW workshops from Arkansas, Nebraska, Oregon, Texas, and Wisconsin. Her findings concluded that BOW participants were more likely to increase their outdoor activities compared to a 
control group who did not attend BOW. BOW participants also indicated they had more positive feelings about hunting, fishing, and other outdoor activities as a result of the program (www.uwsp.edu/cnr/bow/research.htm., 2004).

Lueck's current research efforts focus on ways to include women with disabilities in outdoor recreation programs. She has stated, "We want to make sure women in underrepresented groups are included in this unique program" (www.uwsp.edu/cnr/bow/history.htm, 2004). "Breaking Down Barriers III" was held in 2002 and focused on specific strategies for women with disabilities (www.uwsp.edu/cnr/bow/research.htm, 2004).

The program has expanded to offer "Beyond BOW" events that allow women the opportunity to apply their newly developed skills learned at BOW. These programs consist of everything from an overnight canoeing trip to a day of turkey hunting or fly fishing. Beyond BOW also provides women an opportunity to meet other women with the same interests who may collectively decide to create their own adventure outings together.

BOW has provided women of all ages an opportunity to grow and learn. According to Karina Blizzard, Associate Director for Maryland Wildlife \& Heritage Service's Information and Education Programs, the age range of the participants in the Maryland BOW program is from 35 and 55 and most of the women come from metropolitan areas (Guynn, 2004). Although learning new outdoor skills may be the initial attraction to BOW, Blizzard indicated that "sisters, mothers and daughters, and friends come to spend time with each other" (Guynn, 2004). In addition to learning 
valuable skills in a non-threatening environment, alumnae of the program often boast about what the program did for their self-esteem. In addition, the camaraderie among those attending the event may be equally important as learning new skills. According to the Assistant Director of BOW, Peggy Ferrell, "Women all across the country have told us, 'BOW has changed my life' which involves more than learning how to set up a tent or tie a fly" (www.uwsp.edu/cnr/bow/history.htm, 2004).

\section{Women and Outdoor Adventure Challenges}

According to Roberts (1998), there is a need to further explore the relationship between women and outdoor adventure. In her Guide to Women's Studies in the Outdoors: A Review of Literature and Research, Roberts (1998), highlights some of the most prominent research to date involving a variety of outdoor experiences and the impact on women participants, especially those involved in women-only groups. The current research indicates that women do respond, react and interact with one another in adventure settings differently than men. Recreation programmers, researchers and educators alike can benefit by understanding the impact that outdoor adventure programs have on women. Roberts and Yerkes (2000), encourage researchers and practitioners to examine existing programs which helps to create a mutual respect and share common ground in a "win-win" situation.

"In the outdoors, women often discover aspects of themselves that they did not know existed prior to challenging themselves in this environment" (Henderson, 1996, p. 196). There is a strong indication that a natural setting away from daily obligations 
allows women to relinquish traditional female roles so they may have an opportunity to fully explore a greater sense of self (Henderson, 1996, Sadker \& Sadker, 1986, Yerkes \& Miranda, 1985). Successfully facing these challenges in the outdoors may help women cast aside limitations that have traditionally been imposed by self, family, friends, colleagues and society as a whole (Pohl, 2000). One of the main therapeutic outcomes associated with wilderness and adventure recreation for women is that of empowerment (Bialeschki \& Henderson, 1993; Kohn, 1991; and Mitten, 1994).

In essence, experiences in adventure recreation help women to assert themselves and learn for the first time to "reclaim their voice" for a renewed sense of empowerment (Brown \& Gilligan, 1992, Bialeschki \& Henderson, 1993, Henderson, 1996). Since working women experience the "second shift" syndrome which encompasses home and family responsibilities following their paid work day, an experience such as BOW offers a welcome change (Hochschild, 1989). Mature, professional women are often so caught up in the care of others that they seldom stop to reflect on their own lives and individual life effectiveness. In fact, women often define themselves by their relationships to other people instead of who they are as individuals (Brown \& Gilligan, 1992). It is important for woman to temporarily escape their daily obligations, focus on self while learning new skills, and meet other women with similar interests.

Professional women with children are continually faced with attempting to fulfill all external expectations placed on them while occasionally attempting to accept new roles that may enrich their personal satisfaction with their lives (Henderson, Bialeschki, 
Shaw, \& Freysinger, 1996). In the workplace, managers need to learn more about career development options that help women balance work, family and leisure so they may become more successful at work and feel better about their lives in general (Henderson \& Bialeschki, 1993). Henderson (1992) makes the recommendation that supervisors conduct training to assist both male and female employees on how to create balance in their lives. Given the many obligations of adulthood, women at mid-life often desire to return to the unfinished business of adolescence (Gilligan, 1982).

The further development of training programs designed specifically for women to further their careers and balance their life is desperately needed (Anderson, 2001). Closer examination of all-women programs will provide an increased understanding of the need and importance for women-only endeavors and the impact on life effectiveness. Many women choose women-only programs because they feel that they will have a better opportunity to learn and practice skills and share common interests (Henderson \& Bialeschki, 1986, 1987, McClintock, 1996, Mitten, 1996). This premise provides a concrete foundation for why programs such as Becoming an OutdoorsWoman have experienced such widespread acceptance and success.

BOW is not the first well known organization that has reaped the benefit of realizing the importance of creating an all-women adventure experiences. Woodswomen, Incorporated has offered an adventure based program for women of all ages since the mid-1980's. According to Denise Mitten, Executive Director of Woodswomen, this environment encourages women to interact in a way that makes them feel comfortable by using explicitly "feminine" behaviors and fostering a 
collaborative, not competitive atmosphere (1996). Mitten's work does focus on adventure therapy, especially working with women survivors of sexual abuse. These women are challenged by the unpredictable environment of the outdoors but gain comfort through learning skills, having positive experiences and being with other women, (Mitten \& Dutton, 1993). However, Mitten (1996) suggests the principles established for Woodswomen, Incorporated trips can easily be applied to working with all groups of women in adventure based experiences. Principles such as making sure participants feel emotionally and physically safe and encouraging women to set their own goals instead of prescribing to the pre-set goals of the program helps to minimize undo stress (Mitten, 1996). Using language that does not indicate a win/lose or right/wrong outcome is also important when working with non-therapeutic groups of women in adventure based experiences. "Using Words like "useful," "workable," "not useful in this situation," and "efficient" can help describe what's going on without being critical or judging" (Mitten, 1996, p.83).

All female groups provide an open and supportive environment where women can engage in non-traditional activities (Yerkes \& Miranda, 1982). Although mature professional women may have strong problem-solving skills when tackling work related scenarios developed for training, they may not always have the confidence to apply those same skills in an unfamiliar context when encountered in a real life setting (Jordan, Kaplan, Miller, Stiver \& Surrey, 1991). Yet women who gain strength and confidence in the outdoors are often able to exhibit that same strength and confidence in their everyday lives (Henderson and Bialeschki, 1987). Women have attributed life 
changes and positive experiences to their participation in outdoor endeavors (Mitten, 1992).

In summary, a review of the literature on women and on women and outdoor adventure challenges suggests that there is a need for additional research that examines women-only groups. According to Henderson (1996), “The creation of connections for women through the outdoors reinforces the spirituality of caring for self, for others, and for the natural world". Also, the review suggests that there is a need for additional studies about programs that provide opportunities for women to conduct a thorough examination of self that result in greater empowerment.

\section{Ropes Courses \& Experiential Education}

Participating in an all day ropes course is beneficial to the individual and the group as a whole. There have been a variety of studies which confirm the use of ropes courses as a means for team development and overall group effectiveness (Priest \& Sproul, 1992; Priest, 1996; Sottile, Parker, \& Watson, 2000). Studies have reported that this combination of challenge, mastery, and success can lead to participant growth (e.g., Iso-Ahola \& Graefe, 1988; Dyson, 1995; Witman, 1995). Individuals are given the opportunity to confront challenges and deal with risk and change which impacts group functioning (Hart \& Silka, 1994). When individuals learn about themselves through adventure experiences, they can gain new perspectives on their strengths and limitations, as well as their interactions with others (Driver, Nash \& Haas, 1987). 
Originally introduced by Project Adventure's early leaders, the philosophy for many established courses is that of "Challenge by Choice". This gives greater emphasis to individuals making their own decisions about their level of participation as opposed to being forced or pressured by others in the group (Prouty, 1990). Ropes courses are designed to push individuals out of their comfort zone to experience challenges that are perceived as being "high risk" when in actuality, the risk is quite minimal. The challenges presented in ropes course activities are also thought to have the greatest influence on program outcomes if they increase incrementally (Kimball \& Bacon, 1993). Ropes course activities may also foster positive changes which help participants experience personal growth and development, enabling them to overcome limits that are self-imposed (Eagle, 2000).

Facilitators have begun to align individual and group needs with appropriate metaphoric presentation that will ultimately enhance the experience and provide a lasting impact on the participants. Historically, many agencies offering ropes course options to corporate groups have operated under the "one size fits all" ideology and applied the same tool to every client regardless of his/her particular problems (Falvey, 1988). In some instances, the same tool could work effectively as long as the facilitator is aware of group and individual needs and understands the approach necessary to meet those needs to help create the desired outcome. The closer a metaphor is to one's real life, the greater the likelihood that transference will occur (Hart \& Silka, 1994). A well thought out metaphoric presentation is essential to introduce and work through the various initiatives and elements but the debriefing process can allow participants to 
come full circle in their experience. A metaphoric style of facilitation will provide the platform for participants to feel more comfortable when disclosing their anxieties, feelings and emotions.

Hart and Silka's (1994) model used to study the relationship between ropes course participation and self-efficacy emphasized using the ropes course as a "learning laboratory" (p. 113). This study focused more on how facilitators use women-centered metaphors to impact the ropes course experience for all-women groups. The groups of women studied included women executives, women living in public housing, adolescent women in treatment, adolescents from culturally diverse backgrounds, graduate students and women who have been sexually abused (Hart \& Silks, 1994). Furthermore, the study reported the goals of adventure-based experiences for women are: "1) to help them enjoy self-respect; 2) to take appropriate emotional risks; 3) to transform crises into opportunities for growth; 4) to resolve conflicts without sacrificing integrity; 5) to ask for what is needed; and 6) to recognize life accomplishments while understanding personal and professional potential" (Hart \& Silka, 1994, pg. 113). Despite the diverse backgrounds of those women in the study, there were reported changes in the women's ability to take risks, problem solve and assert their ideas or feelings about the process (Hart \& Silka, 1994).

Women have a tendency to focus on their failures instead of their accomplishments even when participating in a ropes course. In Hart and Silka's study (1994), one woman focused on the fact that she didn't look down while traversing across a $50 \mathrm{ft}$. cable instead of celebrating the fact that she made it across. However, it is 
more typical for group energy and excitement to heighten immediately following a ropes course experience, often referred to as Post Group Euphoria (Priest \& Spoul, 1992). Following up with participants at a later time can provide a more accurate indication of the experience. Depending upon each participant's frame of reference and prior life experiences, a day on the ropes course can often transfer into everyday life by reminding the participants of other challenges they face and how they have chosen to deal with each of them.

Goldenberg et al, (2000), helped provide a better understanding of the range of benefits that result from participating in a ropes course program through a means-end investigation. This investigation centered more on group versus individual outcomes and was conducted using both full-day and half-day, permanent and portable ropes course structures. Other notable benefits of ropes course participation include increased self-esteem, increased physical fitness and enhanced group cooperation (Priest \& Sproul, 1992). Much of the other research regarding ropes courses has focused specifically on therapeutic and treatment use (Gillis \& Cason, 1994) or the impact of facilitation styles on outcomes (Braverman, Brenner, \& Desmond, 1990). The opportunity for personal growth and development that emphasize reflection on one's life provides the theoretical basis to incorporate ropes courses as the treatment for both therapeutic and non-therapeutic groups. 


\section{Life Effectiveness}

The introduction of the Life Effectiveness Questionnaire (LEQ) in the late 1990's has aided in developing a new approach for assessing how individuals feel about his/her personal life. The framework for the LEQ was first developed by Neill, Marsh \& Richards (1997) to measure personal changes likely to occur as a result of adventure education programs. The Tennessee Self-Concept Scale, Rotter's Locus of Control, and Marsh's multidimensional Self-Concept Questionnaires (SDQ's) were widely recognized and regarded as time tested instruments used in the development of the LEQ (Neill, 1999).

Seven major stages of pilot testing preceded the development of the current LEQH. In these studies, both male and female participants of all ages and with diverse backgrounds were studied to ensure a non-biased structure that had widespread application (Neill et al 2001). Confirmatory factor analysis was conducted on the original 64-item questionnaire of which a 24-item, 8 factor model was created (Neill, 1997). This analysis indicated very good reliability and structural validity (Neill, Marsh, \& Richards, 1997). The LEQ has been subjected to rigorous statistical tests to establish its validity and continual tests and retests to establish its reliability (Boyle, 2002). The LEQ has been used as an evaluation tool in other investigations of outdoor education program effectiveness (Eagle, 1999; Neil, 1999; Neill \& Flory, 1999 \& 2000). The LEQ has a high internal consistency with alpha levels from the eight sub-scales ranging from .78 to .93 and test-retest correlations ranging from .60 to .81 (Neill et al, 
1997). In addition, since the instrument is proprietary, permission was received from James Neill to use the LEQ-24 for the purpose of this study.

As part of the development of the LEQ test, Neill (1999) administered the LEQ to over 3,000 participants of all ages and ability levels participating in Outward Bound Australia and related programs lasting 2 to 26 days. Based upon these and prior studies, the areas of self-concept and locus of control related most to women's lives and how they viewed their own life effectiveness. Several other research studies have utilized the LEQ in conjunction with a ropes course experience (Eagle, 2000; Terry, 2002; Boyle, 2002).

Based upon an extensive review of literature, the authors identified independent concepts relating to potential life effectiveness domains (Neill et al, 1997). The designers of the instrument wanted it to be efficient, sensitive to change, relevant to adventure programs and encompass a broad range of skills associated with successful living (Neill, 1997). Although the LEQ was created with adults in mind, the instrument has evolved to include specialized formats such as a corporate adventure training version and a youth-at-risk version. One interesting area that has evolved is using the LEQ following a one-day ropes course. Although this format has been applied to elementary through high school students, no documented research has been done on an all-women group.

The LEQ has most often been used for the purpose of program evaluation. Three such studies administered the LEQ prior to and following a one-day adventure program involving middle school (Terry, 2002; Boyle, 2002) and high school students 
(Eagle, Gordon \& Lewis, 2000). Two of these studies also took place in the state of Maryland. Other programs that have utilized the LEQ instrument have yet to be published but are mentioned on the web-site, www.wilderdom.com, created and updated by one of the authors of the LEQ, James Neill.

In Terry's study (2002), twenty-four adolescents, grade six through eight, from a teen program at the YWCA were studied following a one day adventure course. According to Terry (2002), the LEQ is a well designed instrument but requires individuals to choose one of the pre-determined guidelines for interpreting the effects of an adventure experience as opposed to making open responses. In Terry's study, the LEQ scores remained similar across three measurements, indicating no change in total scores for the two groups studied (journaling or non-journaling) (Terry, 2002).

In Terry's study, half of the participants completed journaling topics associated with social competence, locus of control and self-confidence twice a week for two weeks following the ropes course experience. The other group did not keep a journal. Participation in the groups was voluntary. The Life Effectiveness Questionnaire was administered four times throughout the study. A pre-test (before the ropes course), a post-test (immediately following the ropes course), two weeks following the ropes course (the end of the journaling period) and one month following the adventure course (two week following the journaling period) were administered to both groups.

The results of the study indicated that there were marginally significant differences on the levels of locus of control and on the total LEQ score from the pre-test to the two week follow up. There were no significant differences between the 
journaling group and the non-journaling group. The study did indicate an increase in LEQ due to the adventure course which remained constant at the one month follow up (Terry, 2002).

Boyle's study also examined if the Initiative and Confidence Program influenced participant's perception of certain life effectiveness skills (2002). Participants ranged in age from twelve to fourteen and 137 students participated in the study. The study took place over a period of two days with half of the participants completing the program one day and the other half completing the course the following day. A pre-test was conducted prior to participation in the full day initiatives and low ropes course and the post-test was collected at the end of the same day. No control group was used in this study.

The results of the study indicated an increase in the overall LEQ mean score. Seven of the eight factors of the LEQ had statistically significant increases. Emotional control showed the highest overall increase, whereas, self confidence showed the smallest increase. The varying weather conditions between the two days of testing appeared to have an impact on Task Leadership scores (Boyle, 2002).

Lastly, the LEQ was utilizes in conjunction with a one day ropes course for one hundred school students ages ten to eighteen (Eagle, Gordon and Lewis, 2002). No control group was used in this study. There were slightly more females (54\%) than males and one-third (75\%) of the group had ever completed a ropes course before. The purpose of this study was to determine the effectiveness of a one day adventure program determined by significant improvement in the total LEQ scores from pre-test 
to post-test. The pre-test was administered prior to the day of the program and the post-test was administered one month following the ropes course experience.

The results of the study indicated statistically significant increases in total LEQ scores for the entire group at the time of the post-test one month following the adventure experience. Time Management, Task Leadership and Emotional Control sub scales were also significantly higher. This study concluded that a one-day adventure intervention does have an impact on student's development (Eagle, Gordon and Lewis, 2002).

\section{Eight Factors of the LEQ}

The LEQ is a 24-item instrument with eight factors. This section briefly reviews each of these factors. The eight factors are: Achievement Motivation, 2) Active Initiative, 3) Emotional Control, 4) Intellectual Flexibility, 5) Self-Confidence, 6) Social Competence, 7) Task Leadership, and 8) Time Management (see appendix C). In prior studies conducted by both Neill (2003) and Eagle (2002), the three of the eight factors identified as having significance differences between pre-test and post-test included time management, task leadership and achievement motivation.

Achievement Motivation. Achievement motivation refers to the extent to which the individual is motivated to achieve excellence and put the required effort into action to attain it. This is also being involved in keeping the group "on track" and goaloriented (Neill, Marsh \& Richards, 1997). Motivation theory indicates a need for achievement and power which make people respond in a goal-oriented manner (Ruf \& 
Chusmir, 1991). Factors influencing motivation include direction and intensity of effort, choice of behavior, ability to sustain motivation and resulting behavior change (Priest \& Gass, 1997).

Active Initiative. Active Initiative is best described as the extent to which the individual likes to initiate action in new situations. This would include developing and presenting a plan of action necessary to solve the task at hand (Neill, Marsh \& Richards, 1997).

Emotional Control. Emotional Control is the extent to which the individual perceives she maintains emotional control when faced with potential stressful situations (Neill, Marsh \& Richards, 1997). Societal norms often dictate acceptable emotional displays by both men and women (Kelly \& Hutson-Comeaux, 2000). However, getting excited and overly enthusiastic, common in the anticipation and participation of adventure activities, is not viewed as lacking emotional control.

Intellectual Flexibility. Intellectual flexibility is the extent to which the individual perceives she can adapt her thinking and accommodate new information from changing conditions and different perspectives (Neill, Marsh \& Richards, 1997). Facilitating and supporting the team approach would lead to the most favorable outcomes. “Good leaders are humble, continually learning people who believe they must constantly push themselves out into the unknown to maintain their intellectual flexibility and humility" (Kerfoot, 1997, p. 276).

Self Confidence. Self confidence is described as the degree of confidence the individual has in her abilities and the success of her actions (Neill, Marsh \& Richards, 
1997). These individuals approach situations with an "I can do" attitude and demonstrate self-assurance through their words and actions. Mental clarity can result from wilderness and adventure pursuits and contribute to feeling grounded or at peace with oneself and finding purpose in life (Pohl, Borrie \& Patterson, 2000).

Social Competence. Social competence refers to the degree of personal confidence and self-perceived ability in social interactions (Neill, Marsh \& Richards, 1997). This would include freely and openly interacting with others. Skill deficit, social anxiety and low self esteem frequently imply unskilled or incompetent social behavior (Curran, 1977).

Task Leadership. Task Leadership is another factor represented in the LEQ and is the extent to which the individual perceives she can lead other people effectively when a task needs to be done, and productivity is the primary requirement (Neill, Marsh \& Richards, 1997). The task at hand and the relationship of those attempting the complete the task are two critical dimensions of leadership (Hersey \& Blanchard, 1982). Getting the job done and attempting to maintain a positive atmosphere among the group is the ultimate goal for any task leader (Priest \& Gass, 1997).

Time Management. Time management is the extent that an individual perceives that she makes optimal use of time (Neill, Marsh \& Richards, 1997). These individuals would be aware of time constraints, pre-determined schedules and maximize their experience in the time frame provided. To be able to analyze and assess whether the amount of time spent on a project is aligned with individual or group priorities helps to ultimately manage one's time (Thomas, 2000). 
In summary, compared with other instruments (e.g. self concept), the life effectiveness questionnaire measures a broader range of concepts. This makes it a potentially good instrument to use as a research tool. In addition, aiding in its increased use, the instrument has been tested in terms of its validity and reliability.

Despite the on-going fascination with ropes courses in the United States and around the world, there are few studies which examine the impact that completing a full day ropes course has on an all-women group. In particular, middle-aged professional women in a non-therapeutic setting. Women-only programs, especially those involving outdoor pursuits, have gained in popularity over the past 20 years. These single gender programs, such as the Becoming an Outdoors-Woman, have reportedly attributed to personal growth and empowerment (Henderson \& Bialeschki, 1986). There is a growing need to understand the situations and experiences that may help women feel a greater sense of life effectiveness and overall purpose. Additionally, there is a need to investigate potential modifications for BOW to not only maintain but increase participation. 


\section{Chapter III: Methodology}

The purpose of this study is to examine changes in life effectiveness of women participating in a three-day training entitled "Becoming an Outdoors Woman".

Researchers in the adventure education field must continue to rethink traditional research methodologies and utilize assessment tools that have greater relevance and use for the practitioner (Robert \& Yerkes, 2000). Neill (2002) recommends that in order for future research in adventure-based programs to be more effective, it should describe the program's methods in more detail, investigate individual differences on outcomes, and incorporate effect size benchmarks in program evaluation studies. Agencies and organizations continue to offer outdoor adventure programs based upon the feeling and perception that something wonderful happens when people and adventure meet versus researching exactly what that "wonderful something" is (Ewert, 1987). The study considered most of these basic recommendations suggested by Neill (2002), by providing both a practical and theoretical approach to the study. A variety of methods for both data collection and analysis were employed.

This Chapter is subdivided into seven sections: Research Design, Description of the Program, Instrument Development, Sampling, Collection of the Data, Data Analysis, and Summary. 


\section{Research Design}

This study used a quasi-experimental design where the subjects were women who participated in a three-day "Becoming an Outdoors Woman" (BOW) training during the fall of 2004 . The subjects were randomly divided into a control and experimental group. The experimental group experienced the treatment of the ropes course; the control group did not. The dependent variable, life effectiveness as measured by the LEQ instrument, was measured three times in a pre-test, post-test and follow-up test. This enabled the study to measure the long term differences in life effectiveness that resulted from participation in the ropes course. The research design is presented in Table 1.

\section{TABLE 1}

Quasi-Experimental Research Design

\begin{tabular}{llccc}
\hline Group & Pre-test & Treatment & Post-test & Follow-Up \\
Experimental & $\mathrm{R} \mathrm{O}_{1}$ & $\mathrm{X}_{1}$ & $\mathrm{O}_{2}$ & $\mathrm{O}_{3}$ \\
Control & $\mathrm{R} \mathrm{O}_{1}$ & & $\mathrm{O}_{2}$ & $\mathrm{O}_{3}$ \\
\hline
\end{tabular}

R: Randomly selected participants into two groups $\mathrm{O}_{1-3}$ LEQ

$\mathrm{X}_{1}$ Ropes Course

This study was considered a quasi-experimental study for two reasons. First, in an effort to measure the long term effects, a one-month follow-up test was administered to participants. According to the designs listed in Campbell and Stanley (1963), the use of the follow-up test is different than the standard pre- post-test design. Second, 
although every effort was made to insure that subjects were randomly assigned to the two groups, there was some selective sorting that occurred among participants. This sorting became apparent when the demographic data between the control and experimental groups was analyzed. Again, Campbell and Stanley (1963) noted the importance of randomized selection of participants in differentiating between a truly experimental and quasi-experimental design.

In addition to measuring life effectiveness, this study conducted three other analyses in an effort to triangulate the analysis or to complement the life effectiveness findings. First, a demographic analysis of all participants was conducted prior to conducting the pre-test. Second, a Life Effectiveness Questionnaire Observer Sheet was completed by an observer on each experimental group participant who completed the ropes course. Its assessment of participants paralleled the results of the participants' LEQ test scores. Last, eight one-on-one interviews were conducted on eight randomly selected participants one week after their ropes course experience. Each of theses analyses is discussed in more depth later in this chapter.

\section{Description of Programs}

The ropes course portion of this study was held at the YMCA Camp Letts facility in Edgewater, Maryland. The adventure challenge course at the YMCA Camp Letts is situated on a peninsula located on 219 acres of wooded area along the South River in the eastern shore of Maryland. The course was designed and built by Innerquest, Inc. and the facilitators are also trained by the same agency. In keeping with the YMCA 
mission of developing a strong mind, strong body and strong community, the adventure challenge course proposes to encompass all three (www.ymcawashdc.org, 2004).

Although the woman who participated in the ropes course portion of the study came from all over the state of Maryland, nearby Northern Virginia and West Virginia, the travel time to the course was no more than $1 \frac{1 / 2}{2}$ hour drive for any one participant. Since these women initially met in the most western region of the state during their BOW experience, this experience brought them to the eastern shore for the second part of the study.

At Camp Letts, the adventure challenge course facilitators at the YMCA Camp Letts are well trained young adults with varied degrees of experience. The facilitators' skills and experience proved to be an ideal combination that worked well with a group of professional women. An intensive, full-day adventure experience at a ropes course generally consists of warm-ups and name games, trust and spotting activities, grass games, initiatives, low and high ropes (Rohnke, 1989). Similarly, a typical day at Camp Letts entails name games, trust activities, group initiatives or "grass games" and the team challenge or low ropes course, and the high adventure or high ropes course (YMCA-Adventure Challenge Brochure, 2004). The group did follow this precise progression of events but greater attention and time was placed upon the initiative exercises and less on the low ropes. Only one low ropes element, the Spider Web, was executed and successfully completed. Following lunch, the entire afternoon was dedicated to the high ropes. Overall, the group gave the outward appearances of 
working well together and enjoyed succeeding at the many challenges presented throughout the morning program.

\section{Instrument Development}

The instrument used to collect the data was the Life Effectiveness Questionnaire (see Appendix A). According to Neill, Marsh \& Richards (1997), the LEQ-H or LEQ-24 is simple, yet sensitive to change when administered as a pre-test/post-test and followup assessment. The framework for the LEQ was first developed by Neill, Marsh \& Richards (1997) to measure personal changes likely to occur as a result of adventure education programs.

The LEQ-24 has 24 questions. Each of the 24 questions on the LEQ is scored on a range from 1 to 8 , with 1 being "False, Not Like Me" to 8 being "True, Like Me". Individual scores range from a low of 24 to a high of 192. If someone were to answer "8" or "True, Like Me" for each of the 24 questions, the highest possible total score on the LEQ was 192, the highest level of life effectiveness. Likewise, if "1" or "False, Not Like Me" were the answer to each of the questions, the lowest possible total score on the LEQ was 24 .

In order to better understand the LEQ-24, an operational definition for each of the eight factors is provided. Each of the eight factors has three corresponding questions on the LEQ that is directly attributed to each factor (see Table 2). 
TABLE 2:

Eight Factors of the LEQ-H

\begin{tabular}{|c|c|}
\hline Number & Factor/Questions \\
\hline & TIME MANAGEMENT \\
\hline 1 & I plan and use my time efficiently. \\
\hline 9 & I do not waste time. \\
\hline \multirow[t]{2}{*}{17} & I manage the way I use my time well. \\
\hline & SOCIAL COMPETENCE \\
\hline 2 & I am successful in social situations. \\
\hline 10 & I am competent in social situations. \\
\hline \multirow[t]{2}{*}{18} & I communicate well with people. \\
\hline & ACHIEVEMENT MOTIVATION \\
\hline 3 & When working on a project, I do my best to get the details right. \\
\hline 11 & I try to get the best results when I do things. \\
\hline \multirow[t]{2}{*}{19} & I try to do the best that I possibly can. \\
\hline & INTELLECTUAL FLEXIBILITY \\
\hline 4 & I change my thinking or opinions easily if there is a better idea. \\
\hline 12 & I am open to new ideas. \\
\hline \multirow[t]{2}{*}{20} & I am adaptable and flexible in my thinking and ideas. \\
\hline & TASK LEADERSHIP \\
\hline 5 & I can get people to work for me. \\
\hline 13 & I am a good leader when a task needs to be done. \\
\hline \multirow[t]{2}{*}{21} & As a leader I motivate other people well when a task needs to be done. \\
\hline & EMOTIONAL CONTROL \\
\hline 6 & I can stay calm in stressful situations. \\
\hline 14 & I stay calm and overcome anxiety in new or changing situations. \\
\hline \multirow[t]{2}{*}{24} & I stay calm when things go wrong. \\
\hline & ACTIVE INITIATIVE \\
\hline 7 & I like to be busy and actively involved in things. \\
\hline 15 & I like to be active and energetic. \\
\hline \multirow[t]{2}{*}{23} & I like to be an active 'get into it' person. \\
\hline & SELF CONFIDENCE \\
\hline 8 & I know I have the ability to do anything I want to do. \\
\hline 16 & When I apply myself to something I am confident I will succeed. \\
\hline 24 & I believe I can do it. \\
\hline
\end{tabular}


Careful examination of each of the eight factors that make up the Life Effectiveness Questionnaire provides a greater understanding of the instrument and its application to this study. Tracking each of the factors at the pre-test, post-test and one month follow-up test provided an explanation of what factors effected change in the total LEQ score.

Demographic Survey. Prior to the pre-test, a ten question demographic survey was administered to all of the subjects in the study. The purpose of the demographic survey was to determine if there were any underlying differences between the experimental and control groups. The demographic survey included questions related to age, ethnicity, marital status, children, gross household income, employment status, level of education, and living situation. "Living situation" referred to owning or renting a home or living with family or significant other.

\section{Life Effectiveness Questionnaire Observer Sheet. The Life Effectiveness}

Observation Sheet (see Appendix J) was used by the researcher to track experimental group participant behavior through the day on the ropes course. The purpose of this instrument was to provide a cross-check with participant LEQ scores. The LEQ Observation Sheet consists of nine factors that include time management, social competence, achievement motivation, intellectual flexibility, task leadership, emotional control, active initiative, self-confidence and self-responsibility and is based upon the eight factors that make up the LEQ-24 used in this study. Since self-responsibility is not included in the LEQ-24, it was omitted from consideration. Each of the eight factors were rated on an eight point scale ranging from 1 being "false" to 8 being "true". Scores 
of 2 to 3 are considered "more false than true" and scores of 6 to 7 are considered "more true than false". Scores of 4 to 5 on the scale are "neither true nor false".

The Life Effectiveness Questionnaire Observer Sheet instructed the observer to rate their perceptions of each participant's personal effectiveness in each of the eight categories. The observer rated each of the ropes course participants on each the eight factors. These scores were compared with how participants rated themselves on the Life Effectiveness Questionnaire.

The LEQ-Observer sheet has been commonly used by the parents, teachers or supervisors of the participant being observed as opposed to being used by the researcher. Aside from the instruction provided on the observer sheet which encourages honest observations, there was no scientific method provided for how to score a group of subjects of which there was no prior in-depth relationship previously established. The methods used by this researcher to score the subjects were modified to use the existing Observer sheet to provide for this additional data collection.

The researcher was the only observer who scored each of the nineteen participants using the LEQ Observer Sheet. Since the researcher had extensive experience as a ropes course facilitator working with multiple groups, she collaborated with the facilitators at Camp Letts to set up the group and plan for the progression of activities for the day. The researcher and lead facilitator decided to keep all nineteen women in one group which was both beneficial and restricting. Providing the entire group the same experience helped to ensure consistency yet the large group was limited to initiatives and low ropes elements that could easily engage a group of this size. 
The LEQ-Observer Sheet was arranged by using the eight of the nine factors (self-responsibility was omitted), that make up the Life Effectiveness Questionnaire or LEQ-24. The observer provided a score from 1 through 8 , with 1 being false and 8 being true for each participant throughout the day. The LEQ Observation Sheet data was examined by a trained observer to provide background information regarding individual behavior and actions that occurred during participation on the ropes course. The coding scheme for each of the eight factors was associated with the three statements that equate to each factor. The subscales that were observed and recorded in the same manner included active initiative, social competence and, task leadership. These were ranked based upon the participant's ability to offer solutions, exhibit a comfort level in addressing the others or provide a leadership role for the group. The check marks were tallied at the close of the day to indicate a culminating score for each of these four categories. The participant having the most check marks in each category set the standard and was given the highest score in that category of an 8 . For example, a participant with the most checks in time management with five checks total, was given the score of 8. Participants with four checks received a 7, those with three checks, received a 6 and so on. The one participant not having any checks in time management received the lowest score of 3 which indicated a "false, not like me".

The other four subscales that included achievement motivation, emotional control, self-confidence and intellectual flexibility were given a rating (1-8) for each of the participants following every group initiatives and ropes course activities. At the end of the day, an average of the total score was assigned to each of the nineteen 
participants for these four categories. These subscales were a bit easier to detect as most participants were highly motivated, exhibited emotional stability, gave outward appearances of being confident, and were generally open to new ideas and suggestions of others. If there were no obvious verbal or non-verbal indicators that participants exhibited in these areas, they were given a score of 8 following each new problem. Likewise, a participant who indicated their disapproval of a particular solution without the group talking it through received a minus point in the area of intellectual flexibility, giving them a score of 7 for a particular activity.

The researcher conducted a non-participant observation where the observer is with the group but not participating in the activities. The observer followed the group closely enough to hear the conversations, watch the interactions taking place and take notes. Since the researcher had met the participants previously at BOW, they were aware that the researcher's observations and writings were affiliated with the study.

\section{One-on-One Interviews}

In an effort to determine the "how" and "why" of the ropes course experience, a one-on-one interview was conducted on selected participants. Using a simple random sample, eight participants of the experimental group were randomly selected the day of the ropes course to participate in a follow up interview one week after their ropes course experience. Each interview was conducted via phone and audio recorded with the verbal consent given by each of the participants. Participants were asked to e-mail the researcher regarding what days and times would be most convenient for them. The 
taped interviews were transcribed verbatim and a content analysis was conducted to produce general schemes. The interview questions were asked of each of the selected participants (see Appendix I). The interviews were semi-structured and included seven open-ended questions. The interview questions focused on the "how" and "why" to help answer the research questions. "How" did the ropes course experience effect participants and "why" did the experience have an impact. The observations of the women on the ropes course as well as follow-up random interviews helped to provide a greater understanding of overall impact that ropes courses have on participants. If women perceived their life effectiveness as favorable, they were more likely to experience a balance of work, family, friends and their own leisure. The interviews and observations provide a triangulation approach to analyzing the data and aided the study in providing greater generalization.

\section{Sampling}

The sampling technique used involved a convenience sample of those woman registered for the Becoming an Outdoors-Women (BOW) program. Women who registered for the BOW program were assigned to the control group or the experimental group through self-selection. More than one week prior to the BOW program, preregistered participants received a letter (see appendix E) from the researcher indicating the nature of the study which was accompanied by a letter of endorsement and support for the study by the BOW Coordinator. The letter also indicated that women would be asked to complete the ropes course portion of the study two weeks following BOW. 
The maximum number of participants allowed into the program was 100. At the time the letter was mailed, 89 women were registered.

\section{Collection of Data}

Using the research design described in Table 1, the data was collected during the fall of 2004 at three different points in the study. The following procedures were used to collect the data during the pre-, post-, and follow-up tests.

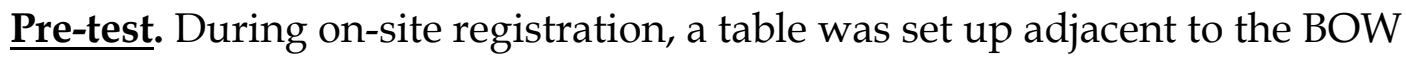
registration table to encourage women to participate in the study. Letters explaining the study (similar to the ones they received in the mail) were also available at this time. Women were asked to sign in by providing their names, addresses, e-mail and phone numbers. Their names were assigned to an identification number that tracked participants throughout the study. Sign in sheets were developed; one with odd numbers and the other with even numbers. Participants were asked to complete a ten question demographic survey and the first of three Life Effectiveness Questionnaires.

Eighty-five of the ninety-one registrants agreed to participate in the study. Participants were asked if they would be available to participate in a ropes course two weeks following the BOW weekend. The date, time commitment and location were given to the participants. From the list of total participants, 25 of the 85 women indicated their interest in participating in the ropes course. A total of five participants not selected for the experimental group was asked to complete a second survey prior to departure but were placed on a list of alternates in the event that others cancelled. 
Post-test. Twenty of the 25 individuals were randomly selected for the experimental group and their names were posted on the main lodge on the second evening of the program. The women not selected were asked to complete a second questionnaire prior to their departure on Sunday. At the evening program, the researcher met briefly with the twenty women and told them about the ropes course. The participants were given information sheets that entailed directions, a basic schedule of events for the day and what to wear. Questions were answered and the researcher indicated that she would be in touch with each of them via e-mail to set up a carpool for any one interested in driving together. Participants were asked to contribute $\$ 15$ per person to offset the cost of the ropes course and help to assure their commitment and participation. Of the original 20 participants, there was a drop out rate of $5 \%$ or one person that did not show on the day of the event due to illness, leaving the experimental group with a total of 19 participants.

The control group did take the post-test LEQ on the last day of the BOW training prior to departure. The research assistant collected the questionnaires in the morning. Both the research assistant and researcher collected the questionnaires during the lunch hour. Sixty-one of the 85 post-test surveys were collected on site. The 20 participants selected to participate in the ropes course did not complete their post surveys at this time. Only four individuals from the control group received post-test surveys in the mail. All four were mailed and returned within the week. After e-mail reminders and phone calls, 19 women participated in the ropes course experience at Camp Letts. The group worked as a whole instead of two smaller groups to ensure consistency. 
Participants were asked to sign a photo waiver so pictures could be taken throughout the day. The LEQ Observation Sheet was used by the researcher throughout the day to track participant behavior as it related to the LEQ-24 instrument. A simple random sample of eight participants or approximately 40 percent of the experimental group were again selected to participate in qualitative interviews one week following the ropes course experience. Following the facilitator debrief at the close of the day, the group gathered and the LEQ was administered to the experimental group for the second time. The group was reminded of the follow-up survey in one month and was told they would be alerted via e-mail prior to the mailing.

Follow-Up Test. One week following the ropes course, eight of the participants were interviewed and asked open ended questions about their ropes course experience and the impact, if any, it had (see Appendix I). The open-ended instrument consisted of seven questions which focused on individual perceptions of their ropes course experience. The first question was "Did you learn more about yourself as a result of participating in the ropes course?" Other questions involved emotions experienced, "real life" analogies and perceptions on group dynamics. Another question explored possible factors that had an impact on participation. Participants were also asked to share any other thoughts about their day on the ropes course. The final and most lighthearted question asked participants to identify a song, book or saying that came to mind when thinking about their day on the ropes course. 
All eight participants were interviewed by phone and asked if the conversation could be audio-taped. All consented and the interviews were taped and later transcribed verbatim. The interviews were all completed over the span of one week.

One month following the BOW program, the 65 participants in the control group were mailed the final surveys. Fifty-eight of the 65 participants provided an e-mail address and were alerted to look for their surveys in the mail. The letter attached to the surveys requested that they complete the surveys immediately. All but nine of the 65 surveys were returned within a three week period of time. Two e-mail reminders were sent to the entire group, 18 phone calls were made and 12 second surveys were mailed to ensure a greater level of return.

The LEQ was administered one final time to the experimental group via mail with prior e-mail notification to those individuals who participated in the ropes course. Again, the cover letter requested that they complete the survey and mail it back immediately. Thirteen of the 19 participants responded within the week. The additional six were e-mailed again and left phone messages. One participant was faxed an additional copy and returned her copy by fax. All of the remaining six surveys were eventually received. The experimental group was sent a slide show via e-mail of their day on the ropes course after the researcher received the final survey. All data were entered and prepared for data analysis. 


\section{Data Analysis}

The Statistical Package for Social Sciences (SPSS) was used to run the data analysis. Three hypotheses were tested in this study. The first hypothesis used the General Linear Model, pairwise comparisons, to measure the differences between the three observations (the pre-test, post-test, and the one month follow-up) for the experimental group. Similarly, the second hypothesis used the General Linear Model, pairwise comparisons, to measure the differences between the three observations (the pre-test, post-test, and the one month follow-up) for the control group. The third hypothesis used an independent samples t-test to measure the differences between the experimental and control group for each of the three observations (the pre-test, posttest, and the one month follow-up).

Complementing the testing of the hypotheses in this study, four other analyses on the data were performed. First, a series of demographic questions were analyzed using descriptive statistics. Second, since the LEQ instrument was constructed using eight sub-scales, a repeated measures ANOVA was used to measure the differences between the three observations for the control and experimental groups for each subscale. Third, the Cronbach's alpha reliability estimates were conducted for each of the eight LEQ factors throughout the three testing cycles (pre, post, and follow-up). Lastly, a qualitative analysis was conducted using the LEQ observation sheets and one-on-one interviews. This analysis is discussed in the following section. 
The LEQ Observation Sheet. The LEQ Observation Sheet data was examined to provide background information regarding individual behavior and actions that occurred during participation on the ropes course. The coding scheme was based on the eight factors of the LEQ. Verbal or non-verbal responses associated with the three statements that equate to each of the factors (see Table 2) would be used for coding. For instance, if one of the participants made a comment about the time allocated toward a particular problem or referenced the need to move on for the sake of time, the category, time management, was reported on the observation form for the individual. The other subscales that were observed and recorded in the same manner included active initiative, social competence and, task leadership. Again, these were ranked based upon the participant's ability to offer solutions, exhibit a comfort level in addressing the others or provide a leadership role for the group. For example, a person stating, "Come on ladies, we need to work together to get this job done" would be coded under task leadership. Likewise, a participant who would be readily available to spot or assist without being asked to do so would be demonstrating active initiative. The checkmarks were tallied at the close of the day to indicate a culminating score for each of the four categories. The researcher ranked the eight participants based on frequency of observed behavior for each of the four categories. Those participants not having any checks in that category would receive the lowest score. In the case of time management, this would be a score of 3 which would indicate a "false, not like me".

The other four subscales that included achievement motivation, emotional control, self-confidence and intellectual flexibility were simply given a rating (1-8) for 
each of the participants following every group initiatives and ropes course activity. At the close of the day, a final score was assigned to each of the nineteen participants for these four categories. These subscales were a bit easier to detect as most participants were highly motivated, exhibited emotional stability, gave outward appearances of being confident and were generally open to new ideas and suggestions of others. If there were no obvious verbal or non-verbal indicators that participants exhibited in these areas, they were given a score of 8 following each new task. Likewise, if a participant indicated their disapproval of a particular solution without the group talking it through, they would receive a minus point in the area of intellectual flexibility, giving them a score of 7 for a particular activity.

The LEQ-Observer sheet has been commonly used by the parents, teachers or supervisors of the participant being observed as opposed to being used by the researcher. Aside from the instruction provided on the observer sheet which encourages honest observations, there was no scientific method provided for how to score a group of subjects of which there was no prior in-depth relationship. The methods used by this researcher to score the subjects were modified to use the existing LEQ Observer sheet to provide for additional data collection.

The qualitative interviews of eight of the nineteen participants were transcribed verbatim and a content analysis was conducted to determine common responses and specific themes associated with their participation on the ropes course. A standardized open-ended interview method was used to increase the comparability of responses (Frankel \& Wallan, 2003). After the text was transcribed, common themes were 
identified and counted for frequency of occurrence. The basis for the content analysis was the response to the seven interview questions by eight of the ropes course participants. The observations and interviews provided the qualitative piece to aid in comparison of the results of the LEQ scores self-reported by the participants.

The multi-method approach provided triangulation when interpreting the results and strengthens the validity of the study findings. In order to better understand both the differences and similarities of the female subjects in this study, the results section will be begin with the response rates followed by the demographic data. Graphs were also created and display the demographic portion of the data.

\section{Summary}

The purpose of this study is to examine changes in life effectiveness of women participating in a three-day training during the summer of 2004 entitled "Becoming an Outdoors Woman". This study tested these effects on 89 participants in a quasiexperimental design that used the LEQ instrument to measure these effects. In addition, the study sought triangulation in its research approach. A demographic survey collected demographic information from all participants prior to the pre-test. Complementing the LEQ data, the Life effectiveness Questionnaire Observer analysis was conducted by the research observer for all the ropes course participants. Third, in depth one-one interviews of randomly selected participants were conducted after their ropes course experience to help further assess the effects of any changes in life effectiveness that might have occurred. 


\section{Chapter IV: Results}

The purpose of this study is to examine changes in life effectiveness of women participating in a three-day training entitled "Becoming an Outdoors Woman". The study used a quasi-experimental design to test its hypotheses. The study results are outlined as follows: Response Rates, Demographic data, Hypothesis Testing results, Qualitative results (observations and interviews), and Summary.

\section{Response Rates}

Pre-Test. The pre-test was conducted during the registration period for the BOW program on Friday afternoon when participants completed the questionnaire. An additional five participants completed their initial questionnaire at the evening program. A total of 85 participants agreed to complete a demographic survey and the first Life Effectiveness Questionnaire.

Post-Test. Sixty-five women comprised the control group and sixty women completed the post-test LEQ prior to departing from the BOW program. Five of the participants in the control group were mailed their second survey since they did not attend breakfast or lunch on the final day of BOW to complete the post-test. All of the participants in the control group returned their second surveys. The experimental group completed their second LEQ after they completed the ropes course which occurred two-weeks following the BOW program. At that time, all nineteen of the experimental group participants completed the post-test LEQ. 
One Month Follow-up. Since the one month follow-up LEQ was sent to the participants via mail with e-mail reminders, only fifty-six of the original sixty-five women in the control group completed the one-month follow up. For the experimental group, all nineteen women completed the one month follow up LEQ after numerous letters, e-mail and phone calls were made to remind the participants to return the questionnaire.

\section{Demographic Data}

The demographic data were collected from all participants during the registration sign-in period for the $\mathrm{BOW}$ program (see Appendix D). Of the ten questions asked pertaining to demographics, only three people chose not to answer the question regarding gross household income. Otherwise, all eighty-five original participants of the study completed the demographic information specified below. A comparative summary of both groups are provided for each of the demographic variables.

Age. The most frequently occurring age group for both the control (30.8\%) and experimental groups $(47.4 \%)$ was the $41-50$ year old (Figure 1). Regardless, the distribution of the two groups was not the same. Almost half of the women in the experimental group (47.4\%) were in the $41-50$ year old category. In contrast, slightly less than one third (30.8\%) of the women in the control group were in this age group. This finding is consistent with other BOW programs where according to Karina 
Blizzard, Coordinator of the Maryland BOW program, most participants were generally middle-age women (personal communication, September 15, 2004). The age distribution of the control group was bimodal, containing more young women and more older women than the experimental group. In the control group $15.4 \%$ of the women were in the 16 to 30 year old categories compared with only $5.3 \%$ of the women in the experimental group. Regarding older participants, over one out of four women (26.1\%) in the control group were over 51 years of age. In contrast, only 10.1 percent of the women in the experimental group were in this same age category. 
Age

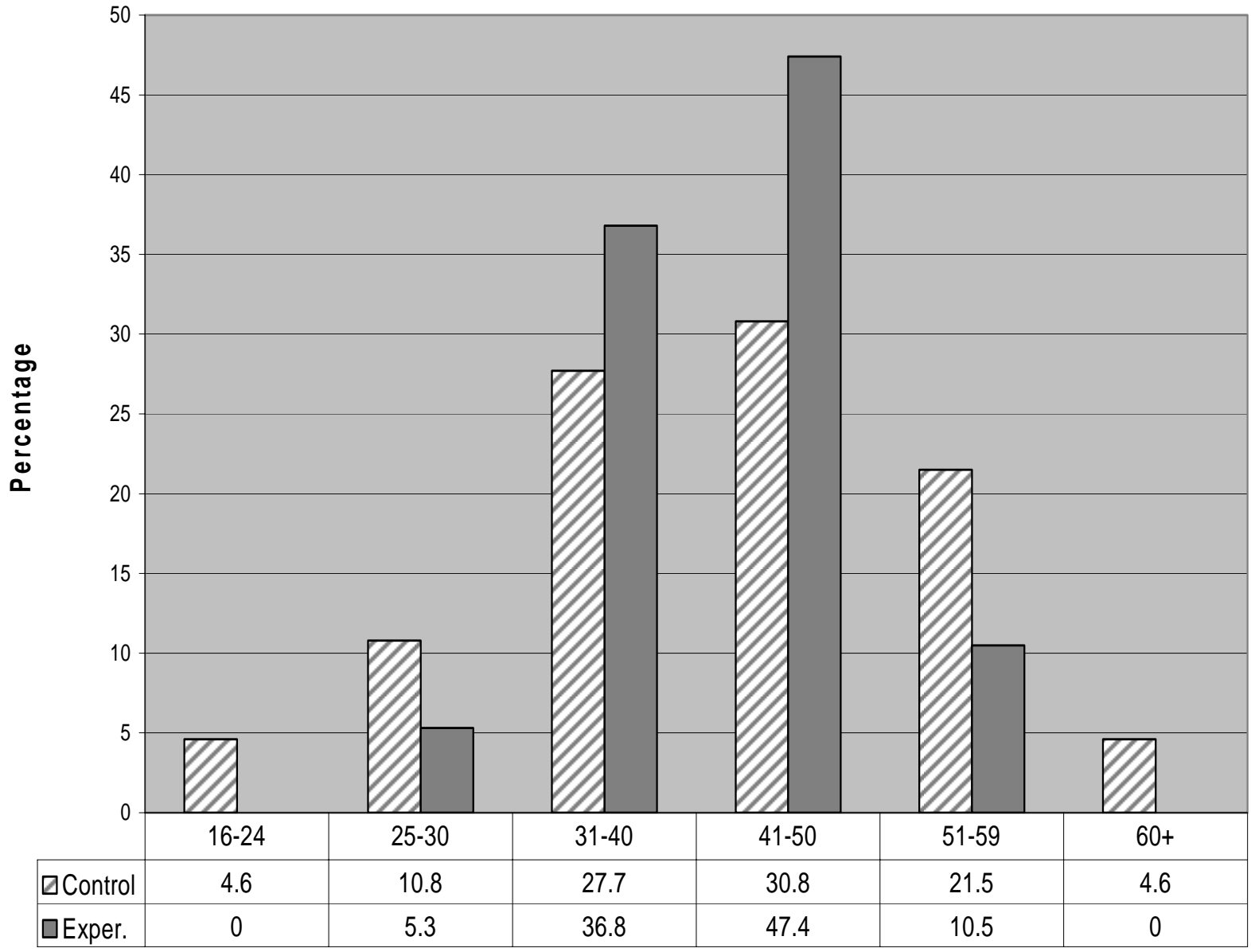

Figure 1: Age distribution for experimental group $(n=65)$ and control group $(n=20)$ participating in the 2004 Maryland Becoming an Outdoors-Women Program. 
Ethnicity. Most participants identified themselves as Caucasian (Figure 2). All the women in the experimental group (100.0\%) and almost all $(96.9 \%)$ of the women in the control group identified themselves as Caucasian. This finding reinforced the delimitation made in Chapter 1 which delimited the subjects to Caucasians.

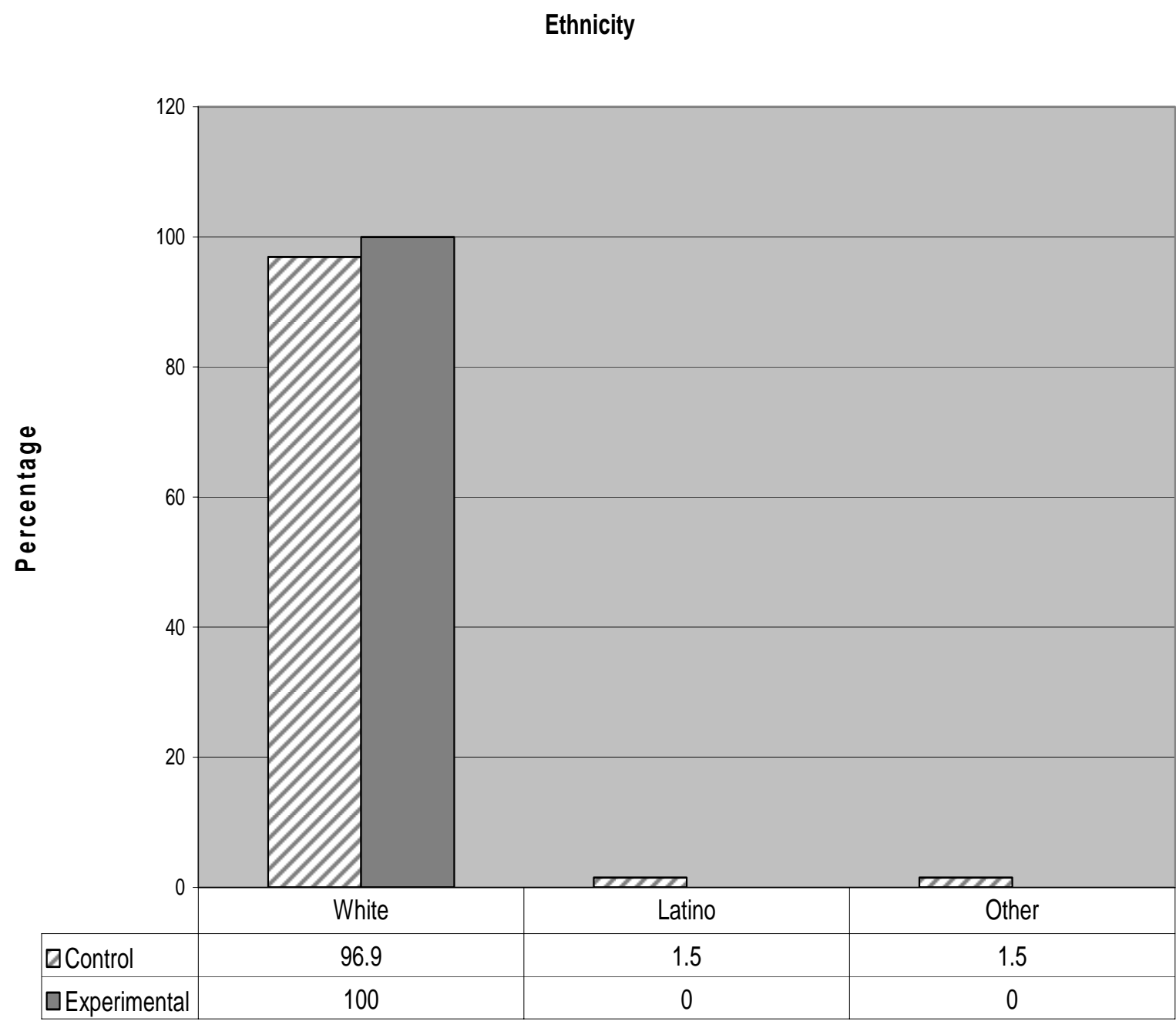

Figure 2: Ethnicity distribution for experimental group $(n=65)$ and control group $(n=20)$ participating in the 2004 Maryland Becoming an Outdoors-Women Program. 


\section{Education.}

In general, women in the experimental group were less educated than their counterparts in the control group. Nearly half $(47.4 \%)$ of the women in the experimental group reported that their highest level of education was a high school, associates, or professional degree. Slightly less than 14 percent of the control group and one-fourth (26\%) of the experimental group's highest educational level was a high school diploma or the equivalency (Figure 3). Nearly half (47\%) of the experimental group's highest degree was an Associates degree. Participants with a Bachelor's degree or higher consisted of 74 percent of the control group and 53 percent of the experimental group. Of those reported percentages, only 10 percent of the experimental group had graduate degrees; and over 30 percent of the control group had graduate or post-graduate degrees. 


\section{Education}

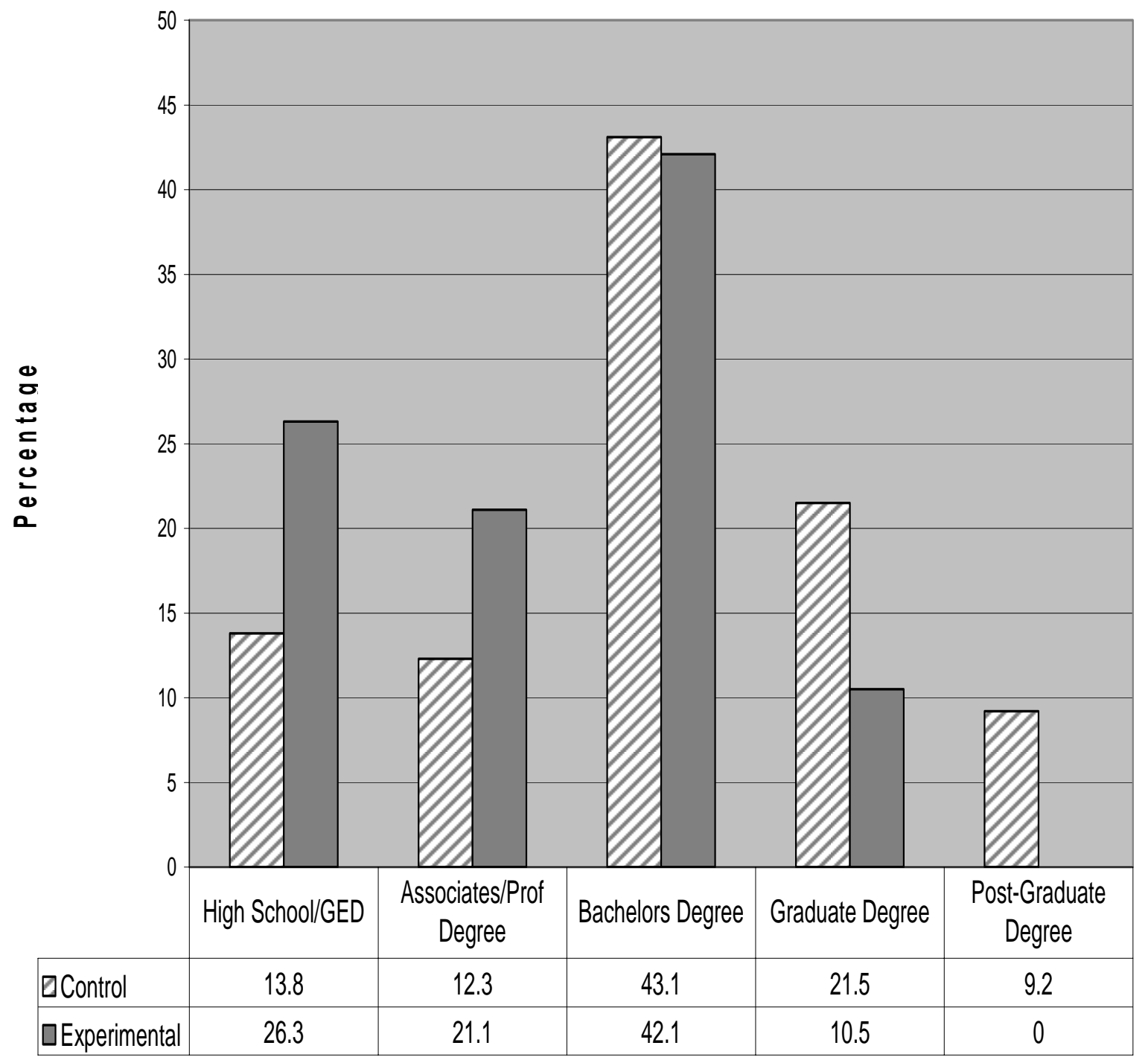

Figure 3: Education distribution for experimental group $(n=65)$ and control group $(n=20)$ participating in the 2004 Maryland Becoming an Outdoors-Women Program. 
Income. In general, women in the control group reported higher income then their counterparts in the experimental group (Figure 4). In addition, the distributions for both groups tended toward bi-modality. For example, 21 percent of the women in the control group reported an income in the $\$ 75,000-100,000$ category, and $24 \%$ reported an income in the $\$ 150,000-\$ 200,000$ category. In contrast, one third (33.3\%) of the experimental group reported income in the $\$ 30,000-\$ 50,000$ category and 27.8 percent reported an income in the $\$ 75,000-\$ 100,000$ category. For gross household income, 58 percent of the control group reported making in excess of $\$ 75,000$ with 46 percent of the experimental group falling into this same category (Figure 4). Twentyfour percent of the control group and 11 percent of the experimental group reported income of $\$ 150,000$ to $\$ 200,000$. Those reporting income ranges of $\$ 30,000$ to $\$ 50,000$ included 33 percent of the experimental group and 16 percent of the control group. 


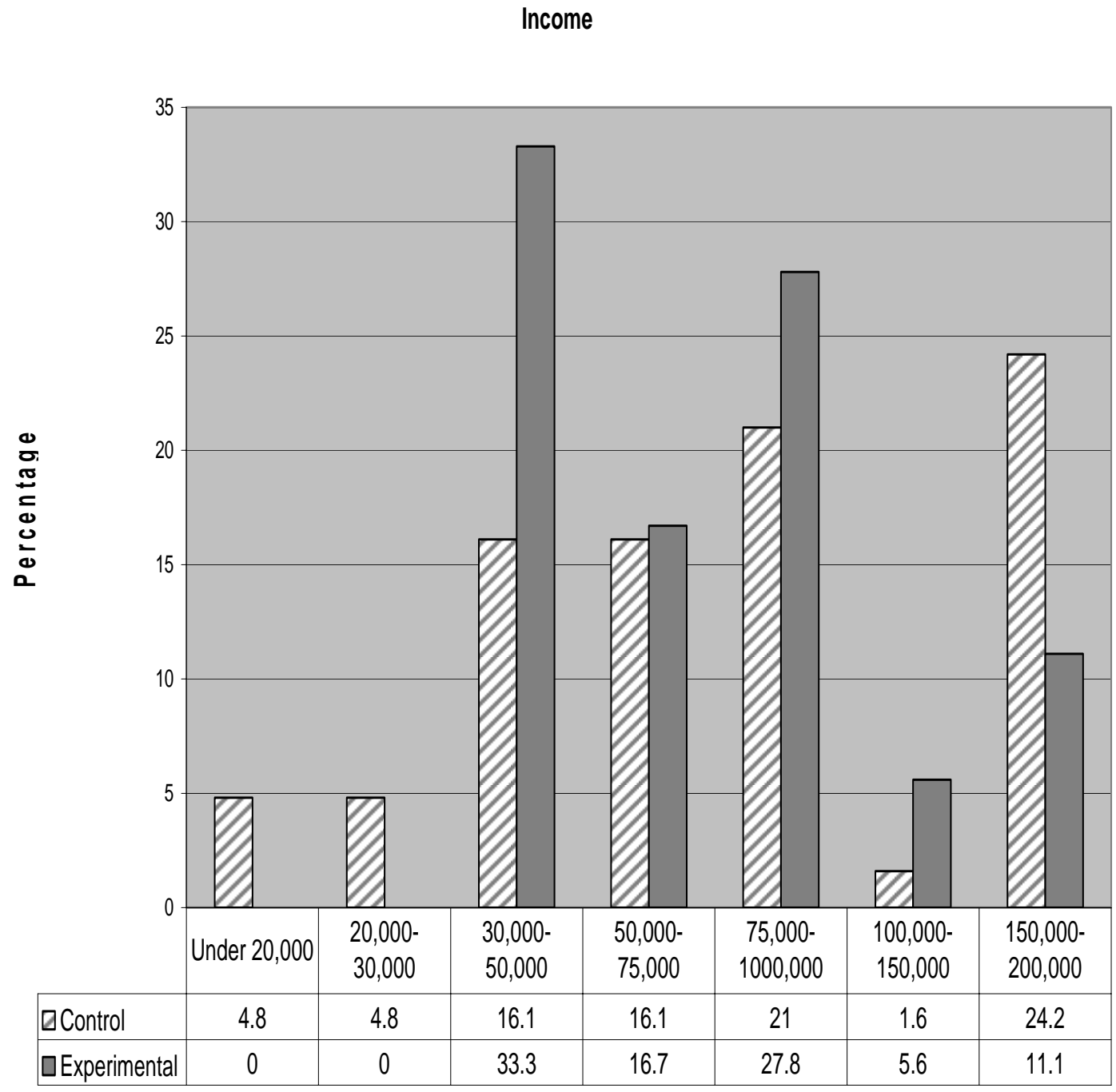

Figure 4: Income distribution for experimental group $(n=65)$ and control group $(n=20)$ participating in the 2004 Maryland Becoming an Outdoors-Women Program. 
Children. Two demographic questions addressed family status. The first question asked how many children the women had and the second question asked how many children were still at home. This section focuses on the first question.

In contrast with the experimental group, almost twice as many women in the control group reported that they had children (Figure 5). Forty-one percent of the women in the control group and 21 percent of women in the experimental group reported having no children. In contrast, almost two out of three women (58.5\%) in the control group indicated that they had children and almost four out of five women $(79 \%)$ in the experimental group reported that they had children. 
Number of Children

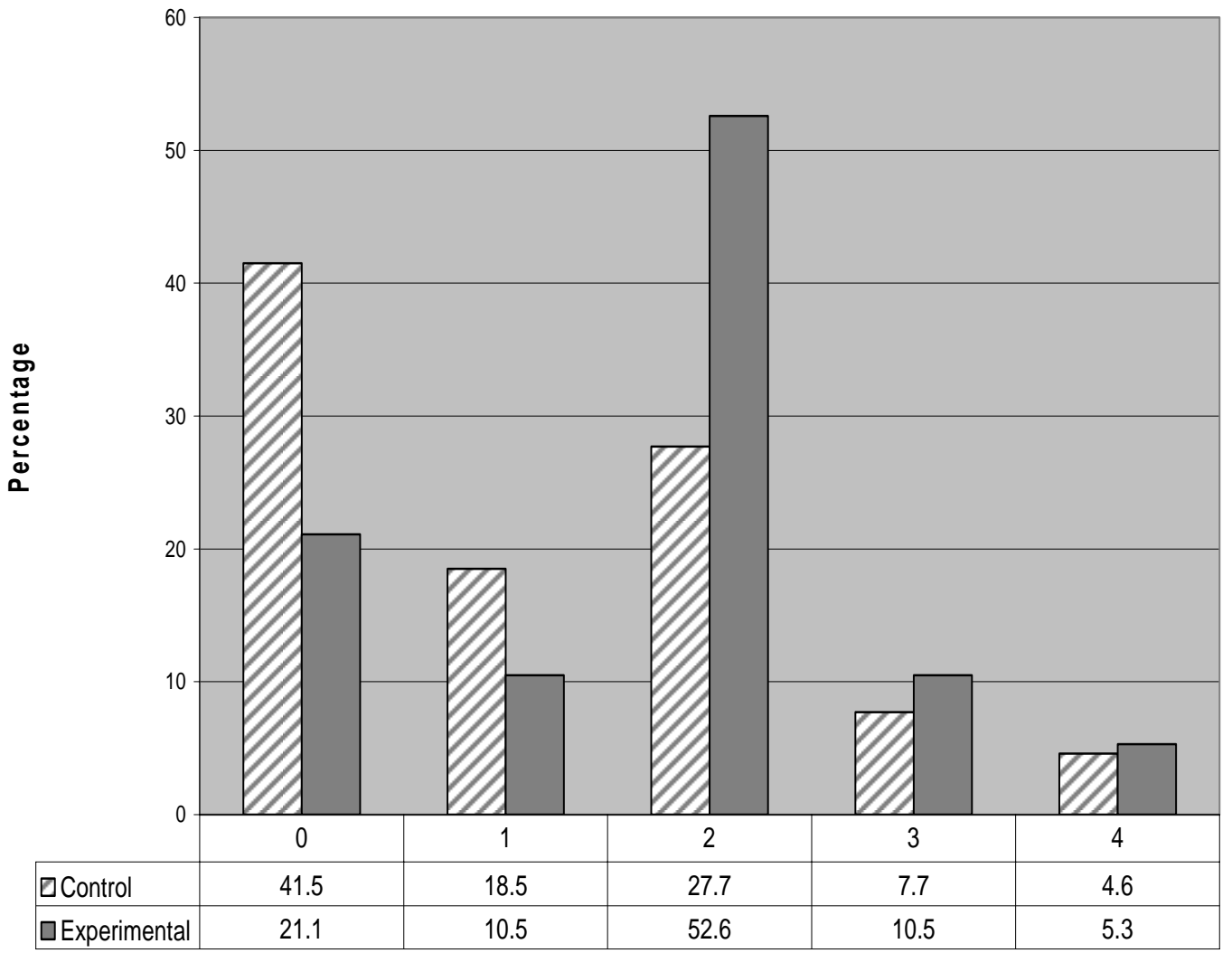

Figure 5: Number of children for experimental group $(n=65)$ and control group $(n=20)$ participating in the 2004 Maryland Becoming an Outdoors-Women Program. 
Children Living at Home. The second question on family status focuses on how many children were still living at home. Similar results to the first question were found. More women in the experimental group (68\%) than the control group (37\%) reported that their children still lived at home (Figure 6). Sixty-three percent of the control group had no children living at home compared to less than one-third $(31 \%)$ of the experimental group who were experiencing the freedom of no children at all or empty nesters.

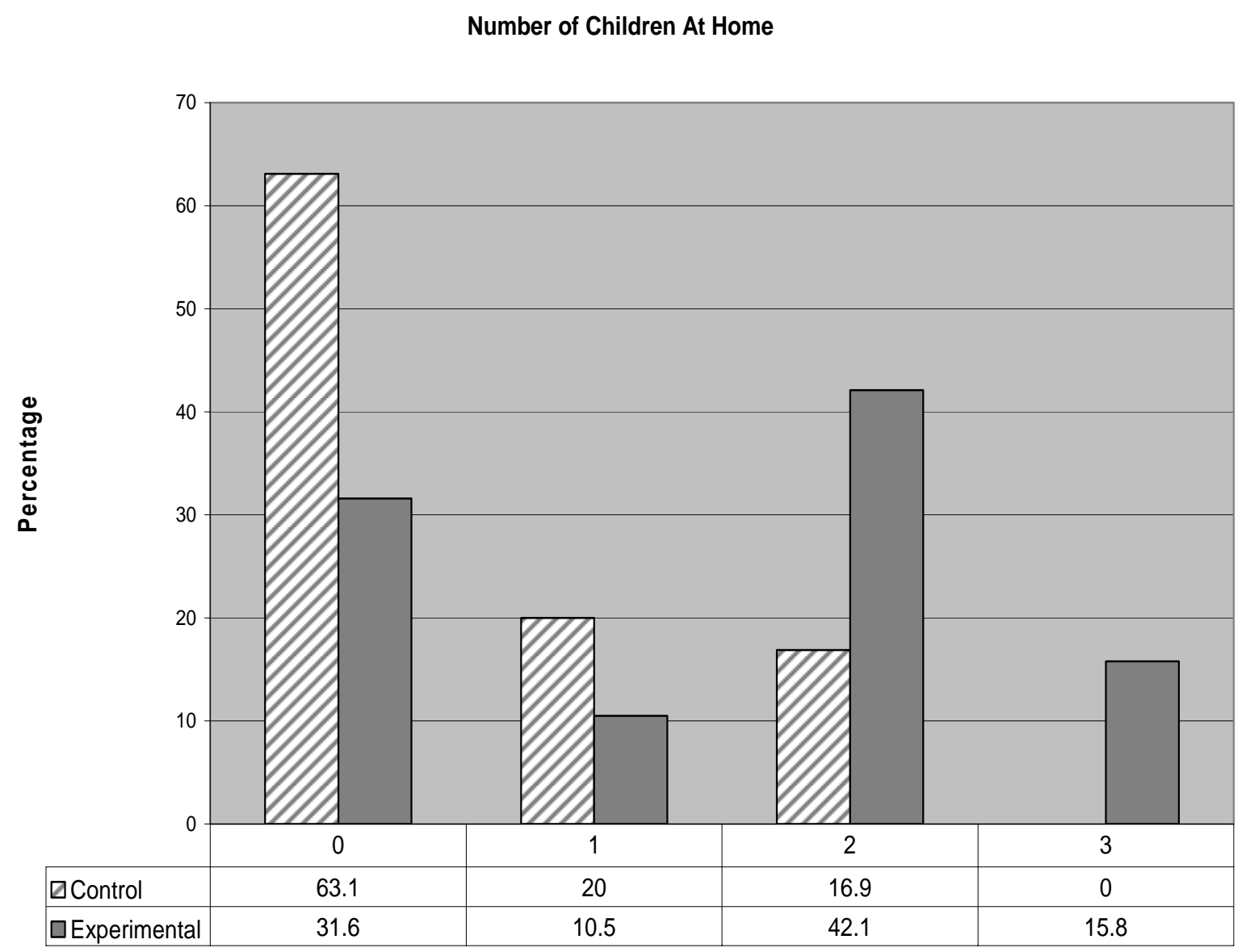

Figure 6: Children living at home for experimental group $(n=65)$ and control group $(n=20)$ participating in the 2004 Maryland Becoming an Outdoors-Women Program. 
Marital Status. Participants of the experimental group were more likely to be married (58\%) than the participants of the control group (43\%) (Figure 7). Those reporting that they were single or living with a significant other were 31 percent of the control group and 21 percent of the experimental group. All other participants reported being separated or divorced.

\section{Marital Status}

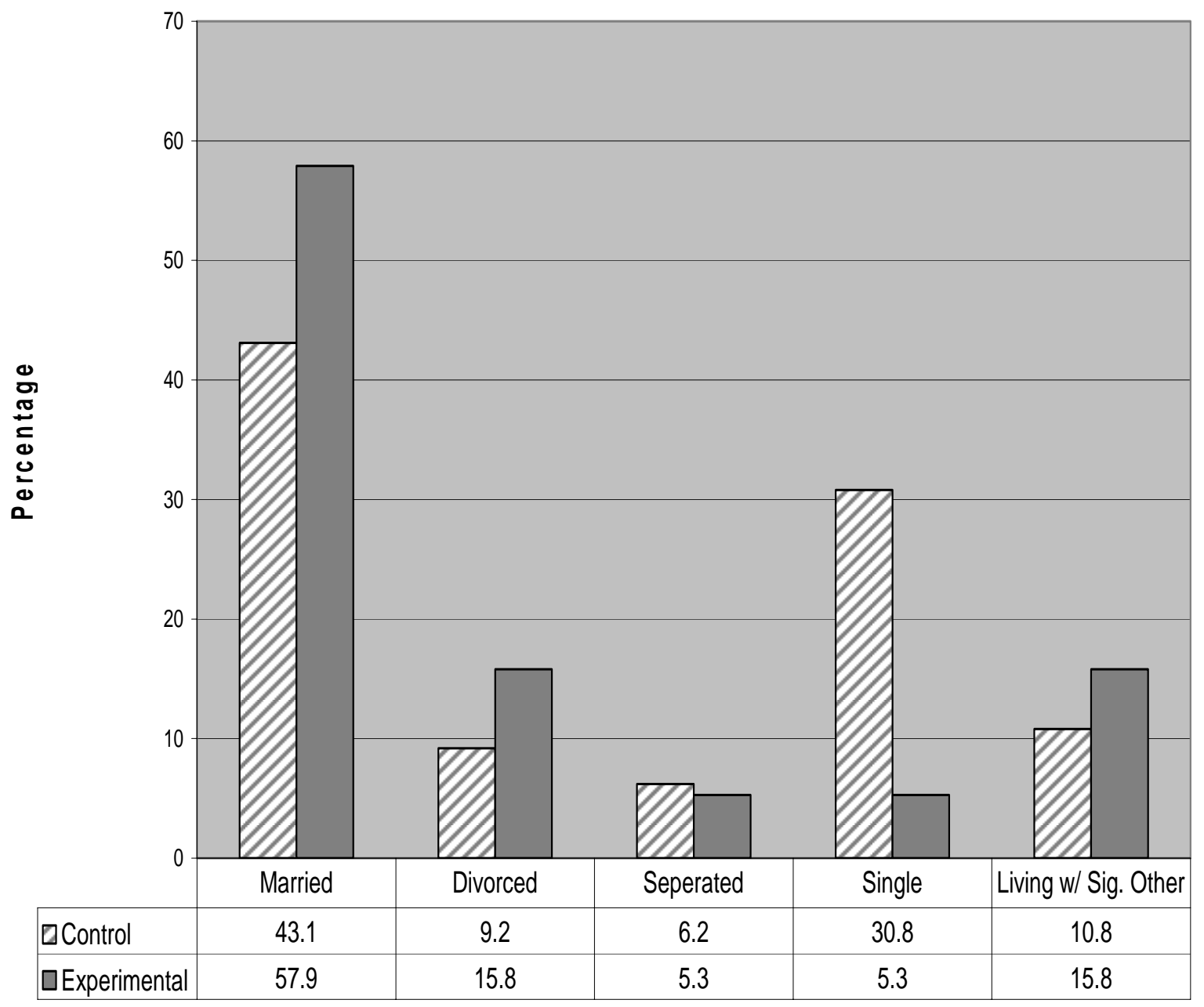

Figure 7: Marital status for experimental group $(n=65)$ and control group $(n=20)$ participating in the 2004 Maryland Becoming an Outdoors-Women Program. 
Employment Status. Most of the women indicated that they worked either full-time or part-time. Slightly less than 77 percent of the women in the control group and 68 percent of the women in the experimental group were employed fulltime. Those reported working part-time comprised 9 percent of those in the control group and 21 percent of those in the experimental group. Of those individuals reporting being unemployed, homemaker or retired, only 14 percent made up the control group and 11 percent were among the experimental group.

\section{Employment Status}

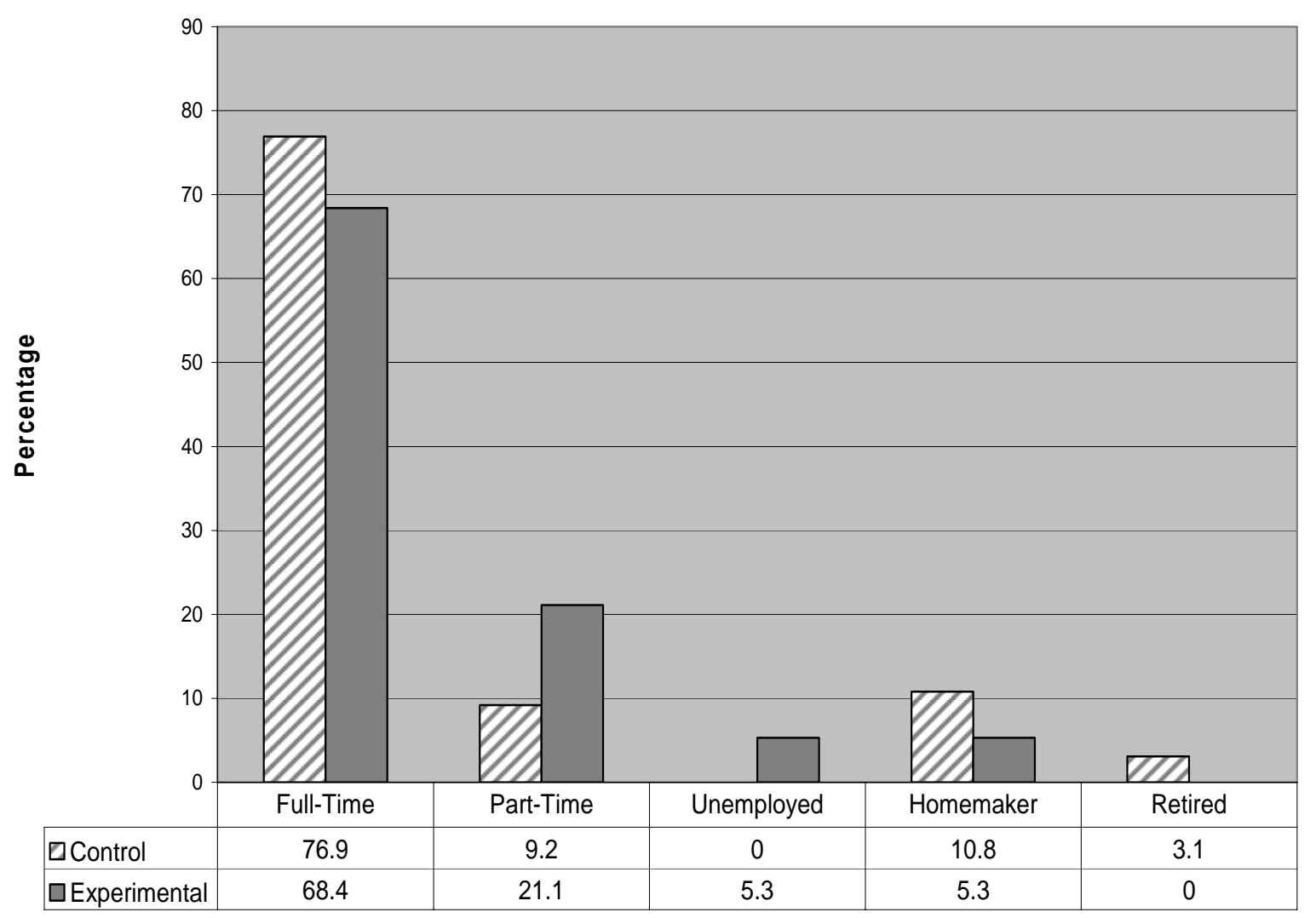

Figure 8: Employment status for experimental group $(n=65)$ and control group $(n=20)$ participating in the 2004 Maryland Becoming an Outdoors-Women Program. 
Residence. Almost three-quarters of both the control (76.9\%) and the experimental $(73.7 \%)$ groups indicated that they owned their own homes (Figure 9).

Slightly more than 66 percent of the control group and 63 percent of the experimental group live in a suburban setting as opposed to a rural or urban setting.

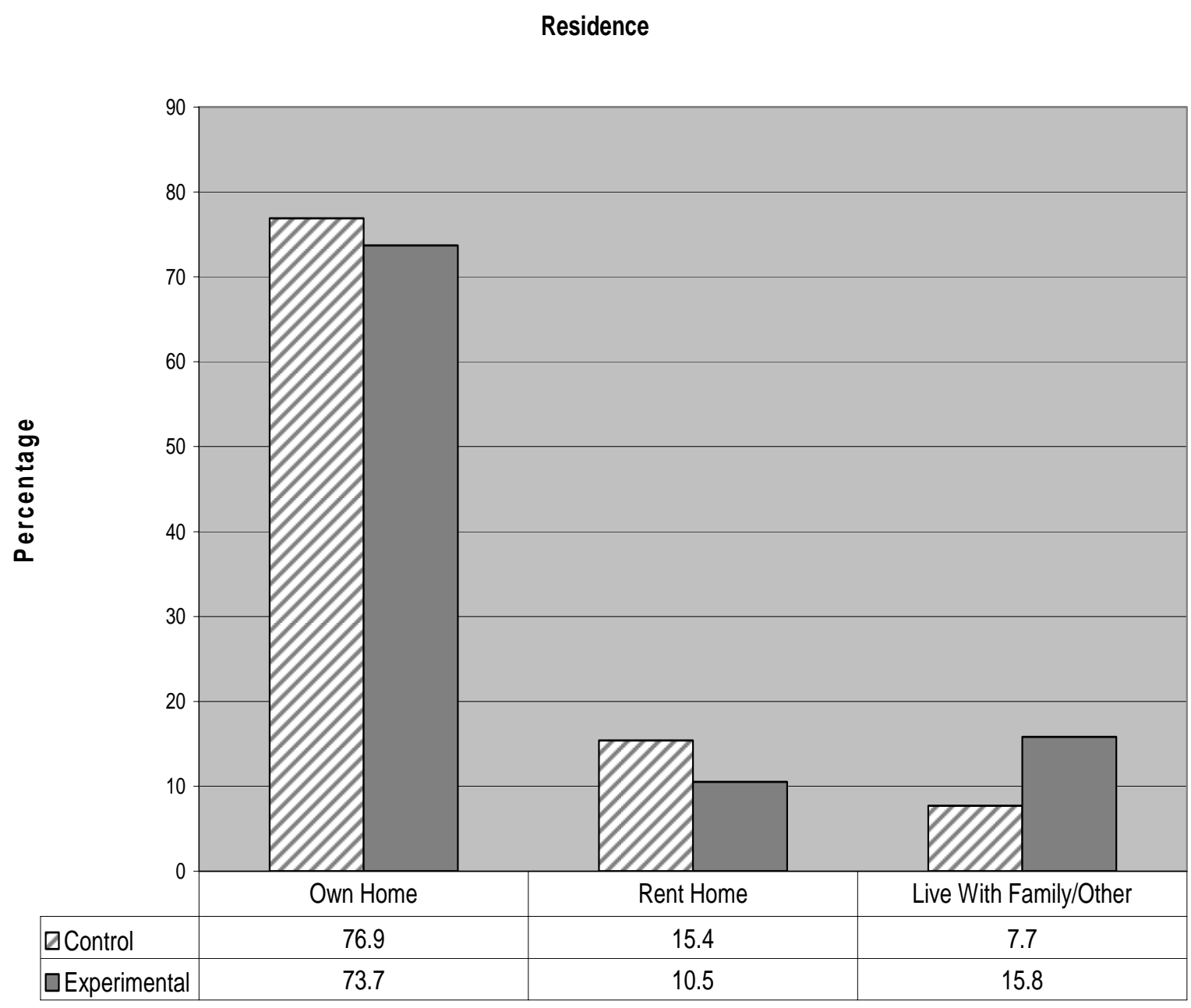

Figure 9: Residence distribution for experimental group $(n=65)$ and control group $(n=20)$ participating in the 2004 Maryland Becoming an Outdoors-Women Program. 
Summary of the Demographic Analysis. When examining the similarities and differences of each group, the women in the experimental group have more obligations associated with raising children, children still living at home, working, owning a house and being married with substantially less overall income than their control group counterparts. Almost three quarters of the experimental group (73\%) were married or living together with 68 percent of this group had children still living at home. Nearly half (47\%) of the experimental group having an AA degree or less as their highest level of education could attribute to the why one-third (33\%) reported being in a lower income bracket $(\$ 30,000-\$ 50,000)$.

In contrast to the experimental group, 63 percent of the control group was single with 42 percent having no children and an additional 21 percent being empty nesters. Nearly three-quarters (72\%) had a Bachelors degree or higher and one out of four $(24 \%)$ had incomes in excess of $\$ 150,000$.

The most noteworthy demographic differences between the groups included the number of children and gross household income. Forty-one percent of the control group and 21 percent of the experimental group reported "having no children", whereas, 59 percent of the control group and 79 percent of the experimental group did report having at least one child. Another factor that may also impact life effectiveness scores is that of gross household income. The highest percentage (58\%) of those in the control group reported making in excess of $\$ 75,000$ with 36 percent of one-third of the control group population in that same category, being in the "over $\$ 150,000$ per year range". On the other hand, the highest percent 
$(78 \%)$ of gross household income for the experimental group was in the "under $\$ 100,000 "$ category with 33 percent or one-third of the experimental group population falling within the “ $\$ 30,000$ - $\$ 50,000$ " range.

Demographic similarities among the two groups included age, with the highest percentage for both groups being 41-50 years old. Ethnicity was also very similar with over 97 percent of the total subjects being Caucasian. Married woman represented the highest percent of participants in both groups. A four-year degree and full-time employment were also most prevalent in both groups. Owning a home in the suburbs was also representative of both groups.

\section{Instrument Testing:}

Since the LEQ-24 is relatively new, especially when administered before and after a ropes course experience, a Cronbach's Alpha Reliability Estimate was conducted for each of the eight LEQ factors at each testing phase throughout the study. In accordance with the original alpha scores reported by Neill, all scores were within the acceptable reliability estimates above .70 . The most reliable factors included six of the eight factors. These factors were time management, achievement motivation, intellectual flexibility, task leadership, emotional control and self confidence. With the exception of emotional control, all alpha scores were between .702 and .941. The least reliable factor was emotional control. Although the reliability still seemed to increase overtime for emotional control, the scores experienced the most significant range from .664 at the pre-test to .808 at the one 
month follow-up. The only factor that became slightly less reliable over time was achievement motivation. The reliability of seven out of the eight factors that make up the LEQ-24 increased overtime which further supports the appropriateness and usefulness of the LEQ (see Table 4).

TABLE 4

Cronbach's Alpha Reliability Estimates for LEQ Factors

\begin{tabular}{|l|l|l|l|}
\hline 8 Factor of the LEQ & $\begin{array}{l}\text { Pre-Test } \\
\text { Reliability }\end{array}$ & $\begin{array}{l}\text { Post-Test } \\
\text { Reliability }\end{array}$ & $\begin{array}{l}\text { Follow-Up } \\
\text { Reliability }\end{array}$ \\
\hline Time Management & .908 & .931 & .941 \\
\hline $\begin{array}{l}\text { Achievement } \\
\text { Motivation }\end{array}$ & .899 & .898 & .890 \\
\hline $\begin{array}{l}\text { Intellectual } \\
\text { Flexibility }\end{array}$ & .732 & .779 & .811 \\
\hline Active Initiative & .701 & .779 & .846 \\
\hline Task Leadership & .864 & .899 & .915 \\
\hline Emotional Control & .664 & .717 & .808 \\
\hline Self-Confidence & .857 & .898 & .888 \\
\hline Social Competence & .883 & .892 & .932 \\
\hline
\end{tabular}




\section{Hypotheses Testing:}

Three hypotheses were tested. The first hypothesis examined the difference in LEQ scores for the experimental group during the pre, post and one month follow up. Similar to the first hypothesis, the second examines the difference in LEQ scores for the control group during all three stages of testing. Finally, the third hypothesis looks at the difference in Life Effectiveness scores between the experimental and control group.

Hypothesis 1. The first hypothesis tested for differences in Life Effectiveness scores for pre, post and one month post scores for the experimental group or ropes course participants. The null hypothesis for Hypothesis 1 was rejected (Table 5). The total mean score experienced a substantial increase following the post-test and increased slightly at the one month follow up.

TABLE 5

Comparison of LEQ Scores for the Experimental Group

\begin{tabular}{lc}
\hline \multicolumn{1}{c}{ Observations } & Mean Total Score \\
\hline Pre-Test $(\mathrm{N}=20)$ & $145^{\mathrm{a}}$ \\
Post-Test $(\mathrm{N}=19)$ & $157^{\mathrm{a}}$ \\
One Month Follow-up $(\mathrm{N}=19)$ & $159^{\mathrm{b}}$ \\
\hline \multicolumn{2}{l}{ Note: two-tailed t-test was used to test significance. } \\
a Significance for the pre- and post test was obtained at the .001 level. \\
b Significance for the pre- and one month follow-up was obtained at .01 level.
\end{tabular}


Significance was obtained between the pre-test and the post-test and between the pre-test and the one month follow-up tests. As indicated in Table 4, the mean scores for each of the testing cycles for the experimental group changed significantly over time (two-sample t-test, two-tailed, $\mathrm{p}<.05)$ in two of three tests administered. There was a significant difference between the LEQ mean pre-test scores and posttest scores, wherein the mean difference was 12.5 (two-tailed $\mathrm{p}<.01)$. The most substantial difference took place between the pre-test and the one month follow-up with total LEQ mean scores indicating an increase of 14.6 over time (two-tailed $\mathrm{p}<.01)$. Although there was no significant difference between the post-test and follow-up, post-tests mean scores were less than one month follow-up scores. The null hypotheses for differences in Life Effectiveness Scores for pre, post and one month scores for the experimental group were rejected.

Hypothesis 2. The second hypothesis tested for differences in Life Effectiveness scores for pre, post and one month post scores for the control group or non-ropes course participants. The null hypothesis for Hypothesis 2 was rejected (Table 6). The mean scores for each of the testing cycles for the control group changed from pre-test to post-test as well as post-test to the one month follow-up. The total LEQ mean scores also increased from the pre-test to the post-test but returned to pre-test levels one month following the BOW program. 
TABLE 6

Comparison of LEQ Scores for the Control Group

\begin{tabular}{lc}
\hline \multicolumn{1}{c}{ Observations } & Mean Total Score \\
\hline Pre-Test $(\mathrm{N}=65)$ & $155^{\mathrm{a}}$ \\
Post-Test $(\mathrm{N}=65)$ & $162^{\mathrm{a}}$ \\
One Month Follow-up $(\mathrm{N}=56)$ & $154^{\mathrm{b}}$ \\
& \\
Note: two-tailed t-test was used to test significance. & \\
a Significance for the pre- and post test was obtained at the .001 level. \\
b Significance for the pre- and one month follow-up was obtained at .004 \\
level.
\end{tabular}

Using a two-tailed t-test, significance was found between the pre-test and post-test groups and between the pre-test and one-month follow-up groups.

Significance at the .001 level was found between the pre-test and the post-test groups and significance at the .004 level was found between the pre-test and one-month follow-up groups. No significance was found between the pre-test and one-month follow-up groups. Although the number of total respondents declined at the one month follow-up, these results still suggest that the BOW program had a positive effect on overall Life Effectiveness scores immediately following, yet the impact of the program was not long term. 
Hypothesis 3. The third hypothesis tested for differences in Life Effectiveness Questionnaire scores between the experimental group (ropes course) and control group (non-ropes course) for pre, post and one-month follow-up tests. The null hypothesis for Hypothesis 3 was rejected (Table 7). Using a two-tailed t-test, significance was obtained between the pre-test groups only.

Significance between the pre-test scores for the experimental and control groups suggests that women in the control group entered the experiment with significantly lower LEQ scores than those women in control group. The differences found were reinforced by the demographics analysis which found differences between the experimental and control groups (e.g., age, education, children, and employment status). Also, the differences found between the two groups upon entering the experiment suggests that there may have been a natural sorting process occurring among participants.

There were no significant differences found between the post-test groups nor were there significant differences found between the one-month follow-up groups. The control group had slightly higher LEQ scores (162) after their post-test observation then the experimental group (157). For the follow-up observations the experimental group had a slightly higher LEQ score (159) than the control group (154). However, this study cannot suggest that the differences between the post-test observation and the follow-up observation are significant. 
TABLE 7

Comparison of LEQ Scores for the Experimental and Control Groups

$\begin{array}{lll}\text { Total LEQ Mean } & \text { Total LEQ Mean } & \text { Total LEQ Mean } \\ \text { Pre-test scores (N) } & \text { Post-test scores (N) } & \text { F/Up Scores (N) }\end{array}$

\begin{tabular}{lllllll}
\hline Experimental Group & $144^{\text {a }}$ & $(19)$ & 157 & $(19)$ & 159 & (19)
\end{tabular}

Control Group $\quad 155^{a} \quad(65) \quad 162 \quad(65) \quad 154 \quad(56)$

Note: two-tailed t-test was used to test significance. Significance was obtained at .05 level.

\section{Results of the Eight Factors of the LEQ for the Control and Experimental Groups:}

In an effort to determine which of the eight factors were contributing to the changes in the overall LEQ-24 scores, the data were examined within each of the eight sub-categories or factors that make up the LEQ-24. A repeated measures ANOVA was used to measure the differences between the three observations for the control and experimental groups.

Within each of the eight factors, the results were broken down to detect significance between the pre and post test, the post-test and the one month follow up and the pre-test and the one month follow up (Tables 8 and 9). There were three results for each of the factors, making a total of 24 categories. Of the twenty-four, 13 were significant for the control group, and 13 were significant for the experimental group. Significance between pre-test and post-test occurred in six of the eight factors in the experimental group versus all eight factors which was the case with the control 
group. There was no significance between post-test and the one month follow up for the experimental group. 
Table 8

Eight Factors of the LEQ: Individual mean scores for Control and Experimental Groups

\begin{tabular}{|l|l|l|}
\hline 8 Factor of the LEQ & $\begin{array}{l}\text { Control Group (non } \\
\text { ropes course) }\end{array}$ & $\begin{array}{l}\text { Experimental Group } \\
\text { (ropes course) }\end{array}$ \\
\hline
\end{tabular}

Time Management

$\begin{array}{lll}\text { Pre-test } & 6.5^{\mathrm{a}} & 6.3^{\mathrm{a}} \\ \text { Post-test } & 6.8^{\mathrm{a}} & 6.7^{\mathrm{a}} \\ \text { Follow Up } & 6.6^{\mathrm{b}} & 6.9^{\mathrm{b}}\end{array}$

Achievement Motivation

$\begin{array}{lll}\text { Pre-test } & 6.1^{\mathrm{a}} & 5.7^{\mathrm{a}} \\ \text { Post-test } & 6.3^{\mathrm{a}} & 6.3^{\mathrm{a}} \\ \text { Follow Up } & 6.1^{\mathrm{b}} & 6.4^{\mathrm{b}}\end{array}$

Intellectual Flexibility

$\begin{array}{lll}\text { Pre-test } & 6.2^{\mathrm{a}} & 5.8^{\mathrm{a}} \\ \text { Post-test } & 6.5^{\mathrm{a}} & 6.1 \\ \text { Follow Up } & 6.2^{\mathrm{a}} & 6.3^{\mathrm{a}}\end{array}$

Active Initiative

$\begin{array}{lll}\text { Pre-test } & 6.9 \text { a } & 6.6\end{array}$

$\begin{array}{lll}\text { Post-test } & 7.1^{\mathrm{a}} & 6.8\end{array}$

$\begin{array}{lll}\text { Follow Up } & 6.8^{\mathrm{b}} & 7.0\end{array}$

Task Leadership

Pre-test

$6.2^{\mathrm{a}} \quad 5.4^{\mathrm{a}}$

$\begin{array}{lll}\text { Post-test } & 6.4^{\mathrm{a}} & 6.0^{\mathrm{a}}\end{array}$

$\begin{array}{lll}\text { Follow Up } & 6.1^{\mathrm{b}} & 6.1^{\mathrm{b}}\end{array}$

Emotional Control

$\begin{array}{lll}\text { Pre-test } & 6.2 \mathrm{a} & 5.7 \mathrm{a}\end{array}$

Post-test $\quad 6.5^{\mathrm{a}} \quad 6.5^{\mathrm{a}}$

Follow Up $6.3 \quad 6.5^{\mathrm{b}}$

Self-Confidence

$\begin{array}{lll}\text { Pre-test } & 6.6^{\mathrm{a}} & 6.1^{\mathrm{a}}\end{array}$

$\begin{array}{lll}\text { Post-test } & 7.0^{\mathrm{a}} & 6.8^{\mathrm{a}}\end{array}$

$\begin{array}{lll}\text { Follow Up } & 6.7^{\mathrm{b}} & 6.9 \mathrm{~b}\end{array}$

Social Competence
Pre-test
Post-test

$\begin{array}{lll}\text { Post-test } & 6.9^{a} & 6.7^{a}\end{array}$

Follow Up $6.5^{\mathrm{b}} 6.8^{\mathrm{b}}$

a Significance for the pre- and post test was obtained at the .01 level.

b Significance for the pre- and one month follow-up was obtained at .05 level. 
Table 9

Eight Factors of the LEQ: Level of Significance for Control and Experimental Groups

\begin{tabular}{|c|c|c|}
\hline 8 Factor of the LEQ & $\begin{array}{l}\text { Control Group (non- } \\
\text { ropes)/level of } \\
\text { significance } \\
\end{array}$ & $\begin{array}{c}\text { Experimental Group } \\
\text { (ropes)/level of } \\
\text { significance }\end{array}$ \\
\hline \multicolumn{3}{|l|}{ Time Management } \\
\hline Pre - Post & .002 & .038 \\
\hline Post - Follow Up & $* *$ & $* *$ \\
\hline Pre - Follow Up & $* *$ & .015 \\
\hline \multicolumn{3}{|c|}{ Achievement Motivation } \\
\hline Pre - Post & .046 & .002 \\
\hline Post - Follow Up & .037 & $* *$ \\
\hline Pre - Follow Up & $* *$ & .001 \\
\hline \multicolumn{3}{|c|}{ Intellectual Flexibility } \\
\hline Pre - Post & .012 & $* *$ \\
\hline Post - Follow Up & $* *$ & $* *$ \\
\hline Pre - Follow Up & $* *$ & .023 \\
\hline \multicolumn{3}{|l|}{ Active Initiative } \\
\hline Pre - Post & .014 & $* *$ \\
\hline Post - Follow Up & .041 & ** \\
\hline Pre - Follow Up & $* *$ & ** \\
\hline \multicolumn{3}{|l|}{ Task Leadership } \\
\hline Pre - Post & .031 & .001 \\
\hline Post - Follow Up & .019 & $* *$ \\
\hline Pre - Follow Up & $* *$ & .000 \\
\hline \multicolumn{3}{|l|}{ Emotional Control } \\
\hline Pre - Post & .016 & .000 \\
\hline Post - Follow Up & $* *$ & $* *$ \\
\hline Pre - Follow Up & $* *$ & .001 \\
\hline \multicolumn{3}{|l|}{ Self-Confidence } \\
\hline Pre - Post & .000 & .000 \\
\hline Post - Follow Up & .007 & $* *$ \\
\hline Pre - Follow Up & $* *$ & .001 \\
\hline \multicolumn{3}{|l|}{ Social Competence } \\
\hline Pre - Post & .002 & .001 \\
\hline Post - Follow Up & .006 & $* *$ \\
\hline Pre - Follow Up & $* *$ & .029 \\
\hline
\end{tabular}


In general, most of the eight factors that comprised the LEQ-24 mimicked or paralleled the overall scores obtained. Overall significance was obtained in the experimental group between the pre-test and post-test and between the pre-test and one month follow-up, but not between the post-test and the one month follow-up. Six of the eight factors (i.e. time management, achievement motivation, task leadership, emotional control, self-confidence, and social competence) obtained similar significance between the pre-test, post-test and one month follow-up. For "intellectual flexibility" significance was only obtained between the pre-test and the one month follow-up. In contrast, no significance was obtained between the three tests for "active initiative". Except for "active initiative," the factors were fairly good predictors of the overall LEQ-24 score for the experimental group.

Similar results were found for the control group. Overall significance was obtained in the control group between the pre- and post test and between the posttest and one month follow-up. Five of the eight factors (i.e. achievement motivation, active initiative, task leadership, self-confidence, and social competence) obtained significance between the post-test and one month follow-up. All eight of the factors obtained significance between the pre-test and the post-test and five of the eight factors (i.e. achievement motivation, active initiative, task leadership, self-confidence, and social competence) obtained significance between the post-test and one month follow-up. All of the factors were fairly good predictors of the overall LEQ-24 score for the control group. 


\section{Observations on Ropes Course using the LEQ-Observation Sheet:}

The next component in the triangulation process was the use of the LEQObservation Sheet. The LEQ-Observer Sheet (see Appendix J) was used to document the behavior of those in the experimental group on the day of the ropes course. The same eight factors from the LEQ-24, previously presented, provided the basis for the observations. Each participant in the experimental group was observed during her day on the ropes course and evaluated by the researcher throughout the day. The observations were compared to how each participant scored herself on the post-test questionnaire.

The individual LEQ-Observer mean scores were compared to the post-test mean scores of the experimental group for each of the eight sub-categories (see Table 10 below). This comparison identifies any discrepancies between what the researcher observed and how the individuals scored themselves. Individualized notes regarding specific areas of the LEQ were also recorded to see if there were any additional discrepancies between what individuals reported and what the researcher witnessed during the day on the ropes course. 
Table 10

Eight Factors of the LEQ: Self-reported post-test compared to LEQ-Observer Experimental Group Only

\begin{tabular}{|c|c|c|c|}
\hline Eight LEQ Factors & $\begin{array}{l}\text { LEQ-Observer } \\
\text { Sheet, Mean } \\
\text { Scores } \\
\text { (post-ropes } \\
\text { experience) } \\
(\mathrm{N}=19)\end{array}$ & $\begin{array}{l}\text { Experimental } \\
\text { Group, Mean } \\
\text { Scores } \\
\text { (post-ropes } \\
\text { experience) } \\
(\mathrm{N}=19)\end{array}$ & $\begin{array}{l}\text { Margin of } \\
\text { difference } \\
\text { between observer } \\
\text { and group scores }\end{array}$ \\
\hline \multicolumn{4}{|l|}{ Time Management } \\
\hline Post-test & 7.1 & 6.7 & 0.4 \\
\hline \multicolumn{4}{|c|}{ Achievement Motivation } \\
\hline Post-test & 6.7 & 6.3 & 0.4 \\
\hline \multicolumn{4}{|c|}{ Intellectual Flexibility } \\
\hline Post-test & 6.8 & 6.1 & 0.7 \\
\hline \multicolumn{4}{|l|}{ Active Initiative } \\
\hline Post-test & 6.4 & 6.8 & 0.4 \\
\hline \multicolumn{4}{|l|}{ Task Leadership } \\
\hline Post-test & 5.7 & 6.0 & 0.3 \\
\hline \multicolumn{4}{|l|}{ Emotional Control } \\
\hline Post-test & 6.1 & 6.5 & 0.4 \\
\hline \multicolumn{4}{|l|}{ Self-Confidence } \\
\hline Post-test & 6.6 & 6.8 & 0.2 \\
\hline $\begin{array}{l}\text { Social Competence } \\
\text { Post-test }\end{array}$ & 6.4 & 6.7 & 0.3 \\
\hline
\end{tabular}

The difference between the LEQ-Observer sheet and the LEQ post-test for the experimental group was minor for most of the eight factors. The researcher indicated a higher score for three of the eight factors. The largest difference was in the area of intellectual flexibility, which is defined as being open to new ideas. The group appeared to work efficiently and combined the suggestions made by its members to 
develop a solution to the proposed challenge. The remaining scores were within a 0.4 margin on an eight point scale.

Overall, the LEQ post-test scores and LEQ-observer scores were both in the higher end (6/7) on each of the eight factors. This method of comparison is subjective, but the scores of the observer and the participants were quite similar.

\section{One-on-One Interviews:}

A detailed summary of the answers to each of the questions are reported in this section using the same coding schemes used for the observations which were derived from the LEQ-24 self-report instrument. The qualitative interviews of eight of the nineteen participants were transcribed verbatim and a content analysis was conducted to determine common responses and specific themes associated with their participation on the ropes course. A standardized open-ended interview method was used to increase the comparability of responses (Frankel \& Wallan, 2003).

After the text was transcribed, common coding methods were identified and counted for frequency of occurrence (see Table 11). The basis for the content analysis was the response to the seven interview questions by eight of the ropes course participants. The LEQ factors having the highest frequency of occurrence throughout the one-on-one interviews were self-confidence and emotional control. The factors with the lowest frequency of occurrence were time management and intellectual flexibility. 
Table 11

\section{Coded Responses to One-on-One Interviews}

\begin{tabular}{lcccccccr}
\hline & \multicolumn{9}{c}{ Interview Questions } & $\mathbf{( 1 - 7 )}$ a & \multicolumn{2}{c}{ Total } \\
Coding Schemes & $\mathbf{1}$ & $\mathbf{2}$ & $\mathbf{3}$ & $\mathbf{4}$ & $\mathbf{5}$ & $\mathbf{6}$ & $\mathbf{7}$ & \\
$\begin{array}{l}\text { Frequency } \\
\mathbf{N = 8}\end{array}$ & & & & & & & & \\
& & & & & & & & \\
\hline Time Management & 1 & 0 & 3 & 2 & 2 & 1 & 0 & 9 \\
Achievement Motivation & 3 & 2 & 2 & 3 & 1 & 1 & 1 & 13 \\
Intellectual Flexibility & 2 & 0 & 1 & 2 & 3 & 0 & 0 & 8 \\
Active Initiative & 0 & 2 & 2 & 2 & 1 & 0 & 5 & 12 \\
Task Leadership & 4 & 1 & 2 & 4 & 5 & 3 & 0 & 19 \\
Emotional Control & 2 & 6 & 3 & 4 & 5 & 2 & 4 & 26 \\
Self-Confidence & 6 & 4 & 5 & 2 & 1 & 5 & 5 & 28 \\
Social Competence & 2 & 3 & 2 & 4 & 3 & 5 & 0 & 19 \\
& & & & & & & & \\
\hline
\end{tabular}

a Interview Questions (1-7)

1. Did you learn more about yourself as a result of participating in the ropes course? Explain?

2. What types of emotions did you experience throughout your day on the ropes course? What emotion prevailed most often?

3. Were you able to make any "real life" analogies between your ropes course experience and your daily life? Please give some examples.

4. Explain your perception of how well the group worked together given the various challenges of the day.

5. Were there any internal or external factors that had an impact on your participation as an individual or as a group? What were they and explain the type of impact.

6. Are there any other thoughts that you would like to share regarding your ropes course experience?

7. What song, show, book or saying comes to mind when you think of your day on the ropes course? 
In addition to recording the frequency of coded schemes, a brief summary is provided below for each of the one-on-one questions.

\section{Q1: Did you learn more about yourself as a result of participating in the} ropes course? Explain?

In general, the participants indicated that they did learn more about themselves from their ropes course experience. Six of the eight responded "yes", one "no" and one said the ropes course helped them somewhat. For example, one divorced woman who was preparing to move and re-marry in several months stated, "I can do more than I or others think I can". Other participants responded by saying they learned to trust or felt a sense of accomplishment or empowered by the experience. The one individual who didn't feel she learned anything new provided no further comment.

Q2: What types of emotions did you experience throughout your day on the ropes course? What emotion prevailed most often?

Individual responses ranged and often encompassed a response other than an emotion. "Exhilaration", "enjoyment", "supported", "tentative, "bold and frustrated", "determination" and "fun" were among the immediate responses. The overwhelming response by six of those interviewed was a sense of camaraderie or fun being with other women and sharing a sense of accomplishment. 
Q3: Were you able to make any "real life" analogies between your ropes course experience and your daily life? Please give some examples.

Five of the women made a connection or analogy between their ropes course experience and their daily lives. The others couldn't identify anything at the time the interview was conducted but thought that there may be something in the future.

One individual related to her tendency of being impatient stated that, "I can overcome challenges in my life if I just slow down and focus". The experience confirmed for another that she doesn't like to be in charge and as long as it's not a life-threatening situation, she is perfectly fine with others making the decisions. However, the other three women made the determination that if they could complete the ropes course, they could take on any challenging or intimidating situation in their lives.

Q4: Explain your perception of how well the group worked together given the various challenges of the day.

Despite the size of the group (19 women), the unanimous response from all eight of the women was consistent with each commenting on how well the group worked together. "Everyone contributed what we could and we worked from that...discovering the strengths and weaknesses of each individual". Another participant was so amazed at the group cohesiveness that she thought about how they built Stonehenge...one stone at a time! Two of the women commented on how vocal and outspoken a few of the participants were. One of the women commented 
that "I'm usually a pretty outspoken person but I was with even more outspoken women so there was a tendency for me to be more quiet than usual".

Q5: Were there any internal or external factors that had an impact on your participation as an individual or as a group? What were they and explain the type of impact.

The women indicated that both internal and external factors impacted their experience. In regards to internal factors, one woman experienced a severe headache through much of the morning, another felt eager and tentative about the day ahead while another woman was typically challenged in social situations. External factors included comments about the wind during the high ropes course, the need for control among some of the women, the positioning of people within the group and having to work within a large group. No one reported that any of these factors had an impact on their entire day or played a significant role within their entire experience.

Q6: Are there any other thoughts that you would like to share regarding your ropes course experience?

The overwhelming response for all the women was that they thoroughly enjoyed being with other women, having fun outdoors and feeling a sense of accomplishment. Rhetorically, one woman wondered how well 19 men would have done executing the various challenges. One woman confessed that she asked the 
facilitator to push her off the platform for the zip line or she may never have gone. "I'm so glad I asked for the push and did it...it was fun!"

Q7: If you could sum up your day using a phrase, song title, show or movie, what would come to mind?

Most of the women were able to provide a phrase, song title, show or movie that summarized their experience. Since all eight women had different answers, each response is listed below. Only one of the participants didn't have an answer for this question.

"I Made it Through the Rain" (even though it didn't rain)

"When you get to the end of your rope, tie a knot and hold on...Eleanor Roosevelt" “Try it, you'll like it"

“The scene from Butch Cassidy and the Sundance Kid when they jumped off the cliff!"

Survivor (the show)

“Wind Beneath My Wings"

“The Little Engine that Could"

In summary, based on the qualitative interviews, , participation in the ropes course had a positive impact and likely attributed to an increase in Life Effectiveness scores on the post-test. According to frequency of the coding schemes, selfconfidence and emotional control were mentioned most often in the interviews. 
These findings were consistent with the other instruments used including the LEQ Observation sheets and the post-test self-reported scores. The highest individual mean score for the experimental group at the post-test was also self-confidence. Likewise, intellectual flexibility was among the lowest individual mean score for the experimental group.

In addition to having good thoughts or feelings about the day, the participants equally enjoyed the camaraderie with other women. All of the women interviewed acknowledged having experienced a greater sense of trust and working well as a team. The high ropes portion of the day produced the most heightened sense of anxiety but also provided the greatest sense of personal accomplishment. Overall, all women indicated that they enjoyed the experience and that they had fun. The observations and interviews provided the qualitative piece to better qualify and compare the results of the LEQ scores self-reported by the participants.

\section{Summary of Study Results}

In summary, all data collected were analyzed to provide a multi-method or triangulation approach to strengthen the validity of the study findings. The study tested three hypotheses and rejected each of the null hypotheses. As part of the triangulation approach, and in an effort to better understand the underlying factors affecting the changes that occurred, a demographic survey, the LEQ observations of the ropes course participants, and the one-on-one interviews of randomly selected participant in the experimental group were conducted. 
In general, the analysis of the data provided an indication that the treatment or ropes course experience had a positive impact on the total life effectiveness scores of the participants immediately after and one month following the experience.

The first hypothesis examined the change in life experience for the experimental group (i.e., ropes course participants). The study found that for the BOW women who participated in the ropes course experience that their LEQ scores increased significantly from the pre- to post-test and that the ropes course experience had a lasting effect in that it remained at a level that was significantly higher in the one month follow-up than in the pre-test results.

The second hypothesis examined the change in life experience for the control group. The study found that for the BOW women who did not participate in the ropes course experience that they too had a significant increase in their LEQ-24 scores from the pre- to post-test. However, this bump was not long term. Their one month follow-up LEQ-24 scores were significantly lower than the post-test results.

The third hypothesis examined the differences between LEQ-24 scores for the pre-test, post-test, and the one month follow-up. A significant relationship was only obtained between the pre-test groups with the experimental group having a significantly lower LEQ-24 score than the control group. The results supported the conclusion that participants may have sorted themselves into the experimental and control groups.

The demographic analysis provides a partial explanation of these differences found. There were demographic differences between the control and experimental 
groups that suggest that they were distinctly different groups and that these differences might explain some of the differences found with the LEQ. The most noteworthy demographic differences between the groups included the number of children and gross household income. Limited financial resources could certainly add to the daily stress that women have when juggling all aspects of their lives and may attribute to overall life effectiveness scores. The most fascinating results occurred from the post-test to the one month follow-up, although not statistically significant, the total LEQ mean score continued to slightly escalate to a higher level beyond that followed immediately after participation in the ropes course. Another factor that may also impact life effectiveness scores is that of gross household income. The highest percentage (58\%) of those in the control group reported making in excess of $\$ 75,000$ with 36 percent of one-third of the control group population in that same category, being in the "over $\$ 150,000$ per year range". On the other hand, the highest percent $(78 \%)$ of gross household income for the experimental group was in the "under $\$ 100,000$ " category with 33 percent or one-third of the experimental group population falling within the “ $\$ 30,000$ - $\$ 50,000 "$ range.

Similarities that the two groups shared regarding demographic data included age, with the highest percentage for both groups being 41-50 years old. Most (97\%) of the participants in the study were Caucasian. Married woman represented the highest percent of participants in both groups. A four-year degree and full-time employment were also most prevalent in both groups. Owning a home in the suburbs was also representative of the majority in each of these groups. The 
demographic data collected helped to differentiate the experimental and control groups beyond the treatment of a ropes course verses no ropes course. In fact, this data helped to provide some distinctions between the groups that may aid in a better understanding of this study. The demographic data collected helped to differentiate the experimental and control groups beyond the treatment of a ropes course verses no ropes course.

The qualitative portion of the study was conducted using both observations of the experimental group and administration of one-on-one interviews to a small sample of that group. The observations indicated higher scores in three of the eight sub-scales by the researcher/observer than what the individual experimental group participants gave themselves. The eight factors of the LEQ were used as the coding schemes for the observations. The observer scored higher in three of the eight subscales that included time management, achievement motivation and active initiative. The score for self-confidence had the smallest margin (0.2) between the observation and the post-test LEQ. Similarly, self-confidence was discussed most frequently during the interviews. The scores for intellectual flexibility between the group and the researcher/observer experienced the largest discrepancy (0.7). Likewise, intellectual flexibility was the LEQ factor mentioned the least in the one-on-one interviews. There were no significant differences between the LEQ post-test and the LEQ-Observations. These data help to confirm the way the participants scored the post-test LEQ was similar to what the researcher observed. 
Last, the one-on-one interviews complemented the data to provide free responses to the open-ended questions of eight of the nineteen experimental group participants. The findings, also coded to correspond with the eight sub-scales that make up the LEQ, produced the highest level of frequency in the areas of selfconfidence, emotional control, task leadership and social competence. The question of "why" do ropes courses have an impact on participants was referred to more than the "how". Comments relating to trust in others and enjoying the camaraderie with other women helped to address the why question. The comparison between the observations, one-on-one interviews and the LEQ post-test helped to confirm the factors that contributed to the most significant changes in the LEQ scores over time. Based upon all study results, there is a strong indication that the ropes course experience has an impact on life effectiveness scores and that the effect appears to be long term. 


\section{Chapter V: Discussion}

The purpose of this study was to examine changes in Life Effectiveness of women participating in a three-day training entitled "Becoming an Outdoors Woman". The discussion section will be divided into four sections that include a summary, conclusion and discussion for each of the hypotheses and research questions, overall implications especially those involving the Becoming an OutdoorsWoman Program and recommendations for future studies.

\section{H1: There is no difference in Life Effectiveness Questionnaire scores for pre, post and one month post scores for ropes course participants.}

In a closer examination of these results, ropes course participation may have had a normalizing effect on the experimental group which helped to bring their post test scores up to where the control group began. Normalizing in a sense that the ropes course experience, which was the only difference in treatment between the two groups, helped the experimental group LEQ scores end where the control group LEQ scores began. The control group started and ended the study with a mean score of approximately the same score (155). The experimental group started with a lower mean (144) at the pre-test and ended with a significantly higher mean (159) at the one month follow-up. The difference in pre-test scores between the control group and experimental group became more apparent after all the data were collected. 
The women in the control group had fewer stresses associated with everyday life than did their experimental group counterpart. In addition, the camaraderie with other women through their experiences at BOW and on the ropes course likely attributed to an increase in overall Life Effectiveness. As mentioned in the previous chapter, women in the experimental group consisted mostly of women who worked, had children living at home, were younger, married and owned their own home. It was also discovered that these women had a substantially lower gross incomes than did the participants of the control group. One could speculate that the women in the experimental group had more responsibilities with fewer financial resources.

Age and income were of particular interest in better understanding participants who chose to be considered for the ropes course portion of the study. Women ages 41-50 represented the majority of the women in the experimental group and were just beginning to enjoy more time for them as their children were becoming older and more independent. According to Stewart and Vandewater (1999), research on women from several generations has suggested that women's life regrets often focus on missed opportunities at midlife. Around age 40, "one begins to take stock in their lives to see how one's life has developed at this point (Jung, 1954). For early middle aged women, regret about past sacrifices associated with traditional roles such as raising children creates a desire for drastic change for some and modest change for others (Stewart \& Vandewater, 1999). Perhaps the ropes course was offered at an ideal time in their lives as these women had just begun to regain some long awaited individual freedom. The increase in LEQ scores at the post-test and the 
consistency of that increase one month later indicated longer effects than that of the participants who only experienced the BOW program. These results provide evidence that the treatment or ropes course experience had a positive impact on the total life effectiveness scores of the participants immediately after and one month following the experience. Those women participating in the experimental group seemed to benefit by the ropes course experience based upon their follow up scores.

The informal discussions among the women, observations and interviews would also suggest this did positively affect them in some manner. The women, who were interviewed, repeatedly discussed their sense of accomplishment and camaraderie with other women. Still others determined that if they could complete the ropes course, then they could also take on other challenging or intimidating situations in their lives. Of the coding schemes used to decipher the interviews, emotional control and self confidence were among the responses occurring most frequently. The increase in self-esteem as a result of ropes course participation is aligned with previous research in this area (Priest \& Sproul, 1992; Goldenberg, 2000). The researcher's observations scored three of the eight sub-scales higher than the participants did themselves and five lower. These areas included time management, achievement motivation and intellectual flexibility. The researcher also observed the participants being highly supportive of one another by offering encouragement and positive reinforcement throughout the day; especially during the high ropes portion of the day. This observation was similar to prior studies which confirmed the use of ropes courses as a means for team development and overall group effectiveness 
(Priest \& Spoul, 1992; Priest, 1996; Sottile, Parker \& Watson, 2000). The qualitative analyses support the overall changes in LEQ scores at the pre, post and one month follow-up. The LEQ scores did increase for all eight of the sub-scales at the post-test period and remained the same or increased again during follow-up testing. Two of the three studies administering the LEQ one month following ropes course participation did report statistical significance on the increase of the total LEQ score (Eagle et al, 2000; Terry, 2002). The areas experiencing the most dramatic increase included emotional control and self confidence. Interestingly, these were the same two scales that experienced the highest amount of frequency during the one-on-one interviews. Likewise, emotional control increased significantly at the one month follow up for the Eagle study with pre-teens and teens (2000). Although all reported scores for the researcher's observations were similar to the LEQ post-test scores, achievement motivation was the only common variable when comparing the outcome of these two analyses. This research provides evidence that ropes course participation is equally beneficial for a group of all women in a non-therapeutic setting.

H2: There is no difference in Life Effectiveness scores for pre, post and one month post scores for non-ropes course participants.

Although the majority of the women in the control group were also in the 4150 age range, they did have increased incomes and educational levels with fewer children, especially those still living at home. One could surmise that these women 
had fewer life stressors with increased income and perhaps greater employment options related to their higher educational levels. Having other obligations or not wanting to commit to something they were unsure about may attribute to some of the reasons why these women were not interested in an additional adventure experience and therefore not selected for the experimental group. This would also help to explain why the control group had higher LEQ pre-test scores than that of their experimental group counterpart.

As suggested by Anderson (2001), there is a need for further development of training programs designed specifically for women to help balance their lives. This is precisely what the BOW program has provided for women. The results of the study also indicated that the participants of the control group experienced an increase in LEQ scores from the pre-test to the post-test. This would indicate that the Becoming an Outdoors-Woman had a positive effect on their overall life effectiveness immediately following the program. Since women who have participated in BOW across the country have reported BOW being a life changing event, the post-test LEQ scores indicate that the Maryland BOW program also left women with a sense of accomplishment and personal fulfillment (www.uwsp.edu/cnr/bow.htm, 2004). These reported life changes have commonly been attributed to the positive experiences associated with outdoor endeavors (Mitten, 1992).

The question becomes, just how long those feeling persisted following the BOW experience. With the scores of the one month follow up returning to pre-test levels, there is no indication that the BOW program had a long term effect on the 
control group participants. Prior research has indicated that although mature professional women have strong problem-solving skills used in trainings such as BOW, they may not always have the same confidence to apply those skills to real life settings (Jordan, Kaplan, Miller, Stiver \& Surrey, 1991).

This study indicates the seemingly powerful and life changing impact that BOW and similar programs have on women participants may not influence changes in Life Effectiveness scores. This creates a greater need to further examine possible modifications to the BOW program.

H3: There is no difference in Life Effectiveness Questionnaire scores for pre, post and one month post scores between the ropes course or experimental group and the non-ropes course or control group.

The two groups started off the study with a significant difference in overall LEQ scores at the pre-test level between the experimental and control groups. The post-test mean scores for the control group did increase significantly beyond the pretest scores, yet the experimental group showed an increase twice that of their control group counterparts. The best indicator for the differences in scores before the two groups were officially established would be the issue of the daily stressors of life. Researcher observation of the experimental group reported the groups discussion about how little time the women had for personal endeavors and they often sacrificed "time for self" and prioritized family time. Those women willing to participate in additional adventure activities may have still been searching for 
opportunities to participate in something new and challenging. At middle age (the 40 's), women may have a greater tendency to express generative impulses in the larger social world outside of traditional family roles and obligations (Stewart \& Ostrove, 1998). In addition, the women in the control group had fewer children living at home or none at all, providing them with a greater level of freedom throughout their lives compared to those just beginning to have more time for themselves.

The most fascinating results occurred from the post-test to the one month follow-up, although not statistically significant, the total LEQ mean score continued to slightly escalate to a higher level beyond that followed immediately after participation in the ropes course. Having the experimental group take a post-test LEQ following the BOW program and again following the ropes course may have helped to decipher a more specific explanation for increased LEQ scores at the one month follow up.

\section{Research Questions Addressed by the Study:}

\section{Q1: Which of the eight factors of the Life Effectiveness Questionnaire attribute to} the change in LEQ scores following BOW and the ropes course experience?

According to the individual mean scores for the eight factors, both groups did increase their mean scores from pre-test to post-test. However, the individual mean scores from pre-test to follow-up were significantly different between the experimental and control groups. The most significant increase $(+0.8)$ for the 
experimental group that likely attributed to the change in the total LEQ scores were in the areas of Emotional Control and Self-Confidence. Other areas that saw a sizeable increase (+0.6-0.7) included Time Management, Achievement Motivation, Task Leadership, and Social Competence. The least significant increase (+.4 -0.5) was in the area of Intellectual Flexibility and Active Initiative.

The control group on the other hand, returned to their pre-test scores at the one month follow-up for both Achievement Motivation and Intellectual Flexibility. They decreased slightly (-0.1) in areas of Active Initiative, Task Leadership and Social Competence and increased slightly $(+0.1)$ in areas of Time Management, Emotional Control, Self-Confidence and Social Competence.

\section{Q2: Why do ropes courses aid women in examining their own life effectiveness?}

This is more difficult to determine as this particular question was not asked in the interview yet many did allude to making an analogy between completing the ropes course and overcoming other challenges or intimidating situations in their lives.

Q3: How do changes with women only groups compare to other populations that have been studied using the LEQ?

Ultimately, the Life Effectiveness Questionnaire was designed for adults yet it has been utilized more by adolescent populations. The three similar studies that used the LEQ with a one-day ropes course (Eagle et al, 2000; Terry, 2002; Boyle, 
2002), all consisted of adolescent and teen populations. The total LEQ mean score for each of these studies increased from pre-test to post-test. In the one study conducted by Terry (2002), the follow-up mean scores only decreased slightly from the post-test scores.

There were both similarities and differences when examining the most significant LEQ factors in relation to prior studies. Boyle (2002), and Eagle et al (2000), also showed a significant increase in emotional control as did this study. However, no other study identified self-confidence as being the most significant factor to influence changes in total LEQ scores over time.

This study may help to bring the instrument back to the framework of its intended purpose and to be utilized by adults in future studies. Studying more adult groups would also help to identify similarities and differences in LEQ factors that contribute to significant changes in total LEQ scores.

\section{Recommendations for the Becoming an Outdoors Woman Program}

Experiencing BOW for the first time, it was interesting to discover there was not more of an effort placed on getting to know the other participants at the start of the weekend. In fact, there seemed to be an underlying assumption that most people did come with a friend or relative so meeting the other BOW participants was up to each individual. In fact, there was one rather large contingency of women from the National Fish and Wildlife Foundation that seemed to dominate the group. Fortunately, there were other opportunities that brought them together by sharing 
cabins, meals and bathrooms. The social activity on the second night of BOW, a skills related race, encouraged more interaction among participants than any other event throughout the weekend. As the researcher conducting the study, I was at a greater advantage to meet others as they signed in or asked questions.

Since the Life Effectiveness scores did increase following the ropes course experience and maintained at that same level one month following, the researcher would recommend some sort of team building activities be added at the first day of the Becoming an Outdoors-Woman Program. The increase in Life Effectiveness scores confirms prior findings that women have an opportunity to fully explore a greater sense of self when daily obligation and traditional female roles are relinquished (Henderson, 1996; Sadker \& Sadker, 1986; Yerkes \& Miranda, 1985). All of the ropes course participants agreed that having some fun, interactive methods such as the initiative exercises conducted prior to the beginning of the BOW program in the future.

As the observer of the ropes course participants, the women enjoyed getting to know each others names and a little about them before the group became involved with more intense challenges. Getting to know each other undoubtedly provided a stronger foundation for the other challenges they faced and a sense of support during the high ropes portion of the day. Following the one-on-one interviews, it did become apparent that there were some women who felt others dominated the group process. However, the benefit of getting to know other women, especially those who 
shared the love of adventure and the outdoors, surpassed the feeling of some who occasionally felt suppressed by the dominance of others in the group.

Based upon the results of the study and individual comments, the BOW program may want to consider incorporating an optional ropes course experience prior to the beginning of BOW. Conceptually, the post-test was completed two weeks following the BOW program at which time the impact for the three day workshop could have begun to dissipate. Methodologically, the ropes course portion of the study should have been completed the same weekend as the BOW program but was logistically and programmatically impossible. Having the ropes course occur the same weekend as BOW would have helped to discern the impact of BOW verses the impact of the ropes course. Another option would include providing group initiatives with some mobile low elements to be held on Friday morning of check-in. This would allow most women in the state of Maryland an opportunity to arrive in time to participate. Yet another option would be a Beyond BOW workshop that would encompass a full day ropes course at another time and location. This would provide an additional opportunity for women to experience a sense of camaraderie that most women identify as being an important component of the existing Becoming an Outdoors-Woman Program.

\section{Eight Factors of the LEQ:}

Considering the group size was extraordinarily large with 19 women, it was truly impressive to observe how well they worked as a group throughout the entire 
day. Interestingly, the women in the experimental group who appeared to lack selfconfidence or social competence initially were quickly immersed in the group process and began to provide input and suggestions for working through the given tasks. Similar to previous findings, (Brown \& Gilligan, 1992; Bialeschki \& Henderson, 1993; Henderson, 1996), this study confirmed that adventure recreation does help women to assert themselves and renew a sense of empowerment.

Although the activity prior to lunch was the only one that the group did not succeed in accomplishing, the overall mood at lunch was upbeat and comfortable. Although small group conversations were initially taking place, the entire group was involved in one collective discussion by the end of lunch as they all eagerly awaited the high ropes portion of the day.

Despite some individuals who indicated their skepticism about actually completing the high ropes challenge, all women were very supportive of each other throughout the afternoon and every participant did complete the experience. Because there were no apparent problems throughout the course of the day and all women remained positive, the debriefing process at the close of the program was of elation and self satisfaction. The program definitely ended on a high note.

\section{LEQ Instrument}

Since the Life Effectiveness Questionnaire is relatively new with few reliability estimates reported to date, a comparison between alpha levels has been reviewed. In early tests, the LEQ showed high internal consistency with alpha levels from the 
eight sub-scales ranging from .78 to .93 and test-retest correlations ranging from .60 to .81 (Neill et al, 1997). This study has helped to reconfirm the reliability and usability of the LEQ as a timely and appropriate application following a ropes course experience. The internal consistency for the pre-test was less than Neill's findings, with alpha levels from the eight sub-scales ranging from .64 to .91 . However, the test-retest correlations in this study experienced a range of .72 to .93 at the post-test and a range of .81 to .94 at the one month follow-up. These results indicate that reliability does increase, especially after repeated use, and helps to ensure internal consistency for pre, post and follow-up testing.

\section{Summary}

A close examination of all the data collected for this study indicates significant differences for both groups. The explanation of the difference between the groups during the pre-test stage may be attributed to the natural sorting of the group since individuals decided if they wanted to participate versus the group being truly randomized. There is also speculation that those women in the experimental group had more daily stressors in life. These stressors were mainly typified by having more children, having lower gross incomes, lower education levels, owning a home and working. These women are continually faced with trying to fulfill all external expectations place on them while occasionally attempting to accept new roles that may enrich their personal satisfaction with their lives as in the case with BOW and the ropes course experience (Henderson, Bialeschki, Shaw, \& Freysinger, 1996). On 
the other hand, members of the control group had no or fewer children, higher educational levels and higher levels of income.

The women in the experimental group may have been more open to opportunities other than the BOW program to participate in an adventure experience for the purpose of connecting with other women. Interestingly, many of the women in the experimental group commented how their children were becoming increasingly more independent which was beginning to allow them more time for their own personal interests. This confirms Gilligan's (1982) previous findings that women at mid-life often desire to return to the unfinished business of adolescence which allows them to challenge themselves mentally, physically, and emotionally. Perhaps another issue was the lack of time given to the BOW participants to consider giving up another day to travel to the other end of the state to participate in a full day program two weeks following their three-day weekend with BOW. The women, who knew their day was free of commitment or had the necessary support to fill in on their behalf for the day, were also more likely to consider another adventure program.

The prior speculation about the group regarding increase stressors or the issue that women in the experimental group were just beginning to enjoy the long awaited "me time" again as their children were getting older would be the best indicator for lower than average scores for the pre-test. Although the majority age range overall was between 41-50, many women would have older, more independent children at this stage. 


\section{Recommendations for Future Research}

Conceptually, the experimental design was sound. However, in practice the ropes course experience was conducted on a different date and the participants may psychologically treated it as a separate event. This may account for the high LEQ scores for the experimental group during the post-test. In regards to suggestions for a replication study, the one factor worthy of further investigation is the issue of conducting a post-test for the experimental group following the all-women training and a second post-test following the ropes course participation. To continue the examination of women-only groups is important as prior research has reported that these programs do provide a better opportunity to learn and practice skills and share common interests (Henderson \& Bialeschki, 1986, 1987; McClintock, 1996; Mitten, 1996). Adding this additional research component to the study would have provided more specific evidence of the impact of the BOW program verses the impact of the ropes course.

Methodologically, there is a need to study a true random sample of the BOW population instead of having participants self select. Other studies may want to provide a greater ethnic diversity among the female participants. Despite national efforts put forth by the 1999 Breaking Down Barriers II workshop (www.uwsp.edu/cnr/bow/history.htm, 2004) to attract more minority women to participate in the Becoming an Outdoors-Woman Program, over 97 percent of the total subjects in the Maryland study were Caucasian. Examining another type of allwomen training not related to outdoor adventure prior to having experimental 
groups participate in a full day ropes course experience would also provide a new approach to the current study. Since the Becoming an Outdoors Program does exist in thirty-nine other states and 4 Providences in Canada, it would be interesting to see the same study conducted in other regions. By replicating the existing study with minor changes to both the conceptual and methodological approach, there are many new outcomes to explore when using ropes courses the enhance life effectiveness for women in non-therapeutic settings.

One recommendation made on behalf of one of the ropes course participants that was interviewed was to examine the differences in gender. With essentially all other factors being equal, create a study with a group of men and a group of women completing the same schedule of activities on the same course with the same facilitators but held on different days. Both of these groups could be comprised of men and women in a non-therapeutic setting with professional careers and children. Gaining a greater understanding of the issues that impact overall life effectiveness for both men and women could aid employers and individuals in feeling more satisfied about themselves and their lives.

One final recommendation would entail a method to determine how study participants interpret and categorize the stress factors in their individual lives. What one person finds stressful, others may welcome as opportunity. For instance, a fulltime career for a single woman may be viewed as challenging and invigorating whereas a full-time career for a wife and mother of two may be highly stressful. 
Adding this dimension to a similar study would also provide a greater insight to what outlets people choose to participate in during their leisure time. 


\section{References}

Anderson, D. M., (2001). The current status of women in the parks and recreation profession. Parks \& Recreation, 36 (5), 22-28.

Backert, D. (1990). Historical evolution of NOLS: The National Outdoor Leadership School. In J.C. Miles \& S. Priest (Eds.), Adventure Education (pp. 83-88). State College, PA: Venture.

Becoming an Outdoors-Woman History. (Diane Lueck, webmaster). Retrieved December 14, 2005 from http:// www.uwsp.edu/cnr/bow/history.htm.

Becoming an Outdoors-Woman Research. (Diane Lueck, webmaster). Retrieved December 14, 2005 from http://www.uwsp.edu/cnr/bow/research.htm

Bialeschki, M. D., \& Henderson, K. A. (1993). Expanding outdoor opportunities for women. Parks and Recreation, 28 (8), 36-40.

Blizzard, K. (personal communication, September 15, 2004).

Boyle, C., (2002). Executive Summary: Initiative and Confidence Program: Project Champions. An unpublished manuscript.

Braverman, M., Brenner, J., Fretz, P \& Desmond, D., (1990). Three Approaches to Evaluation: A Ropes Course Illustration. Journal of Experiential Education, Vol. 13 (10), 23-30.

Brown, L. M. \& Gilligan, C. (1992). Meeting at the crossroads: Women's psychology and girl's development. New York: Ballantine Books.

Bunting, C. J., \& Donley, J.P. (2002). Ten Years of Challenge Course Research: A Review of Affective Outcome Studies. Poster presented at the 6th Coalition for the Education in the Outdoors Research Symposium, January 11-13, Bradford Woods, IN.

Campbell, D. T., \& Stanley, J.C. (1963). Experimental and Quasi-Experimental Designs for Research. Houghton Mifflin: Boston.

Carroll, C., (1999). Alisal adds ropes course to team-building plan. Travel Weekly, $58,(53), 30-35$. 
Curran, J.P., (1977). Skills training as an approach to the treatment of heterosexualsocial anxiety: A review. Psychological Bulletin, 84: 140-57.

Daniels, M., (1994). Outdoor adventure and organizational development: A ropes course intervention. Public Administration Quarterly, Summer, (18), 237-249.

DeGraaf, D.G., Jordan, D.J., \& Degraff, K.H., (1999). Programming for Parks, Recreation and Leisure Services. State College, PA: Venture Publishing, Inc.

Driver, B.L., Nash, R., \& Haas, G. (1987). Wilderness benefits: A state-of-knowledge review. In H. Ken Cordell (Principle investigator), Outdoor Recreation in American Life: A National Assessment of Demand and Supply Trends (p. 2-14) Champaign, IL: Sagamore Publishing.

Dyson, B. P. (1995). Students'voice in two alternative elementary physical education programs. Journal of Teaching in Physical Education, 14, 394-407.

Eagle, H., (1999). Long-term differences between participants and non-participants in "Beyond the Limits" adventure education program. (Doctoral dissertation, University of Maryland College Park, 1999). Dissertation Abstracts International.

Eagle, H., Gordon, J., Lewis, L., (2000). The Effects of a Public School System's One Day Adventure Experience. Fifth Biennial Research Symposium Proceedings: Coalition for Education in the Outdoors.

Ewert, A., (1983). Outdoor adventure and self-concept: A research analysis. Eugene, OR: Center of Leisure Studies, University of Oregon.

Ewert, A., (1987). Research in experiential education: An overview. Journal for Experiential Education, 10, 4-7.

Ewert, A., (1988). Reduction of trait anxiety through participation in Outward Bound. Leisure Sciences, 10(2), 107-117.

Falvey, J., (1987). Before spending \$3 million on leadership. Wall Street Journal.

Frankel, J.R. \& Wallen, N.E. (2003). How to Design and Evaluate Research in Education (5 $5^{\text {th }}$ Ed.) McGraw Hill Publishing.

Gilligan, C. (1982). In a Different Voice: Psychological Theory and Women's Development. Harvard University Press. 
Gillis, H.L. \& Carson, D. (1994). A meta-analysis of outdoor adventure programming with adolescents. Journal of Experiential Education, 17, 40-47.

Goldenberg, M.A. (1997). Understanding the benefits of ropes course experiences using means-end analysis. Unpublished master's thesis, Purdue University, Indiana.

Goldenberg, M. A., Klenosky, D. B., O'Leary, J. T., and Templin, T. J. (2000). A Means-End Investigation of Ropes Course Experiences. Vol. 32, 2. Journal of Leisure Research.

Goldenberg, M.A., (2002). Understanding the Outcome of Outdoor Adventure Experiences Using Means-End Analysis. (Doctoral dissertation, University of Minnesota, 2002). Dissertation Abstracts International.

Guynn, Susan (2004, October 17). Women in the Outdoors: Learning skills to make them feel at Home. The Frederick News-Post, p. D-1 \& D-4.

Hans, T. (2000). A meta-analysis of the effects of adventure programming on locus of control. Journal of Contemporary Psychotherapy, 30(1), 33-60.

Hart, L. \& Silka, L. (1994). Building self-efficacy through women-centered ropes course experiences. In E. Cole, E. Erdman, \& E.D. Rothblum (Eds.), Wilderness therapy for women: The power of adventure (p. 111-128). New York: Harrington Park Press.

Henderson K. A. (1996). Women and the outdoors: Toward spiritual empowerment, In K. Warren (Ed.), Women's voices in experiential education (p. 193-2020). Dubuque, Iowa: Kendall/Hunt Publishing Company.

Henderson, K.A., Bialeschki.D. (1987, Summer). A qualitative evaluation of a women's week experience. Journal of Experimental Education, 25-28.

Henderson, K.A., Bialeschki, D., Shaw, S. M., Freysinger, V.J. (1996). Both Gains and Gaps: Feminist Perspective on Women's Leisure. Venture Publishing.

Hersey, P., \& Blanchard, K. (1982). Management of organizational behavior: Utilizing human resources ( $4^{\text {th }}$ ed.). Englewood Cliffs, NJ: Prentice-Hall.

Hochschild, A. (1989). The Second Shift: Working Parents and the Revolution at Home. Viking Publishing. 
Iso-Ahola, S. E., \& Graefe, A. R., (1988). Perceived competence as a mediator of the relationship between high risk sports participation and self-esteem. Journal of Leisure Research, 21, (1), 32-39.

Jordan, J.V., Kaplan, A.G., Miller, J.B., Stiver, I.P., \& Surrey, J.L (1991). Women's growth in connection. New York: The Guilford Press.

Jung, C.G. (1954). Marriage as a psychological relationship. In W. McGuire (Ed.), The development of personality: The collected works of C.G. Jung (Vol. 17, pp.187201). New York: Pantheon Books. (Original work published 1925).

Kelly, J., \& Hutson-Comeaux, S.L.,(2000). The appropriateness of emotional expression in women and men: The double-blind of emotion. Journal of Social Behavior \& Personality, 15, (4), 516-30.

Kerfoot, K.(1997). Leadership: When success leads to failure. Nursing Economic\$, 15, (5), 275-76.

Kimball, R. O., \& Bacon, S. B.(1993). The wilderness challenge model. In M.A. Gass (Ed.), Adventure Therapy: Therapeutic applications of adventure programming (pp.11-41). Dubuque, IA: Kendall/Hunt Publishing Company.

Kohn, S. (1991). Specific programmatic strategies to increase empowerment. The Journal of Experiential Education, 14(1), 6-12.

Long, A. (2001). Learning the Ropes: Exploring the Meaning and Value of Experiential Education for Girls at Risk. The Journal of Experiential Education, 24(2), 100-108.

Mack, H. (1996). Inside Work, Outdoors: Women, metaphor and meaning. In K. Warren (Ed.), Women's voices in experiential education (p. 193-2020). Dubuque, Iowa: Kendall/Hunt Publishing Company.

Marsh, H.W., Richards, G.E., \& Barnes, J., (1986). Multidimensional self-concepts: the effects of participation in an Outward Bound program. Journal of Personality and Social Psychology, 50, 195-204.

McKenzie, M.D. (2000). How are Adventure Education Program Outcomes Achieved?: A review of the literature. Australian Journal of Outdoor Education (5)1, 19-26. 
McClintock, M. (1996). Why Women's Outdoor Trips? In K. Warren (Ed.), Women's Voices in Experiential Education (p. 83). Dubuque, IA: Kendall/Hunt Publishing Company.

Miles, J.C., \& Priest, S. (1999). Adventure Programming. State College, PA. Venture Publishing, Inc.

Mitten, D., \& Dutton, R. (1993). Outdoor leadership considerations with women survivors of sexual abuse. Journal of Experiential Education, 16(1), 7-13.

Mitten, D. (1996). A Philosophical Basis for a Women's Outdoor Adventure Program. In K. Warren (Ed.), Women's Voices in Experiential Education (p. 83). Dubuque, IA: Kendall/Hunt Publishing Company.

Mitten, D. (1994). Ethical considerations in adventure therapy: A feminist critique. In E. Cole, E. Erdman, \& E.D. Rothblum (Eds.), Wilderness therapy for women: The power of adventure (pp. 55-84). New York: Harrington Park Press.

Mitten, D. (1992). Empowering girls and women in the outdoors. Journal of Physical Education, Recreation and Dance, 63 (2), 56-60.

Moses, S. (1990). Morale programs face effectiveness questions. APA Monitor, Jan., p. 20.

Neill, J.T., (2004). What is Life Effectiveness?, www.wilderdom.com/tools/leq/LEQWhatislifeeffectiveness.html, 2004).

Neill, J.T., Marsh, H.W., \& Richards, G.E. (1997). The Life Effectiveness Questionnaire: Development and Psychometrics. Unpublished manuscript: University of Western Sydney.

Neill, J. T. (1999). The melting pot of outdoor education effects: Testing the flavours of program type, duration and participant age. In Proceedings of the 11th National Outdoor Education Conference, 11-15 January, Perth, Western Australia: Camping and Outdoor Education Association of Western Australia, pp. 112-118.

Neill, J. T.(1999). Personal development outcomes of outdoor education programs. Poster presented to the 11th Australian Human Development Conference, Sydney, Australia, July 8 - 10, 1999.

Neill, J.T., \& Flory, M. (1999). A Pilot Study of the Effects of the Women's Wilderness Institute "Girlz in the Woods" Courses on Adolescents' Personal Effectiveness and Self Esteem. Unpublished report. 
Neill, J.T., \& Flory, M. (2000). Brief Report on the effects of a Colorado Outward Bound School program on the Life Effectiveness of Adult Gay and Lesbian Participants. Unpublished report.

Neill, J. T. (2003). Meta-Analytic Research on the Outcomes of Outdoor Education. Paper presented to the 6th Biennial Coalition for Education in the Outdoors Research Symposium, Bradford Woods, IN, 11-13 January.

Neill, J. T., Marsh, H., Richards, G. (2003). The Life Effectiveness Questionnaire: Development and Psychometrics. Sydney University of Western Sydney.

Pazmino-Cevallos (2003). The effects of an adventure education experience on team development of K-12 teachers. (Doctoral dissertation, University of Southern Mississippe, 2003). Dissertation Abstracts International.

Pohl, S.L., Borrie, W. T., \& Patterson, M.E. (2000). Women, wilderness, and everyday life: A documentation of the connection between wilderness recreation and women's everyday lives. Journal of Leisure Research, 32(4), 415-434.

Priest, S. (1990). The Semantics of Adventure Education. In J.C. Miles \& S. Priest (Eds.), Adventure Education (pp. 111 - 114). State College, PA Venture Publishing, Inc.

Priest S., and Sproul, (1992). The Ropes Course as an Educational Tool. The Ontario Journal of Outdoor Education.

Priest, S. and Lesperance, M.A., (1993). Times Series Trend Analysis in corporate team development. Journal of Experiential Education, 17(1), 34-39.

Priest, S. (1996). Developing Organizational Trust: Comparing the effects of ropes courses and group initiatives. Journal of Experiential Education, 19(1), 37-39.

Priest, S., \& Gass , M., (1997). Effective leadership in adventure programming.USA: Human Kinetics.

Prouty, D. (1990). Project adventure: A brief history. In J. C. Miles and S. Priest (Eds.), Adventure education (pp. 97-109). State College, PA: Venture Publishing, Inc.

Prouty, D. (2002). Project Adventure at thirty. Zip Lines (Spring), 6-13. [pdf; 1.7mb] 
Roberts, N. (1998). A Guide to Women's Studies in the Outdoors: A Review of Literature and Research with Annotated Bibliography. Simon \& Schuster Custom Publishing.

Roberts, N. \& Yerkes, R. (2000). Journal of Experiential Education, Fall, Vol. 23, (2), 61-63.

Rohnke, K., (1989). Cowstails and Cobras II. Dubuque, Iowa: Kendall/Hunt.

Ruf, B., \& Chusmire, L.H.,(1991). Dimensions of success and motivation needs among managers. Journal of Psychology, 125, (6), 631-641.

Sadker, \& Sadker (1986). In Henderson, K.A., Bialeschki, D., Shaw, S. M., Freysinger, V.J. Both Gains and Gaps: Feminist Perspective on Women's Leisure. Venture Publishing., pg. 187.

Schoel, J., Prouty, R., \& Radcliffe, P. (1988). Islands of Healing. Hamilton, MA: Project Adventure, Inc.

Sottile, J.M., Parker, S. \& Watson, G. (2000). The impact of an experiential instructional design on college student development. Paper presented at the Annual Meeting of the Eastern Educational Research Association.

Stewart A.J. \& Ostrove, J.M. (1998). Women's Personality in Middle Age: Gender, History, and Midcourse Corrections. American Psychologist. Vol. 53 (11), pp.11851194.

Stewart A.J. \& Vandewater, E.A. (1999). "If I Had It to Do Over Again...": Midlife Review Midcourse Corrections, and Women's Well-Being in Midlife., Journal of Personality and Social Psychology. Vol. 76, No. 2, 270-283.

Stopha, B. (1994). Women on the ropes: Change through challenge. In E. Cole, E. Erdman, \& E.D. Rothblum (Eds.), Wilderness therapy for women: The power of adventure (p. 101-109). New York: Harrington Park Press.

Terry, L. (2002). A quantitative and qualitative analysis on the effects of an adventure course: An intervention with female adolescents. Undergraduate Thesis, Scripps College, Claremont, CA.

Thomas, C. (1997). Becoming an Outdoors Woman: My Outdoor Adventure (Preface). Falcon Press Publishing Col, Inc. 
Walsh, V., \& Golins, G. (1976). The Exploration of the Outward Bound Process. Denver, CO: Colorado Outward Bound School.

Witman, J. P. (1995). Characteristics of adventure programs valued by adolescents in treatment. Monograph on Youth in the 1990's, 4, 127-135.

Yerkes, R., \& Miranda, W. (1982). The need for research in outdoor education programs for women. Journal of Physical Education, Recreation, and Dance, 37(4), 82-85.

YMCA Adventure Challenge. (2004). YMCA Camp Letts in Edgewater, MD. [Brochure]. Peckins, S: Author.

YMCA Adventure Challenge Brochure. (2004). [Brochure]. Peckins, S: Author.

YMCA of Metropolitan Washington. YMCA Camp Letts. Retrieved November 7, 2004, from http:/ / www.ymcawashdc.org.

Yerkes, R., \& Miranda, W. (1985). Women outdoors: Who are they? Parks \& Recreation, 20(3), 48-1, 95. 


\section{$\underline{\text { Appendices }}$}

Appendix A: LEQ-24 Questionnaire

Appendix B: Eight Factors of the LEQ and Related Questions

Appendix C: Eight Factors and Definitions

Appendix D: Demographic Questionnaire

Appendix E: Cover Letter to BOW Participants

Appendix F: Information Letter to the Ropes Course Participants

Appendix G: Cover Letter for One Month Follow Up to Control Group

Appendix H: Cover Letter for One Month Follow Up to Experimental Group

Appendix I: Telephone One-on-One Interview

Appendix J: LEQ-I Observer Sheet 


\section{PLEASE DO NOT TURN OVER YET}

\section{READ THESE INSTRUCTIONS}

This is a chance for you to consider how you think and feel about yourself in some ways. This is not a test - there are no right or wrong answers, and everyone will have different responses. It is important that you give your own views and that you be honest in your answers and do not talk to others while you think about your answers. They will be used only for research purposes and will in no way be used to refer to you as an individual at any time.

Over the page are a number of statements that are more or less true (that is like you) or more or less false (that is unlike you). Please use the eight point scale to indicate how true (like you) or how false (unlike you), each statement is as a description of you. Answer the statements as you feel now, even if you have felt differently at some other time in your life. Please do not leave any statements blank.

\section{FALSE}

NOT LIKE ME

1

\section{2}

This statement doesn't describe me at all; it isn't like me at all
TRUE LIKE ME 
NAME:

AGE: (years) DATE:

MALE / FEMALE (circle one) COURSE CODE: GROUP:

STATEMENT

FALSE not like me

01. I plan and use my time efficiently.

$\begin{array}{llllllll}1 & 2 & 3 & 4 & 5 & 6 & 7 & 8\end{array}$

02. I am successful in social situations.

$\begin{array}{llllllll}1 & 2 & 3 & 4 & 5 & 6 & 7 & 8\end{array}$

03. When working on a project, I do my best to get the details right.

$\begin{array}{llllllll}1 & 2 & 3 & 4 & 5 & 6 & 7 & 8\end{array}$

04. I change my thinking or opinions easily if there is a better idea.

$\begin{array}{llllllll}1 & 2 & 3 & 4 & 5 & 6 & 7 & 8\end{array}$

05. I can get people to work for me.

$\begin{array}{llllllll}1 & 2 & 3 & 4 & 5 & 6 & 7 & 8\end{array}$

06. I can stay calm in stressful situations.

$\begin{array}{llllllll}1 & 2 & 3 & 4 & 5 & 6 & 7 & 8\end{array}$

07. I like to be busy and actively involved in things.

$\begin{array}{llllllll}1 & 2 & 3 & 4 & 5 & 6 & 7 & 8\end{array}$

08. I know I have the ability to do anything I want to do.

$\begin{array}{llllllll}1 & 2 & 3 & 4 & 5 & 6 & 7 & 8\end{array}$

09. I do not waste time.

$\begin{array}{llllllll}1 & 2 & 3 & 4 & 5 & 6 & 7 & 8\end{array}$

10. I am competent in social situations.

$\begin{array}{llllllll}1 & 2 & 3 & 4 & 5 & 6 & 7 & 8\end{array}$

11. I try to get the best results when I do things.

$\begin{array}{llllllll}1 & 2 & 3 & 4 & 5 & 6 & 7 & 8\end{array}$

12. I am open to new ideas.

$\begin{array}{llllllll}1 & 2 & 3 & 4 & 5 & 6 & 7 & 8\end{array}$

13. I am a good leader when a task needs to be done.

$\begin{array}{llllllll}1 & 2 & 3 & 4 & 5 & 6 & 7 & 8\end{array}$

14. I stay calm and overcome anxiety in new or changing situations.

$\begin{array}{llllllll}1 & 2 & 3 & 4 & 5 & 6 & 7 & 8\end{array}$

15. I like to be active and energetic.

$\begin{array}{llllllll}1 & 2 & 3 & 4 & 5 & 6 & 7 & 8\end{array}$

16. When I apply myself to something I am confident I will succeed.

$\begin{array}{llllllll}1 & 2 & 3 & 4 & 5 & 6 & 7 & 8\end{array}$

17. I manage the way I use my time well.

$\begin{array}{llllllll}1 & 2 & 3 & 4 & 5 & 6 & 7 & 8\end{array}$

18. I communicate well with people.

$\begin{array}{llllllll}1 & 2 & 3 & 4 & 5 & 6 & 7 & 8\end{array}$

19. I try to do the best that I possibly can.

$\begin{array}{llllllll}1 & 2 & 3 & 4 & 5 & 6 & 7 & 8\end{array}$

20. I am adaptable and flexible in my thinking and ideas.

$\begin{array}{llllllll}1 & 2 & 3 & 4 & 5 & 6 & 7 & 8\end{array}$

21. As a leader I motivate other people well when tasks need to be done. $\begin{array}{llllllll}1 & 2 & 3 & 4 & 5 & 6 & 7 & 8\end{array}$

22. I stay calm when things go wrong.

$\begin{array}{llllllll}1 & 2 & 3 & 4 & 5 & 6 & 7 & 8\end{array}$

23. I like to be an active, 'get into it' person.

$\begin{array}{llllllll}1 & 2 & 3 & 4 & 5 & 6 & 7 & 8\end{array}$

24. I believe I can do it.

$\begin{array}{llllllll}1 & 2 & 3 & 4 & 5 & 6 & 7 & 8\end{array}$

(C) These materials are copyright and may only be used with the permission of Garry Richards or James Neill ${ }^{\circledR}$ 
1. I plan and use my time efficiently.

9. I do not waste time.

17. I manage the way I use my time well.

\section{SOCIAL COMPETENCE}

2. I am successful in social situations.

10. I am competent in social situations.

18. I communicate well with people.

\section{ACHIEVEMENT MOTIVATION}

3. When working on a project, I do my best to get the details right.

11. I try to get the best results when I do things.

19. I try to do the best that I possibly can.

\section{INTELLECTUAL FLEXIBILITY}

4. I change my thinking or opinions easily if there is a better idea.

12. I am open to new ideas.

20. I am adaptable and flexible in my thinking and ideas.

\section{TASK LEADERSHIP}

5. I can get people to work for me.

13. I am a good leader when a task needs to be done.

21. As a leader I motivate other people well when a task needs to be done.

\section{EMOTIONAL CONTROL}

6. I can stay calm in stressful situations.

14. I stay calm and overcome anxiety in new or changing situations.

24. I stay calm when things go wrong.

\section{ACTIVE INITIATIVE}

7. I like to be busy and actively involved in things.

15. I like to be active and energetic.

23. I like to be an active 'get into it' person.

\section{SELF CONFIDENCE}

8. I know I have the ability to do anything I want to do.

16. When I apply myself to something I am confident I will succeed.

24. I believe I can do it. 
Apprendix C: Eight Factors and Definitions

\begin{tabular}{|c|c|}
\hline LEQ Sub scale & Definition \& Example of Question Asked \\
\hline Active Initiative & $\begin{array}{l}\text { The extent to which the individual likes to } \\
\text { initiate action in new situations. } \\
\text { I like to be an active "get into it" person. }\end{array}$ \\
\hline Achievement Motivation & $\begin{array}{l}\text { The extent to which the individual is } \\
\text { motivated to achieve excellence and put the } \\
\text { required effort into action to attain it. } \\
\text { I try to do the best I possibly can. }\end{array}$ \\
\hline Emotional Control & $\begin{array}{l}\text { The extent to which the individual perceives } \\
\text { he/she can adapt his/her thinking and } \\
\text { accommodate new information from } \\
\text { changing conditions and different } \\
\text { perspectives. } \\
\text { I can stay calm in stressful situations. }\end{array}$ \\
\hline Intellectual Flexibility & $\begin{array}{l}\text { The extent to which the individual perceives } \\
\text { he/she can adapt his/her thinking and } \\
\text { accommodate new information from } \\
\text { changing conditions and different } \\
\text { perspectives. } \\
\text { I am adaptable and flexible in my thinking and } \\
\text { ideas. }\end{array}$ \\
\hline Self-Confidence & $\begin{array}{l}\text { The degree of confidence the individual has } \\
\text { in his/her abilities and the success of their } \\
\text { actions. } \\
\text { I know I have the ability to do anything I want to } \\
\text { do. }\end{array}$ \\
\hline Social Competence & $\begin{array}{l}\text { The degree of personal competence and self- } \\
\text { perceived ability in social situations. } \\
\text { I am open to new ideas. }\end{array}$ \\
\hline Task Leadership & $\begin{array}{l}\text { The extent to which the individual perceives } \\
\text { he/she can lead other people effectively } \\
\text { when a task needs to be done and } \\
\text { productivity is a primary requirement. } \\
\text { I can get people to work for me. }\end{array}$ \\
\hline Time Management & $\begin{array}{l}\text { The extent that an individual perceives } \\
\text { he/ she makes optimum use of time. } \\
\text { I plan and use my time efficiently. }\end{array}$ \\
\hline
\end{tabular}




\section{Apprendix D: Demographic Survey}

BOW Participants, plase take a moment to complete the following information. Please circle your answers or fill in the blank when indicated... Thank You!

1. What is your age range?
a. $18-24$
b. $25-30$
c. $31-40$
d. $41-50$
e. $51-59$
f. $60+$

2. Ethnicity:
a. Caucasian
b. African-American
c. Asian-American
d. Latino
e. Other:

3. Educational Level:
a. High School or Equivalent
b. Associates Degree or Certificate
c. Bachelors Degree
d. Graduate Degree
e. Post-Graduate Degree

4. Do you have children?

YES

(If no, go to question 6)

5. How many children do you have?

How many children still live with you?

6. What is your gross household income?
a. Under $\$ 20,000$
b. $\$ 20-30,000$
c. $\$ 30-50,000$
d. $\$ 50-75,000$ 

e. $\$ 75-100,000$
f. $\$ 100-150,000$
g. $\$ 150-200,000$
h. Over $\$ 200,000$

7. Current Status: (Please circle)
a. Married
b. Divorced
c. Separated
d. Single
e. Living with a Significant Other

8. What category best describes your current situation?
a. Employed Full-time / outside of the home or work out of your home
b. Employed Part-time / outside of the home or work out of your home
c. Unemployed and looking for new opportunities
d. Homemaker
e. Retired

9. What is your highest level of education:
a. High School or GED
b. Associates degree or Professional Certificate Program
c. Bachelor's Degree
d. Graduate degree
e. Post-Graduate degree

10. Residence: Do you :
a. Own your home
b. Rent your home
c. Live with family 


\section{Appendix E: Cover Letter to BOW Participants}

October 1, 2004

Dear “Becoming an Outdoors-Woman" program participants,

Thank you for agreeing to participate in this research that is being conducted in partial fulfillment of the requirement for my dissertation at West Virginia University. The purpose of this study is to examine the impact of participating in the BOW program and subsequent ropes course experience on changes in life effectiveness. Completing this survey and demographic information will take approximately twelve minutes. In addition, participants will be asked to complete a post-survey on Sunday morning prior to departure. For those participants selected to complete the ropes course portion of this study, they will be asked to take the survey upon completion of the ropes course. Finally, a follow-up survey will be mailed one month following participation in the program at which time a select few individuals may be contacted via phone for a brief one-on-one interview.

Your responses will help to guide future BOW programs as well as provide a better understanding of the relationship between participation in outdoor pursuits and overall life effectiveness for women. Your answers are strictly confidential and you can choose not to answer every question. Additionally, participation is voluntary and individuals wishing not to participate in the study will not be affected in any way by refusal to participate or withdrawing from the study all together.

I am grateful for your help in making this long awaited research project become a reality. If you have any further questions, please feel free to ask as I will be in attendance at the BOW program all weekend. Following this weekend, I can be reached using the information below:

Maureen Dougherty

7414 Ridge Road

Frederick, MD 21702

Phone: 301.371 .6886

E-mail: Mdougherty4@juno.com

Once again, thank you for your help and cooperation!

Maureen Dougherty

WVU Doctoral Candidate

Division of Forestry/Recreation, Parks \& Tourism Resources 


\section{Appendix F: Information Letter to the Ropes Course Participants}

\section{Dear Ropes Course Participants,}

Thank you once again for your interest in the research study and your willingness to participate in the ropes course portion of the study on Sunday, October 17, 2004. The course is located at the YMCA Camp Letts in Edgewater, Maryland (see directions below). Please be sure to give your $\$ 15$ fee to Maureen before departing from the BOW weekend to confirm your space. Checks can be made payable to YMCA Camp Letts. Although I will be sending everyone a reminder, please mark the date on your calendar as soon as you return home and be prepared to play rain or shine.

Please plan to arrive between 8:30-8:45am on the $17^{\text {th }}$ as we would like to review some information prior to getting started promptly at 9:00am. There will be coffee \& muffins available upon your arrival. I suggest you wear long pants (sweat pants usually are best and allow you to move more freely). Tennis shoes or light hikers will be the best footwear and layering your tops is also a good idea as you may work up a sweat but need a fleece jacket or sweatshirt when sitting idle. Again, we will go "rain or shine" so please bring rain gear along in case.

If you are interested in getting a glimpse at the ropes course at Camp Letts, visit www.campletts.org/ADVCOURSE.pdf. As always, I will be available if you have any questions or concerns prior to our next meeting on October 17th. I can be reached at Mdougherty4@adelphia.net or by calling my home 301-371-6886 or my cell 240-446-3961.

I look forward to seeing you soon...thanks again!

Maureen Dougherty 
Appendix G: Cover Letter for One Month Follow Up to Control Group

October 27, 2004

Dear Research Participant,

Can you believe that it has almost been a month since we gathered together at BOW? As we prepare to turn the clocks back this weekend and say "hello" to November, I'm sure you are quite busy at work, home and play. However, I would like to ask you to take a few minutes right now to fill out this FINAL survey and send it back in the envelope provided.

PLEASE do not place this in your "things to do" pile as it may not be unearthed until next year (or at least that is what happens in my house). Your continued participation in the study is vitally important and greatly appreciated!

Again, thank you for your timely response and cooperation with this study! If you have any questions, please feel free to call or write. I hope to see you at another BOW event or just out there enjoying the wonderful outdoors!

Sincerely,

Maureen

Maureen Dougherty

Mdougherty4@adelphia.net

301-371-6886 
Appendix H: Cover Letter for One Month Follow Up to Experimental Group

November 15, 2004

Dear Research Participant,

Can you believe that it has almost been a month since we last met at Camp Letts? I'm sure you are quite busy at work, home and play as we enter the second half of November. However, I would like to ask you to take a few minutes right now to fill out this FINAL survey and send it back in the envelope provided.

PLEASE do not place this in your "things to do" pile as it may not be unearthed until next year (or at least that is what happens in my house). Your continued participation in the study is vitally important and greatly appreciated!

Again, "thank you" for your timely response and cooperation with this study! If you have any questions, please feel free to call or write. I hope to see you at another BOW event or just out there enjoying the wonderful outdoors!

Sincerely,

Maureen

Maureen Dougherty

Mdougherty4@adelphia.net

301-371-6886 


\section{Appendix I: Telephone One-on-One Interview}

Questions for One-on-One Interviews following the Ropes Course portion of the study.

1. Did you learn more about yourself as a result of participating in the ropes course? Please elaborate.

2. What types of emotions did you experience throughout your day on the ropes course? What emotion prevailed most often?

3. Were you able to make any "real life" analogies between your ropes course experience and your daily life? Please give some examples.

4. Explain your perception of how well the group worked together given the various challenges of the day.

5. Were there any internal or external factors that had an impact on your participation as an individual or as a group? What were they and explain the type of impact.

6. Are there any other thoughts that you would like to share regarding your ropes course experience?

7. What song, show, book or saying comes to mind when you think of your day on the ropes course? 


\section{Appendix J: $\quad$ L.E.Q. - I- $\quad$ Observer ${ }^{\circ}$}

\section{PLEASE DO NOT TURN OVER YET READ THESE INSTRUCTIONS}

This is a chance for you to consider how your son/daughter thinks and feels about him/herself in some ways. This is not a test - there are no right or wrong answers, and everyone will have different observations. It is important that you give your own views and that you be honest in your answers and do not talk to others while you think about your answers. Your responses will be used only for research purposes (they will NOT be shown to your son/daughter) and will in no way be used to refer to you or your son/daughter as an individual at any time.

Over the page are a number of statements that are more or less true (that is like your son/daughter) or more or less false (that is unlike your son/daughter). Please use the eight point scale to indicate how true (like your son/daughter) or how false (unlike your son/daughter), each statement is as a description of your son/daughter. Answer the statements as you think your son/daughter feels now, even if you think he/she may have felt differently at some other time in his/her life. Please do not leave any statements blank.

FALSE

NOT LIKE ME

1
2

This statement doesn't describe him/her at all; it isn't like him/her at all
TRUE LIKE ME 


\section{L.E.Q. - I - Observer}

NAME of Observer:

MALE / FEMALE (circle one) DATE:

NAME of Person being Observed: RELATIONSHIP:

$\begin{array}{ll}\text { FALSE } & \text { TRUE } \\ \text { Not like me } & \text { like me }\end{array}$

01. If this person tries hard enough, he/she can succeed at anything.

$\begin{array}{llllllll}1 & 2 & 3 & 4 & 5 & 6 & 7 & 8\end{array}$

02 . This person plans and uses his/her time efficiently.

$\begin{array}{llllllll}1 & 2 & 3 & 4 & 5 & 6 & 7 & 8\end{array}$

03 . This person is successful in social situations.

$\begin{array}{llllllll}1 & 2 & 3 & 4 & 5 & 6 & 7 & 8\end{array}$

04. When working on a project, this person does his/her best to get the details right. $\begin{array}{lllllllllllllllllll}1 & 2 & 3 & 4 & 5 & 6 & 7 & 8\end{array}$

05. This person changes his/her thinking or opinions easily if there is a better idea. $\begin{array}{llllllllll}1 & 2 & 3 & 4 & 5 & 6 & 7 & 8\end{array}$

06. This person is in control of things that happen to him/her.

07. This person can get people to work for him/her.

08 . This person can stay calm in stressful situations.

09. This person likes to be busy and actively involved in things.

10. This person knows that he/she has the ability to do anything he/ she wants to do. $\begin{array}{llllllll}1 & 2 & 3 & 4 & 5 & 6 & 7 & 8\end{array}$

$\begin{array}{llllllll}1 & 2 & 3 & 4 & 5 & 6 & 7 & 8\end{array}$

$\begin{array}{lllllllll}1 & 2 & 3 & 4 & 5 & 6 & 7 & 8\end{array}$

$\begin{array}{llllllll}1 & 2 & 3 & 4 & 5 & 6 & 7 & 8\end{array}$

$\begin{array}{llllllll}1 & 2 & 3 & 4 & 5 & 6 & 7 & 8\end{array}$
11. This person does not waste time.

12. This person is competent in social situations.

13. This person tries to get the best results when he/she does things.

14. This person is open to new ideas.

15. This person believes that he/she is responsible for all his/her action

$\begin{array}{llllllll}1 & 2 & 3 & 4 & 5 & 6 & 7 & 8 \\ 1 & 2 & 3 & 4 & 5 & 6 & 7 & 8 \\ 1 & 2 & 3 & 4 & 5 & 6 & 7 & 8 \\ 1 & 2 & 3 & 4 & 5 & 6 & 7 & 8 \\ 1 & 2 & 3 & 4 & 5 & 6 & 7 & 8\end{array}$

$\begin{array}{llllllll}1 & 2 & 3 & 4 & 5 & 6 & 7 & 8\end{array}$

16. This person is a good leader when a task needs to be done.

$\begin{array}{llllllll}1 & 2 & 3 & 4 & 5 & 6 & 7 & 8\end{array}$

17. This person stays calm and overcomes anxiety in new or changing situations.

$\begin{array}{llllllll}1 & 2 & 3 & 4 & 5 & 6 & 7 & 8\end{array}$

19. When this person applies him/herself to something he/ she is confident he/she will succeed.

20. This person manages the way he/she uses his/her time well.

$\begin{array}{llllllll}1 & 2 & 3 & 4 & 5 & 6 & 7 & 8\end{array}$

21. This person communicates well with people.

$\begin{array}{llllllll}1 & 2 & 3 & 4 & 5 & 6 & 7 & 8\end{array}$

22. This person tries to do the best that he/she possibly can.

$\begin{array}{llllllll}1 & 2 & 3 & 4 & 5 & 6 & 7 & 8\end{array}$

23. This person is adaptable and flexible in his/her thinking and ideas.

$\begin{array}{llllllll}1 & 2 & 3 & 4 & 5 & 6 & 7 & 8\end{array}$

24 . This person doesn't believe in chance, fate or destiny.

$\begin{array}{llllllll}1 & 2 & 3 & 4 & 5 & 6 & 7 & 8\end{array}$

25. As a leader this person motivates other people well when tasks need to be done. $\begin{array}{lllllllll}1 & 2 & 3 & 4 & 5 & 6 & 7 & 8\end{array}$

26. This person stays calm when things go wrong.

$\begin{array}{llllllll}1 & 2 & 3 & 4 & 5 & 6 & 7 & 8\end{array}$

27. This person likes to be an active, 'get into it' person.

28. This person believes he/she can do it.

$\begin{array}{llllllll}1 & 2 & 3 & 4 & 5 & 6 & 7 & 8\end{array}$

29. This person can change the way he/she thinks and behaves.

$\begin{array}{llllllll}1 & 2 & 3 & 4 & 5 & 6 & 7 & 8\end{array}$

$\begin{array}{llllllll}1 & 2 & 3 & 4 & 5 & 6 & 7 & 8\end{array}$ 